\title{
Emulação de um Gerenciador de Dados Orientado a Objetos através de uma Interface de Programação de Aplicativos sobre um Gerenciador Relacional ${ }^{1}$
}

\author{
Elaine Parros Machado de Sousa
}

Orientação:

Prof. Dr. Caetano Traina Júnior

Dissertação apresentada ao Instituto de Ciências Matemáticas e de Computação da Universidade de São Paulo como parte dos requisitos para a obtenção do título de Mestre em Ciências - Área de Ciências de Computação e Matemática Computacional.

ICMC - USP, São Carlos

Novembro de 2000

\footnotetext{
${ }^{1}$ Trabalho realizado com auxílio da FAPESP
} 
"Ao Humberto e aos meus pais com muito amor" 


\section{Agradecimentos}

Ao Prof. Dr. Caetano Traina Jr., meu orientador e amigo, pelo precioso trabalho de orientação, estímulo e confiança.

Ao Prof. Dr. Mauro Biajiz e ao Prof. Dr. Carlos Valêncio, pela colaboração no embasamento teórico deste trabalho.

À Prof. Dra. Maria Cristina Ferreira e à Prof. Dra. Rosely Sanches, que prontamente me auxiliaram como orientadora e co-orientadora acadêmica, respectivamente.

Às funcionárias Beth, Laura, Marília, Adriana e Sandrinha, pelo atendimento atencioso na secretaria da pós-graduação e na seção de bolsas.

À FAPESP, pelo apoio financeiro que viabilizou o desenvolvimento deste trabalho.

À Prof. Dra. Agma Traina, por todo o incentivo e o carinho demonstrados.

Aos amigos do Grupo de Bases de Dados e Imagens do ICMC, por toda a ajuda prestada no decorrer do trabalho.

Ao meu marido Humberto, por estar sempre perto e pronto a me apoiar profissionalmente e pessoalmente.

Aos meus pais, Celso e Maria Helena, pelo incentivo, apoio e confiança que sempre dedicaram durante toda minha vida.

Aos amigos, que direta ou indiretamente, contribuíram para a realização deste trabalho. 


\section{Resumo}

Este trabalho mostra o desenvolvimento de uma Interface de Programação de Aplicativos (Application Program Interface - API) para um gerenciador de dados orientado a objetos. A API é composta por um conjunto de primitivas que integram a definição e a manipulação de objetos em uma representação compatível com uma linguagem de programação orientada a objetos.

A definição da API explora os recursos básicos de modelos de dados orientados a objetos e baseia-se nas extensões de um metamodelo baseado em quatro abstrações: classificação, generalização, agregação e composição. O suporte à abstração de classificação com hierarquias em múltiplos níveis é tratado com especial destaque, pois resulta em uma das características predominantes da API: o tratamento homogêneo de tipos e instâncias em tempo de execução, unificando comandos usualmente separados em DDL (Data Definition Language) e DML (Data Manipulation Language).

A implementação da API sobre um gerenciador relacional emula um gerenciador de dados orientado a objetos. Os conceitos envolvidos no trabalho de emulação foram aplicados no desenvolvimento de uma versão com núcleo relacional do Gerenciador de Objetos SIRIUS, criando em ambiente experimental, precursor à versão com núcleo nativo desse gerenciador. A API definida neste trabalho é compatível com ambas as versões do Gerenciador SIRIUS, permitindo que uma aplicação utilize qualquer uma das versões sem alterações em seu código fonte.

Para exemplificar a utilização prática da API, foi implementado um utilitário de bases de dados destinado à representação de modelagens baseadas no modelo de dados SIRIUS usando a versão relacional do Gerenciador de Objetos SIRIUS. Esse utilitário, além de demonstrar a utilização da API, demonstra também como as operações típicas da DDL e da DML são integradas em um único conjunto de comandos que não faz diferença entre a definição de tipos e de instâncias. 


\section{Abstract}

This work develops an Application Program Interface (API) for an object oriented data manager. The API is composed by a set of methods that includes object definition and manipulation appropriated for an object oriented programming language.

The API definition explores basic resources of object oriented data models. It is based on extensions of a meta-model based on four abstractions: classification, generalization, aggregation and composition. One of the API predominant characteristics is the support to the classification abstraction. It is used a multiple-level classification hierarchy, enabling a seamless treatment of types and instances, unifying the commands usually divided in the DDL and DML parts of the query language.

The API was constructed employing a relational manager, aiming to emulate an object oriented data manager. The target data model was based on the SIRIUS model, creating a relational version of the SIRIUS Object Manager. Thus, this relational version is an experimental environment, aiding the development of the full native version of that manager. The API defined in this work is compatible with both versions of the SIRIUS Manager, allowing applications to use any version without modifications in their codes.

In this work, the API usage is exemplified with the development of a database tool designed to represent target modeling based on SIRIUS data model, using the relational version of the SIRIUS Object Manager. This utility also shows how the DDL and DML parts of the query language are unified in a unique, seamless command set, in which there is no distinction between types and instances. 


\section{Sumário}

\section{Lista de Figuras}

\section{Lista de Tabelas}

\section{Siglas e Abreviações}

1 INTRODUÇÃ 0 ............................................................................................................ 1

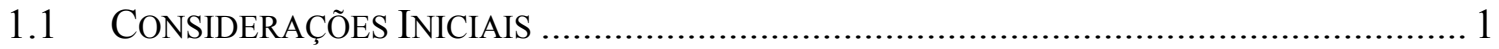

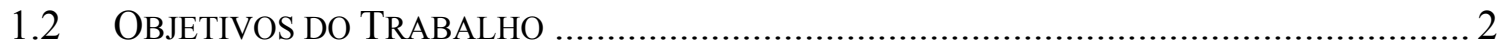

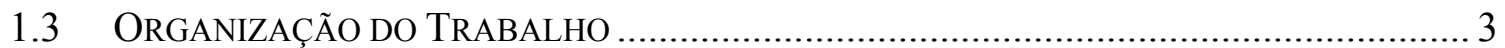

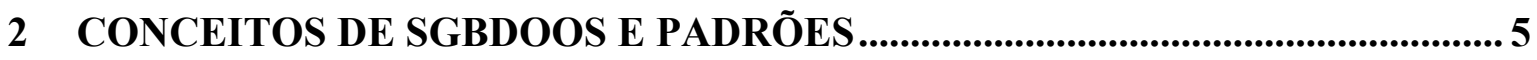

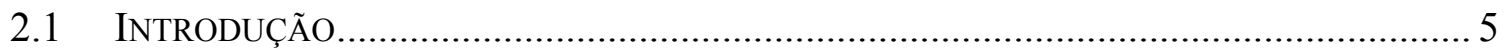

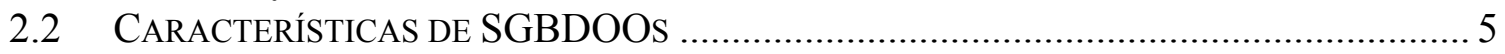

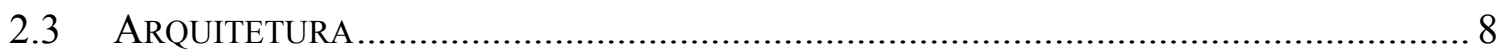

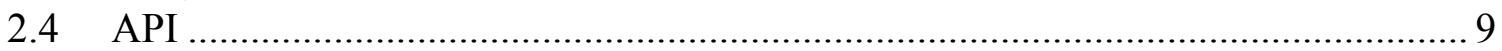

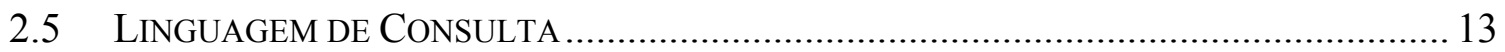

2.6 PAdRÕES PARA GERENCIAMENTO DE DAdOS ORIENTAdOS A OBJETOS ................... 14

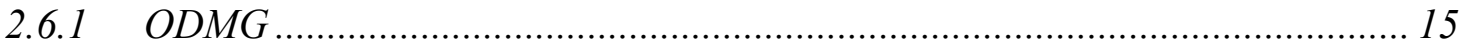

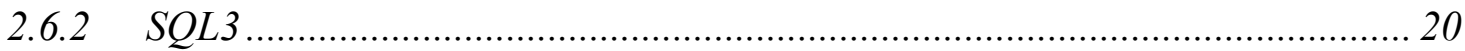

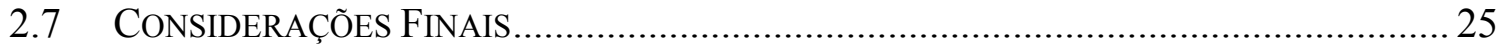

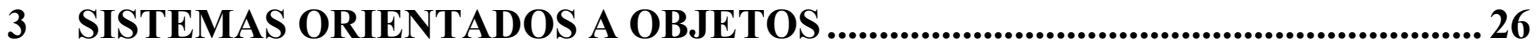

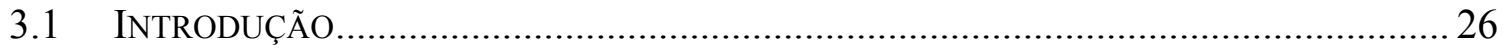

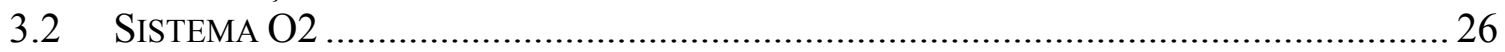

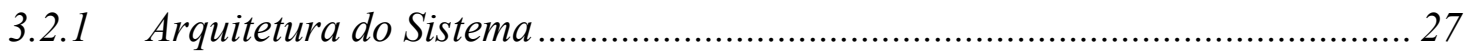

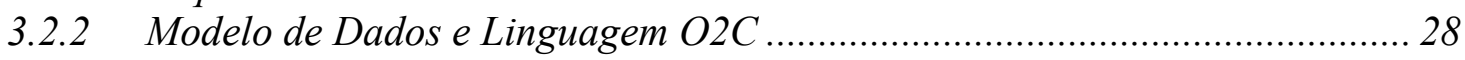

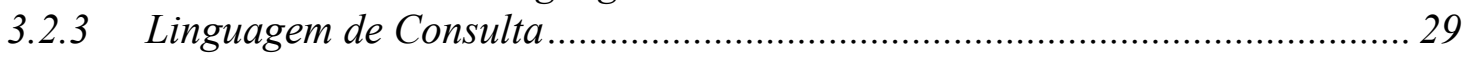

3.2.4 Interfaces para Linguagens de Programação ................................................ 30

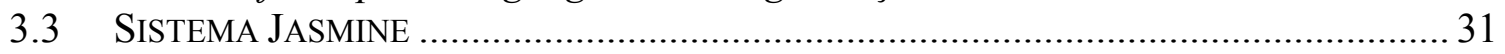

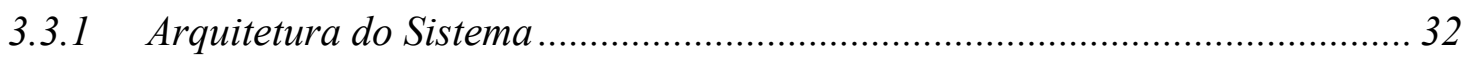

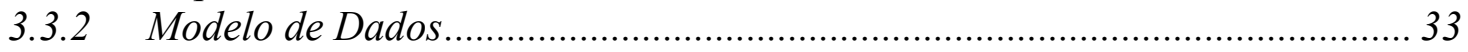

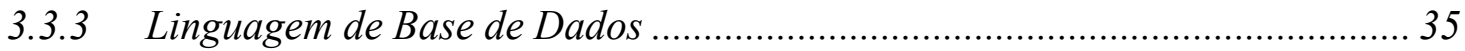

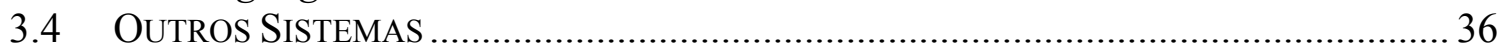

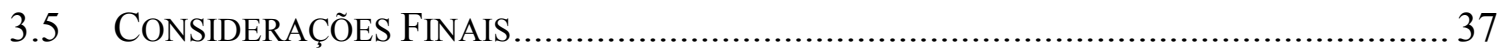

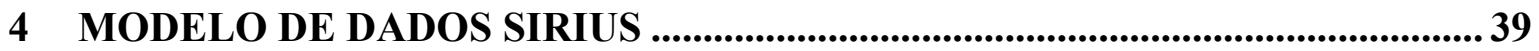

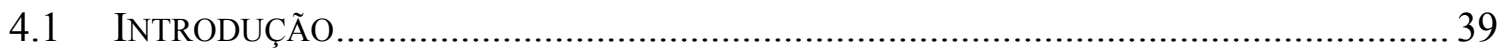

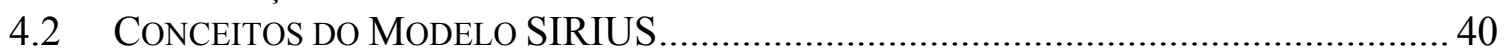

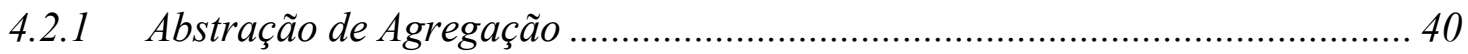

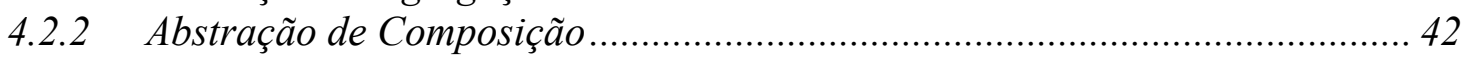

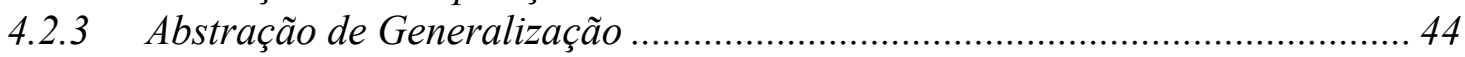

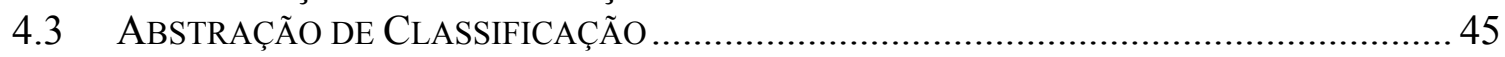

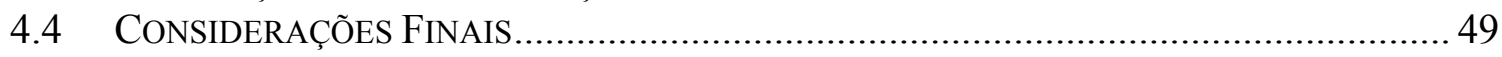


5 API DO GERENCIADOR SIRIUS.......................................................................50

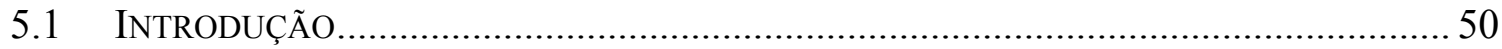

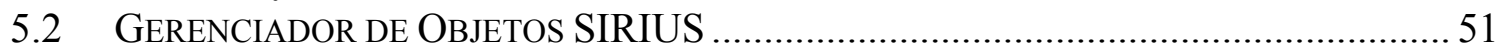

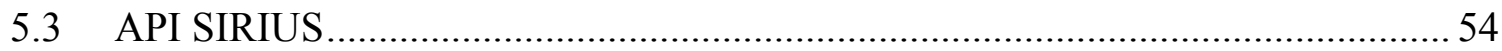

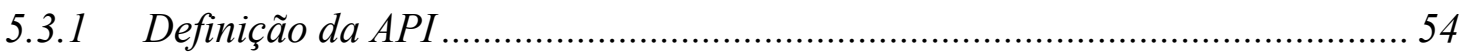

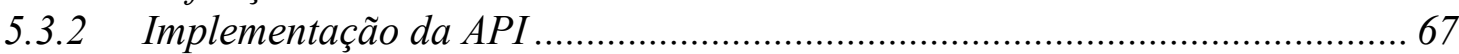

5.4 CONSIDERAÇÕES FINAIS.................................................................................... 71

6 EDITOR DE ESQUEMAS SIRIUS ..................................................................... 72

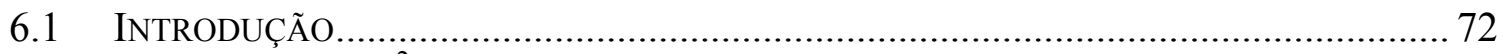

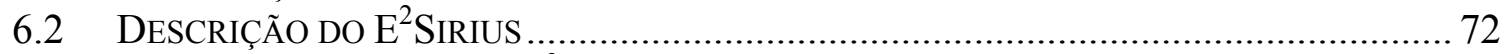

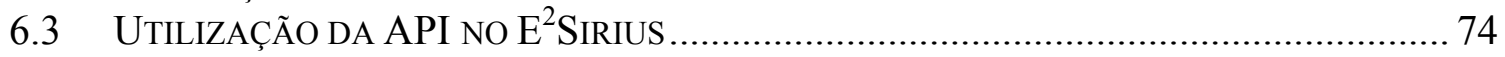

6.4 CONSIDERAÇÕES FINAIS................................................................................. 78

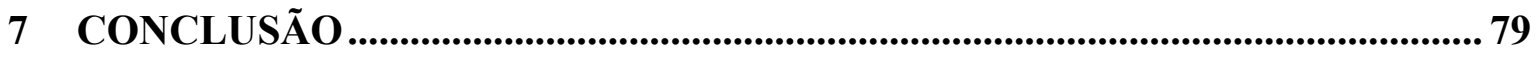

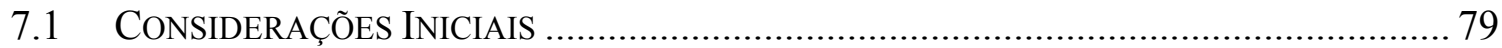

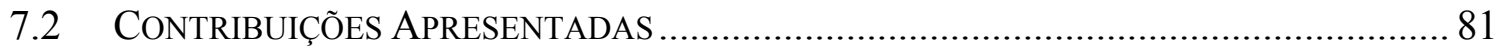

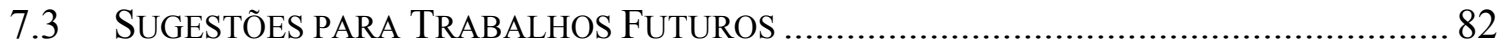

\section{Referências Bibliográficas}

Anexo: API do Gerenciador SIRIUS 


\section{Lista de Figuras}

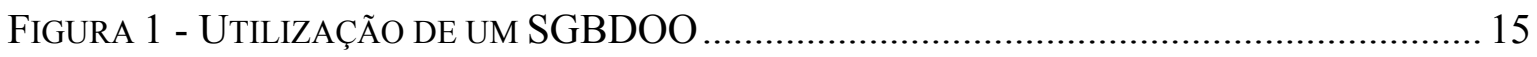

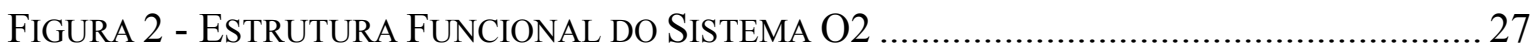

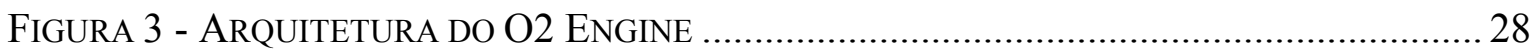

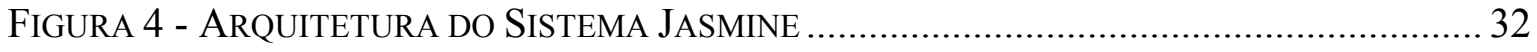

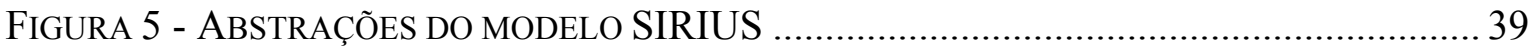

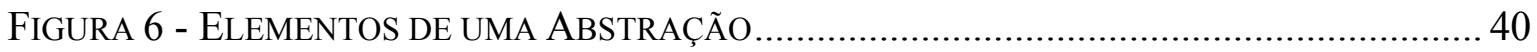

FigURA 7 - EXEMPLO DA ABSTRAÇÃO DE AGREGAÇÃO ....................................................... 42

FigURA 8 - EXEMPLO DA ABSTRAÇÃO DE COMPOSIÇÃO ....................................................... 43

FigURA 9 - EXEMPLO DA ABSTRAÇÃO DE GENERALIZAÇÃo ................................................. 44

FiguRA 10 - EXEMPLO DA ABSTRAÇÃO DE ClaSSIFICAÇÃo ................................................ 46

FIGURA 11 - EXEMPLO DE ATRIBUTO EXTRA NA HIERARQUIA DE CLASSIFICAÇÃO .................48

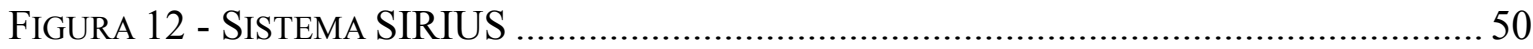

FIGURA 13 - GERENCIADOR SIRIUS COM NÚCLEO NATIVO …......................................... 52

FIGURA 14 - GERENCIADOR SIRIUS COM NÚCLEO RELACIONAL ....................................... 53

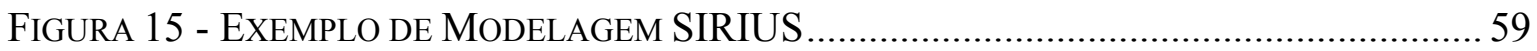

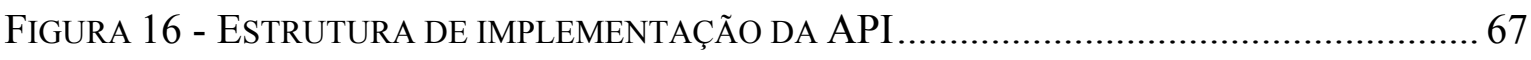

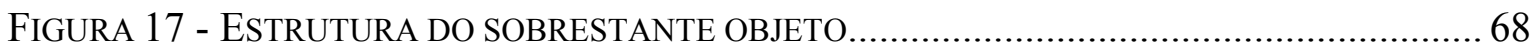

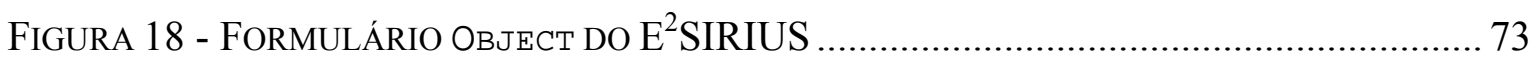

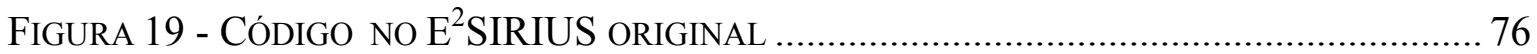

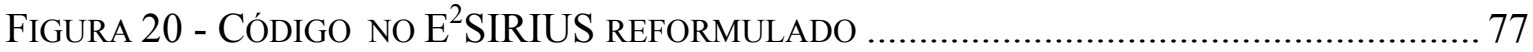




\section{Lista de Tabelas}

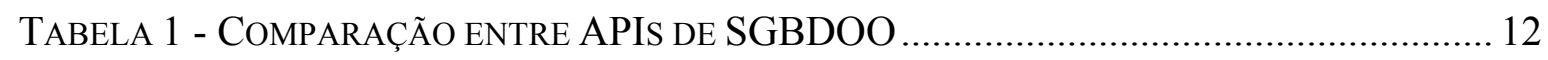

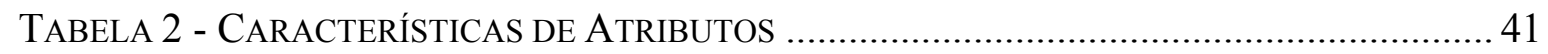

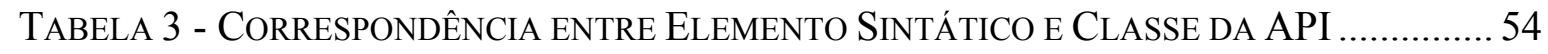

TABELA 4 - CORRESPONDÊNCIA ENTRE CARACTERÍSTICA DE ATRIBUTO E ClASSE DA API. 55

TABEla 5 - CORRESPONDÊNCIA ENTRE CONJUNTO RECUPERAdO E ClasSE DA API............ 55

TABELA 6 - Composição dos Módulos SEMÂNTICOS ....................................................... 56

TABELA 7 - CARACTERÍSTICAS DE API NO GERENCIADOR SIRIUS .................................... 66 


\section{Siglas e Abreviações}

API

Application Program Interface

CAD Computer-Aided Design

CAM Computer-Aided Manufacturing

CASE Computer-Aided Software Engineering

CIM Computer Integrated Manufacturing

DDL Data Definition Language

DHC Diagrama Hierárquico de Colônias

DML Data Manipulation Language

DRI Diagrama de Representação de Instâncias

ODBC Open Database Connectivity

ODL Object Definition Language

ODMG $\quad$ Object Database Management Group

OId Object Identifier

OIF Object Interchange Format

OML Object Manipulation Language

OQL Object Query Language

SGBD Sistema de Gerenciamento de Base de Dados

SGBDOO Sistema de Gerenciamento de Base de Dados Orientado a Objetos

TAD Tipo Abstrato de Dado 


\section{Introdução}

\subsection{Considerações Iniciais}

Sistemas de Gerenciamento de Bases de Dados Orientados a Objetos (SGBDOOs) surgiram da necessidade de atender exigências de aplicações não convencionais, voltadas predominantemente para problemas técnicos e científicos [Cattell_94]. Ao contrário das aplicações tradicionais, voltadas para ambientes de negócio, as aplicações não convencionais possuem características particulares, como por exemplo, estruturas de dados heterogêneas e complexas, que não são eficientemente suportadas por Sistemas de Gerenciamento de Bases de Dados (SGBDs) relacionais [Elmasri_00]. Por outro lado, a flexibilidade inerente à abordagem de orientação a objetos, integrando modelos de dados, bases de dados e linguagens de programação, oferece o suporte necessário para projeto e desenvolvimento de tais aplicações.

As aplicações em questão abrangem o desenvolvimento de ambientes de projeto voltados para engenharia $\left(\mathrm{CASE}^{1}, \mathrm{CAD}^{2}, \mathrm{CAM}^{3}\right.$ e $\left.\mathrm{CIM}^{4}\right)$, sistemas de apoio à medicina, aplicações científicas, sistemas baseados em conhecimento, automação de escritório e sistemas que manipulam imagens médicas, informações geográficas, partituras musicais e informações multimídia em geral. Com o advento dessa nova abordagem, pesquisas envolvendo desenvolvimento e formalização de modelos de objetos [Bertino_91], implementação de gerenciadores de objetos [Cattell_94], projeto de linguagens de consulta a objetos [Bertino_92] e algoritmos de suporte a conceitos orientados a objetos fornecem os subsídios para a construção de SGBDOOs. Neste contexto, foram desenvolvidos vários SGBDOOs [Cattell_94] [Zand_95], incluindo sistemas comerciais e protótipos

\footnotetext{
${ }^{1}$ Computer-Aided Software Engineering

${ }^{2}$ Computer-Aided Design

${ }^{3}$ Computer-Aided Manufacturing

${ }^{4}$ Computer-Integrated Manufacturing
} 
experimentais. Além disso, alguns padrões [Cattell_94] [Cattell_95] [Cattell_97] [Eisenberg_98], combinando modelos de dados e linguagens de base de dados, foram criados com o objetivo de permitir melhor produtividade dos programadores, representações mais completas e principalmente portabilidade de aplicações não convencionais.

A API do SGBDOO é um mecanismo de comunicação entre a aplicação e a base de dados. O ODBC (Open Database Connectivity) [ODBC_00a] [ODBC_00b], por exemplo, é uma API padrão de acesso a bases de dados relacionais compatível com diferentes SGBDs, como Oracle, Sybase, InterBase, Access, Fox, entre outros.

$\mathrm{Na}$ maior parte dos sistemas de bases de dados tradicionais, as APIs são especificadas através da inserção de linguagens de manipulação de dados (DML) em linguagens de programação convencionais. Esta abordagem, no entanto, exige dos programadores a utilização de duas ou mais linguagens (ou modelos de dados) nas fases de projeto e implementação das aplicações [Perez_91]. Em SGBDOOs, a integração transparente entre base de dados e linguagem de programação orientada a objetos permite que o programador utilize apenas uma linguagem, ou modelo de dados, no processo de desenvolvimento da aplicação. Para tanto, a API de um SGBDOO é composta por rotinas compatíveis com a linguagem de programação utilizada.

Em geral, a API de um SGBDOO deve permitir a definição de tipos e classes e a manipulação de objetos, ou instâncias, das classes e tipos definidos. Além disso, é fundamental que a API suporte consultas a objetos armazenados da base de dados, abrangendo consultas efetuadas no contexto da aplicação e consultas independentes [Perez_91].

\subsection{Objetivos do Trabalho}

Este trabalho tem como objetivo emular um gerenciador de dados orientado a objetos através da definição e implementação de uma API sobre um gerenciador relacional.

O processo de definição da API foi baseado nos conceitos de um modelo de dados semanticamente mais rico do que atualmente pode ser considerado como um modelo de 
dados orientado a objetos padrão, incluindo um maior conjunto de abstrações do que o considerado básico. Em particular, os modelos de dados orientados a objetos padrões consideram a existência de duas Abstrações de Dados principais: Generalização e Agregação (e suas respectivas abstrações inversas). Neste trabalho, foram consideradas também as Abstrações de Classificação e de Composição, procurando explorar principalmente o suporte à hierarquia de classificação em múltiplos níveis e a conseqüente unificação entre os comandos de manipulação de dados (DML) e os comandos de definição de dados (DDL) das linguagens de acesso a bases de dados.

A implementação da API sobre um gerenciador relacional emula um gerenciador de dados orientado a objetos baseado nos conceitos inerentes às abstrações de agregação, generalização, classificação e composição. Portanto, além do suporte necessário a operações de definição e manipulação de dados, a API desenvolvida disponibiliza um conjunto de primitivas para o tratamento de particularidades dessas abstrações, destacandose o tratamento homogêneo a tipos e instâncias em tempo de execução, fundamental para abstração de classificação.

\subsection{Organização do Trabalho}

O Capítulo 2 apresenta uma revisão bibliográfica abrangendo os principais conceitos dos SGBDOOs, dentre os quais estão os recursos básicos presentes em sistemas de bases de dados, as diferentes abordagens para arquitetura, as principais características da API de um gerenciador, aspectos de linguagens de consulta, e padrões como o ODMG e o SQL3, difundidos como mecanismos de aceitação e utilização da tecnologia de bases de dados orientadas a objetos.

O Capítulo 3 descreve alguns sistemas de bases de dados orientados a objetos, destacando as principais características do modelo de dados, arquitetura e linguagem de consulta de cada um. Sistemas como o O2 e o Jasmine oferecem suporte ao desenvolvimento de aplicações não convencionais, e assim como tantos outros, comerciais ou experimentais, vêm contribuindo para o desenvolvimento de tecnologia para a resolução de problemas em diferentes áreas de conhecimento, tais como engenharia e medicina. 
O Capítulo 4 apresenta o Modelo de Dados SIRIUS, descrevendo seus principais conceitos e o tratamento dado às abstrações de classificação, generalização, agregação e composição. A abordagem diferencial da abstração de classificação no modelo SIRIUS é apresentada com mais detalhes, enfatizando a hierarquia de tipos em múltiplos níveis suportada nesse modelo.

O Capítulo 5 é dedicado a descrever o trabalho desenvolvido. As principais características de definição e implementação da API são descritas com o objetivo de mostrar como as abstrações de agregação, composição e classificação são suportadas na API e emuladas num gerenciador relacional.

O Capítulo 6 tem por objetivo validar a API, mostrando a sua utilização no desenvolvimento de um utilitário de bases de dados genérico centrado num gerenciador de dados orientado a objetos emulado. Os resultados obtidos com o protótipo do utilitário são satisfatórios, validando a API desenvolvida como uma interface consistente para um gerenciador de objetos.

O Capítulo 7 conclui o trabalho, apresentando suas principais contribuições e propostas para trabalhos futuros.

Em seqüência, estão as referências bibliográficas e um Anexo contendo a descrição das classes da API, detalhando a funcionalidade e a interface de cada método. 


\section{Conceitos de SGBDOOs e Padrões}

\subsection{Introdução}

Sistemas de Gerenciamento de Bases de Dados Orientados a Objetos são genericamente definidos como SGBDs que integram a funcionalidade dos gerenciadores de bases de dados e a funcionalidade das linguagens de programação orientadas a objetos. Em um SGBDOO os objetos da base de dados são tratados como objetos da linguagem de programação.

SGBDOOs possuem características que abrangem princípios inerentes a sistemas de bases de dados e princípios do paradigma de orientação a objetos. Algumas características podem ou não estar presentes num SGBDOO, dependendo da abordagem adotada para o mesmo. Analogamente, o modelo de dados, a API, a linguagem de programação e a linguagem de consulta podem apresentar particularidades compatíveis com as prioridades do SGBDOO do qual fazem parte.

As seções seguintes apresentam uma visão geral das principais características dos SGBDOOs, algumas abordagens para a arquitetura destes sistemas, características importantes da API e da linguagem de consulta, e padrões para a construção de aplicações apoiadas em SGBDOOs, destacando os padrões ODMG e o SQL3.

\subsection{Características de SGBDOOs}

Como citado anteriormente, os SGBDOOs incorporam recursos de sistemas de bases de dados, como persistência, gerenciamento de armazenamento secundário, controle de concorrência, recuperação de falhas e mecanismo de consulta, e recursos do paradigma de orientação a objetos, como objetos complexos, identidade de objetos, encapsulamento, 
tipos ou classes, herança, sobrecarga (polimorfismo), binding atrasado (late binding), extensibilidade e completude computacional [Atkinson_94] [Cattell_94][Elmasri_00] [Nierstrasz_89]. Essas características são discutidas brevemente nos itens a seguir.

- Persistência - os dados (objetos) de um processo (ou transação) persistem após o término da execução do mesmo. Persistência é um requisito evidente para bases de dados, mas não para linguagens de programação, cujos objetos não "sobrevivem" à execução do processo, ou seja, são transientes. Persistência deve ser ortogonal, isto é, permitir que qualquer objeto, independente de seu tipo, torne-se persistente.

- Gerenciamento de armazenamento secundário - característica clássica de SGBDs que provê independência entre o sistema lógico e o sistema físico. É usualmente suportada através de mecanismos como gerenciamento de índices, buffering de dados, seleção de caminhos de acesso, alocação de espaço em disco, transferência de dados para a memória principal, otimização de consulta, entre outros. Tais mecanismos, embora críticos para a performance do sistema, são transparentes ao programador.

- Controle de concorrência - gerenciamento de múltiplos usuários interagindo simultaneamente com o sistema.

- Recuperação de falhas - capacidade de, em caso de falhas de software ou hardware, retornar o sistema e seus dados a um estado anterior consistente.

- Mecanismo de consulta - realização de consultas à base de dados. Uma consulta dever ser especificada através de uma expressão de alto nível, além de ser eficiente em termos de tempo de resposta e independente da aplicação.

- Objetos complexos - suporte a objetos "grandes" em tamanho (objetos complexos não-estruturados) e a objetos estruturados, como conjuntos, listas, tuplas e vetores. Conseqüentemente, torna-se necessário o suporte às operações que manipulam estes objetos.

- Identidade de objetos - cada objeto da base de dados deve possuir um identificador único e imutável (OId - Object Identifier), gerado automaticamente pelo sistema. Um OId deve ser utilizado apenas uma vez, o que significa que mesmo que o objeto seja 
removido da base de dados, aquele OId não deve ser novamente associado a nenhum outro objeto.

- Encapsulamento - um objeto da base de dados encapsula dados que definem sua estrutura interna e operações que definem seu comportamento. A estrutura interna e a definição do comportamento de um objeto ficam escondidas, e o objeto é acessado através das operações pré-definidas para seu tipo.

- Tipos, classes e herança - suporte a hierarquias de tipos ou hierarquias de classes através do conceito de herança, o que permite que novos tipos (classes) sejam definidos a partir de tipos (classes) pré-definidos. Os subtipos (subclasses) herdam os atributos e as rotinas dos supertipos (superclasses), podendo no entanto possuir atributos e rotinas próprios.

- Sobrecarga (polimorfismo) - permite que um mesmo nome de operação seja utilizado para implementações diferentes, dependendo do tipo de objeto ao qual a operação é aplicada.

- Binding atrasado ou dinâmico - realiza a "tradução" de nomes das operações em endereços de programas em tempo de execução. O binding realizado em tempo de compilação, ao contrário, é chamado de binding estático (static binding). O binding atrasado, embora seja lento e dificulte a checagem de tipos, é necessário para viabilizar a utilização de sobrecarga de operações. O grau de checagem de tipos em tempo de compilação depende do sistema, mas quanto maior este grau, menor a quantidade de potenciais erros de tipo em tempo de execução.

- Extensibilidade - o conjunto de tipos pré-definidos do sistema deve ser extensível, permitindo que o programador defina novos tipos. Embora o tratamento de tipos definidos pelo usuário seja diferente do tratamento de tipos do sistema, esta diferença deve ser imperceptível para o programador e para a aplicação.

- Completude computacional - um SGBD computacionalmente completo possui uma linguagem de acesso à base de dados que pode realizar as mesmas operações realizadas por uma linguagem de programação. Esta característica pode ser alcançada através de uma conexão coerente entre o sistema de base de dados e uma linguagem de programação. Um sistema computacionalmente completo também possui recursos para 
desfazer tudo o que for construído, ou seja, pode levar o sistema passo a passo para qualquer estado anterior que já tenha existido, a partir de qualquer estado atual.

Além dos princípios discutidos nos itens anteriores, algumas características adicionais podem aumentar a funcionalidade de um SGBDOO, como suporte a versões, distribuição e transações planejadas (transações longas e transações aninhadas).

\subsection{Arquitetura}

Os SGBDOOs, de um modo geral, são construídos com base em três abordagens principais [Cattell_94]:

- Sistemas baseados em linguagens de programação orientadas a objetos - integram linguagens de programação orientadas a objetos e a tecnologia de bases de dados. As aplicações são desenvolvidas em uma extensão de uma linguagem de programação existente. A linguagem e sua respectiva implementação (pré-processador, compilador e ambiente de execução) são estendidos para incorporar a funcionalidade e as características das linguagens de bases de dados. Dentre os sistemas que adotam essa abordagem estão O2 [Bancilhon_92] [Deux_90] [Deux_91], ObjectStore [Lamb_91], GemStone [Butterworth_91] e Objectivity/DB [Cattell_94].

- Sistemas relacionais estendidos - possuem modelo de dados relacional e linguagem de consulta estendidos, de forma a incorporar os conceitos do paradigma de orientação a objetos e a funcionalidade das linguagens de programação. Sistemas que adotam essa abordagem utilizam uma base de dados relacional como repositório de dados. $\mathrm{O}$ sistema POSTGRES [Stonebraker_91], que utiliza o gerenciador relacional INGRES para armazenamento de dados, é provavelmente um dos mais poderosos sistemas relacionais estendidos [Cattell_94].

- Sistemas baseados em modelos de dados orientados a objetos - baseados em modelos de dados originalmente orientados a objetos. Os sistemas que seguem essa abordagem são construídos a partir dos princípios do modelo de dados, de modo a suportar os conceitos formalizados no modelo. São exemplos os sistemas IRIS [Fishman_89] [Wilkinson_90] e SIRIUS [Araujo_98a] [Biajiz_96a] [Biajiz_96b]. 


\section{$2.4 \mathrm{API}$}

As características da API de um SGBDOO [Perez_91] podem ser classificadas em características relevantes para o sistema de base de dados e características relevantes para os objetos individuais manipulados pela aplicação e gerenciados pelo sistema de base de dados. Embora as APIs possam diferir de um SGBDOO para outro, algumas características consideradas fundamentais são apresentadas nos itens seguintes.

Interface do sistema de base de dados - a API de um SGBDOO deve incorporar interfaces que permitam que o programa da aplicação defina os limites entre a base de dados e a execução das transações.

- Shutdown e Startup do sistema - uma aplicação deve indicar ao SGBDOO que pretende iniciar ou finalizar uma interação com o sistema, de forma que este possa realizar as ações necessárias para, respectivamente, atender às requisições da aplicação, ou terminar a conexão de maneira apropriada e eficiente. A API deve oferecer suporte para o shutdown e o startup. Entretanto, o modo de execução destas ações, explicitamente pela aplicação ou implicitamente através da semântica da linguagem de programação, é uma decisão de projeto. Vale enfatizar que a execução implícita reduz o número de ações codificas explicitamente, o que pode contribuir para uma maior produtividade do programador da aplicação.

- Início e fim de transações - interações envolvendo definições de classes e de objetos podem alterar o estado do sistema e portanto devem ser inseridas no contexto de uma transação, garantindo a consistência da base de dados em caso de eventuais falhas durante a transação. Sendo assim, a API do sistema deve permitir a indicação do início de uma transação, possibilitando que o sistema seja preparado para as operações de manipulação de objetos. Analogamente, após o término das operações envolvendo a base de dados, a aplicação deve efetivar (commit) o trabalho realizado, salvar os objetos persistentes e atualizar o estado da base; ou abortar o trabalho, sem alterar o estado da base de dados. Além disso, a aplicação deve indicar o término da transação para que o sistema execute as ações apropriadas e mantenha a base de dados num estado consistente. As especificações de projeto determinam se as operações de inicialização e finalização de transação 
são executadas diretamente através da API ou através de construtores da linguagem de programação que implicitamente utilizam as interfaces apropriadas.

Interface de objetos individuais - a API de um sistema de base de dados deve incorporar interfaces para a criação, recuperação e manipulação de objetos persistentes, bem como para a manipulação dos estados dos objetos na base.

- Alocação e desalocação de objetos - o programador da aplicação deve dispor de recursos para alocar e desalocar objetos, persistentes ou transientes, quando necessário ${ }^{1}$. Para tanto, a linguagem de programação pode possuir construtores diferentes para objetos persistentes e objetos transientes, ou utilizar o mesmo construtor para ambos (ortogonalidade de persistência), o que é mais eficiente em termos de produtividade do programador.

- Atribuição e comparação de referências para objetos persistentes - a API deve permitir a atribuição de uma referência a um objeto persistente, bem como a atribuição de uma referência a outra, e a comparação entre valores de duas referências. De maneira análoga à alocação de objetos, a ortogonalidade de persistência para essas operações depende do projeto dos construtores da linguagem de programação.

- Indicação de persistência de objetos - numa aplicação, os objetos potencialmente persistentes alocados em uma transação podem tornar-se persistentes através da indicação de persistência, que deve ser feita antes do término da transação em questão. A API deve fornecer interfaces para esta operação, que pode ser ativada implicitamente quando da alocação de um objeto ou explicitamente antes do término da transação. Ambas as opções são decisões de projeto.

- Indicação de modificação para objetos persistentes - quando uma transação é finalizada com êxito, o sistema deve ser informado, através da API, de todos os objetos lidos da base para a memória e modificados durante uma transação, pois estes objetos devem ser atualizados na base de dados.

\footnotetext{
${ }^{1}$ Nas considerações a respeito da API, o termo persistente é utilizado para objetos persistentes e para objetos potencialmente persistentes (objetos transientes que podem tornar-se persistentes); o termo transiente é utilizado para objetos completamente transientes (objetos transientes que nunca se tornarão persistentes)
} 
- Recuperação de objetos persistentes - a API deve possibilitar a recuperação de objetos armazenados na base de dados, trazendo-os para o espaço de trabalho da aplicação. Os objetos podem ser recuperados implícita ou explicitamente através da API do SGBDOO, dependendo das decisões de projeto do sistema. Quando a aplicação avalia o valor de uma referência para obter o endereço de um objeto persistente, é necessário verificar se o objeto está ou não em memória, pois se não estiver, este deve ser recuperado da base de dados. Esta verificação pode ser feita implicitamente pelo sistema, o que causa um overhead em tempo de execução, ou pode ser explicitamente executada na aplicação, o que potencialmente pode causar erros se o teste de verificação for esquecido.

- Ajuste de referência - quando um objeto é definido em memória e posteriormente passa a receber referências a partir de outros objetos persistentes, as referências originalmente feitas em memória precisam ser convertidas para referências persistentes em disco.

Algumas características adicionais podem ser integradas à API de um SGBDOO com o objetivo de aumentar sua funcionalidade. Dentre as características adicionais relevantes para a interface do sistema de base de dados estão o suporte a transações aninhadas e o suporte a agrupamento de objetos, visando uma melhor performance nas operações de recuperação. Finalmente, dentre as características adicionais relacionadas à interface de objetos individuais destacam-se: recuperação de versões anteriores do objeto (em sistemas que armazenam mais de uma versão de um mesmo objeto), suporte a travamento (locking) de objetos em bases de dados compartilhadas e nomeação de objetos para facilitar a recuperação dos mesmos.

Como ilustração, a Tabela 1 apresenta uma comparação em relação às características apresentadas pelas APIs de alguns SGBDOOs e do padrão ODBC. Os símbolos $\mathrm{S}, \mathrm{N}$ e ? indicam respectivamente, SIM (característica existente), NÃO (característica inexistente), e indeterminado (não está claro na literatura disponível se a característica existe ou não). Os números referem-se a observações relevantes às APIs dos sistemas, e são apresentadas logo após a Tabela 1. O dados referentes aos sistemas GemStone, ObjectStore, POSTGRES e Iris são encontrados em [Perez_91], e os dados do padrão ODBC foram incluídos neste trabalho apenas com o objetivo de ilustrar as características de uma API 
padrão de acesso a bases de dados relacionais, comparando-as a APIs de SGBDOO e SGBD relacionais estendidos.

\begin{tabular}{|c|c|c|c|c|c|c|}
\hline & & ODBC & GemStone & ObjectStore & POSTGRES & IRIS \\
\hline \multirow[t]{2}{*}{ Interface } & Startup & $\mathrm{S}$ & $\mathrm{S}$ & $\mathrm{S}$ & $\mathrm{S}$ & $\mathrm{S}$ \\
\hline & Shutdown & S & S & S & S & $\mathrm{S}$ \\
\hline Do & Início de Transação & $\mathrm{S}$ & $\mathrm{S}$ & $\mathrm{S}$ & $\mathrm{S}$ & $\mathrm{S}$ \\
\hline \multirow[t]{2}{*}{ Sistema } & Commit de Transação & $\mathrm{S}$ & $\mathrm{S}$ & $\mathrm{S}$ & $\mathrm{S}$ & $\mathrm{S}$ \\
\hline & Abort de Transação & $\mathrm{S}$ & $\mathrm{S}$ & $\mathrm{S}$ & $\mathrm{S}$ & $\mathrm{S}$ \\
\hline \multirow[t]{3}{*}{ Interface } & Alocação/Desalocação & $\mathrm{S}$ & $\mathrm{S}$ & $\mathrm{N}$ & $?$ & $?$ \\
\hline & Atribuição/Comparação & $\mathrm{S}$ & $\mathrm{S}$ & $\mathrm{S}$ & $?$ & $?$ \\
\hline & Persistência & $\begin{array}{l}\text { "não se } \\
\text { aplica" }\end{array}$ & $\mathrm{N}$ & 1 & $?$ & 2 \\
\hline \multirow[t]{2}{*}{ Objetos } & Modificação & $\mathrm{S}$ & $\mathrm{S}$ & $\mathrm{S}$ & $\mathrm{S}$ & 2 \\
\hline & Recuperação & $\mathrm{S}$ & $\mathrm{S}$ & $?$ & $\mathrm{~S}$ & $\mathrm{~S}$ \\
\hline \multirow{5}{*}{ Outras } & Transações Elaboradas & $\mathrm{N}$ & $\mathrm{N}$ & $\mathrm{N}$ & $?$ & $?$ \\
\hline & Grupos de Objetos & $\mathrm{N}$ & $\mathrm{S}$ & $\mathrm{S}$ & $?$ & $\mathrm{~S}$ \\
\hline & Versões Anteriores & $\mathrm{N}$ & $\mathrm{N}$ & $\mathrm{S}$ & $\mathrm{S}$ & $?$ \\
\hline & Locks em Objetos & S & S & $?$ & S & $?$ \\
\hline & Nomeação de Objetos & $\mathrm{S}$ & S & $\mathrm{N}$ & $\mathrm{N}$ & $?$ \\
\hline
\end{tabular}

Tabela 1 - Comparação entre APIs de SGBDOO

\section{Observações da Comparação:}

1. O ObjectStore permite apenas alocação de objetos completamente transientes ou completamente persistentes. Objetos não podem ser alocados como transientes e posteriormente indicados como persistentes.

2. No sistema IRIS todos os objetos são persistentes. 


\subsection{Linguagem de Consulta}

A linguagem de consulta é um importante componente para qualquer SGBD. No entanto, algumas linguagens de consulta de SGBDOOs não são tão poderosas quanto em sistemas relacionais e sistemas relacionais estendidos [Cattell_94]. Em SGBDOOs, a sintaxe da linguagem de consulta usualmente é uma extensão da linguagem de programação, possuindo a mesma estrutura de tipos e sendo executada no mesmo do processo. A linguagem de consulta orientada a objetos não possui construtores próprios, pois pretende combinar os construtores de tipos da linguagem de programação orientada a objetos numa linguagem de consulta declarativa de alto nível [Bertino_92], no estilo da linguagem de consulta relacional.

As linguagens de consulta orientadas a objetos têm como característica principal o suporte a conceitos do paradigma de orientação a objetos [Bertino_92] [Chan_94], como os citados nos itens a seguir.

- Identidade de objetos - a linguagem de consulta precisa operar sobre os identificadores dos objetos (OIds). Os predicados de igualdade, por exemplo, são aplicados sobre os valores dos objetos e sobre seus identificadores. Este conceito também é válido para valores e identificadores de propriedades.

- Métodos - num sistema orientado a objetos, os métodos são a interface de acesso ao conteúdo de um objeto. Portanto, uma característica importante das linguagens de consulta orientadas a objetos é o suporte à invocação de métodos.

- Objetos complexos - uma linguagem de consulta orientada a objetos deve suportar resultados de diferentes tipos, pois consultas sobre objetos complexos podem resultar em valores básicos, em objetos ou em coleções. Além disso, é importante que a linguagem permita a navegação em objetos complexos estruturados e a utilização de expressões de caminho para formular consultas (joins implícitos) para estruturas aninhadas.

- Hierarquia de classes - é importante que a linguagem de consulta possibilite que uma consulta aplicada a uma classe seja estendida a suas subclasses, explorando a informação semântica representada através da hierarquia de classes. 
- Binding atrasado - o princípio de sobrecarga, ou polimorfismo, da orientação a objetos requer que a linguagem de consulta suporte a noção de binding atrasado, o que permite a correta execução de métodos sobrecarregados quando de sua invocação.

Além dos princípios básicos da orientação a objetos, uma linguagem de consulta orientada a objetos pode aumentar sua funcionalidade através do suporte a consultas recursivas, consultas aninhadas e criação dinâmica de objetos no contexto de uma consulta [Bertino_92] [Chan_94].

\subsection{Padrões para Gerenciamento de Dados Orientados a Objetos}

Padrões representam uma parte importante no estudo de sistemas de base de dados, pois permitem a construção de aplicações portáveis [Cattell_94]. Os SGBDs relacionais, por exemplo, embora apresentem alto nível de independência de dados e um modelo de dados simples, alcançaram seu sucesso, tanto comercialmente como em pesquisas, devido à padronização que oferecem. O padrão SQL [Date_97], amplamente aceito e utilizado por sistemas relacionais, possibilita alto grau de portabilidade e interoperabilidade entre sistemas, além de simplificar o aprendizado de novos SGBDOOs.

Os padrões para SGBDOOs são essenciais para viabilizar o entendimento e a aceitação da tecnologia de bases de dados orientadas a objetos, pois sistemas que utilizam esta abordagem diferem muito em relação aos modelos de dados e às linguagens de programação [Cattell_94]. O objetivo principal é a utilização de padrões para a construção de aplicações portáveis baseadas em SGBDOOs, cuja principal característica é a integração entre base de dados e linguagem de programação.

Alguns padrões, projetados e especificados por organizações e comitês de padrões [Eisenberg_98], são amplamente difundidos e utilizados em aplicações baseadas SGBDOOs. As seções seguintes descrevem dois dos padrões que se destacam: ODMG e SQL3. Ambos os padrões, se analisados como recursos utilizados por aplicações para acesso a bases de dados, podem ser considerados como APIs para SGBDs. 


\subsubsection{ODMG}

O padrão ODMG (Object Database Management Group) [Barry_98a] [Cattell_94] [Cattell_97] [ODMG_00] foi projetado para SGBDs orientados a objetos com arquiteturas baseadas em linguagens de programação. O objetivo principal do ODMG é viabilizar a construção de aplicações portáveis que possam ser executadas em diferentes SGBDOOs. Para tanto, o esquema de dados, o binding da linguagem de programação e as linguagens de manipulação de dados e de consulta também devem ser portáveis.

De maneira geral, o ODMG pretende ser adotado como um padrão de desenvolvimento de aplicações centradas em sistemas que integram linguagens de programação e bases de dados orientadas a objetos. Para tais aplicações o padrão ODMG pode apresentar resultados mais satisfatórios em relação, por exemplo, ao padrão SQL3 [Barry_98b].

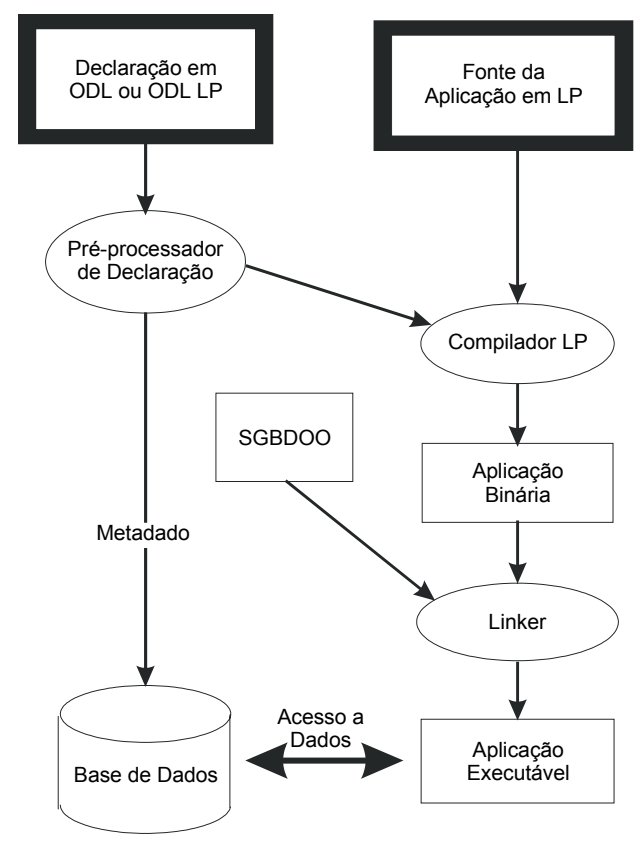

Figura 1 - Utilização de um SGBDOO

A Figura 1 [Cattell_97] apresenta uma visão genérica de como um SGBDOO é utilizado no processo de desenvolvimento de uma aplicação. Como ilustrado, o programador escreve as declarações para o esquema e o programa fonte com a implementação da aplicação. $O$ código fonte é escrito em uma linguagem de programação (LP) determinada pelo programador e utiliza uma biblioteca de classes que fornece uma linguagem completa de manipulação de objetos da base de dados (OML - Object Manipulation Language), incluindo transações e consultas aos objetos. As declarações do esquema podem ser escritas em uma extensão da linguagem de programação, chamada na Figura 1 de ODL 
LP, ou em uma linguagem de definição de objetos (ODL - Object Definition Language) independente da linguagem de programação. Em ambos os casos, um pré-processador transforma as declarações de acordo com a sintaxe exigida pelo compilador da linguagem de programação utilizada. As declarações e o programa fonte são compilados e integrados (linked) com o SGBDOO, gerando a aplicação executável. A aplicação acessa a base de dados, cujos tipos devem ser compatíveis com as declarações do esquema. Uma mesma base de dados pode ser compartilhada entre diversas aplicações ao longo de uma rede, considerando-se que um SGBDOO deve prover serviços de compartilhamento através de transações e gerenciamento de locks, permitindo que dados sejam armazenados e manipulados em memória cache no espaço de trabalho da aplicação.

Com base no contexto ilustrado na Figura 1, o ODMG integra os seguintes componentes: Modelo de Objetos, Linguagens de Especificação de Objetos, Linguagem de Consulta a Objetos e Bindings padrões de SGBDOOs para as linguagens C++, Smalltalk e Java. Uma visão geral destes componentes é apresentada nas subseções seguintes, destacando as principais características de cada um deles. Descrições detalhadas sobre o Modelo de Objetos, sobre a sintaxe, a gramática e as particularidades das Linguagens de Especificação (ODL e OIF) e da Linguagem de Consulta (OQL), bem como especificações dos componentes ODL, OML e OQL dos bindings para as linguagens $\mathrm{C}++$, Smalltalk e Java, podem ser encontradas em [Cattell_97].

\subsubsection{Modelo de Objetos}

O padrão ODMG define um modelo de objetos que especifica os tipos de informações semânticas que podem ser suportados em um SGBDOO compatível com o ODMG. A semântica do Modelo de Objetos determina, entre outras coisas, as características dos objetos, os tipos de relacionamento entre eles e como os objetos podem ser nomeados e identificados.

O Modelo de Objetos do ODMG tem como primitivas básicas de modelagem o objeto, que possui identificador único (OId), e a literal, que não tem identificador. Objetos e literais são categorizados de acordo com seus tipos, o que implica que todos os elementos de um mesmo tipo possuem conjuntos de estados e comportamento comuns. O estado de um objeto é determinado pelos valores de suas propriedades, as quais podem ser atributos ou relacionamentos. Por outro lado, o comportamento do objeto é definido pelo conjunto de 
operações que podem ser executadas sobre ou pelo objeto. Os construtores do modelo, destacados acima, são utilizados na modelagem de aplicações centradas em SGBDOOs, permitindo a declaração explícita de relacionamentos e operações. O modelo de objetos gerado para uma aplicação corresponde ao esquema lógico na base de dados.

\subsubsection{Linguagens de Especificação de Objetos}

O padrão ODMG possui linguagens de especificação, independentes da linguagem de programação, que são usadas para a definição de esquemas, operações e estados dos objetos da base de dados de um SGBDOO. Essas linguagens têm como objetivo facilitar a portabilidade de bases de dados em implementações "ODMG compiláveis". Além disso, as linguagens de especificação auxiliam a interoperabilidade entre SGBDOOs de diferentes vendedores. O ODMG possui duas linguagens de especificação principais: ODL - Object Definition Language e OIF - Object Interchange Format.

A linguagem ODL, utilizada para a especificação dos tipos de objetos do Modelo de Objetos do ODMG, oferece suporte a todos os construtores semânticos do modelo. A ODL atua como uma linguagem de definição para a especificação de objetos (DDL para tipos de objetos) e não como uma linguagem de programação completa.

A ODL pode ser adotada em projetos de aplicações sem levar em consideração a linguagem de programação a ser utilizada na implementação. Desta forma, os resultados de um projeto podem ser utilizados diretamente no SGBDOO ou traduzidos para uma linguagem qualquer de descrição de dados. No entanto, as especificações ODL podem ser traduzidas ou implementadas com mais eficiência pelas linguagens C++, Java e Smalltalk, para as quais estão definidos bindings ODMG. Além disso, a ODL permite que uma mesma base de dados seja compartilhada por diferentes linguagens de programação, possibilitando ainda que uma aplicação seja portada para uma linguagem diferente sem que a definição do esquema seja re-escrita. A ODL também fornece um contexto de integração de esquemas de origens variadas, mesmo que estes esquemas tenham sido definidos a partir de modelos de dados e linguagens de definição diferentes. Por exemplo, padrões como o SQL3 podem ter seus modelos mapeados para especificações ODL, formando uma base que permite que vários modelos sejam integrados com uma semântica comum. 
A OIF é uma linguagem de especificação utilizada para salvar em arquivos o estado corrente da base de dados, e para ler dos arquivos esta mesma informação. A OIF também é utilizada para migrar objetos entre bases de dados, fornecer documentação e gerenciar conjuntos de testes na base.

\subsubsection{Object Query Language (OQL)}

O padrão ODMG possui uma linguagem de consulta, OQL, que oferece suporte aos construtores do Modelo de Objetos. A OQL é uma linguagem declarativa destinada a consultas e atualizações de objetos da base de dados. É simples e completa no que se refere a linguagens de consulta que acessam SGBDOOs, embora não seja computacionalmente completa.

A linguagem OQL incorpora algumas formas sintáticas da linguagem SQL, além de apresentar algumas características similares ao padrão SQL2 e ser compatível com o SQL3. As principais extensões da OQL em relação ao SQL2 são de suporte às noções de orientação a objetos, como objetos complexos, identidade de objetos, polimorfismo, expressões de caminho, invocação de operações e binding atrasado.

A OQL fornece primitivas de tratamento eficiente de construtores como listas, vetores e estruturas em geral, mas não restringe o tratamento de conjuntos de objetos a estes construtores. Como linguagem funcional, a OQL permite a composição de operadores, desde que os operandos respeitem o sistema de tipos. Esta restrição é uma conseqüência direta do fato de que o resultado de qualquer consulta pode ser consultado novamente, e portanto deve ter um tipo pertencente ao sistema de tipos do ODMG.

As cláusulas OQL podem ser chamadas por implementações em linguagens de programação para as quais existam bindings ODMG. Analogamente, cláusulas OQL podem chamar operações programadas nessas linguagens.

\subsubsection{Bindings para Linguagens de Programação}

A noção de binding no padrão ODMG é baseada na utilização e extensão da sintaxe e da semântica das linguagens de programação para fornecer suporte ao desenvolvimento de aplicações apoiadas em SGBDOOs [Cattell_94]. Em sua versão 2.0 [Cattell_97], o ODMG possui bindings definidos para as linguagens $\mathrm{C}++$, Smalltalk e Java, e para cada um deles 
existem três componentes: ODL, OML e OQL. O componente ODL trata a definição do esquema da base de dados, enquanto o OML manipula as instâncias dos tipos definidos no esquema, a partir dos OIds dos objetos. O componente OQL é um subconjunto do OML destinado a consultas associativas, ou seja, acesso baseado em valores associados às propriedades (atributos e relacionamentos) dos objetos.

O objetivo principal dos bindings para linguagens de programação é tornar a existência de duas linguagens (linguagem de programação e linguagem de base de dados) transparente para o programador, ou seja, o programador deve "pensar" que está trabalhando com apenas uma linguagem. Conseqüentemente, o sistema de tipos da linguagem de programação e da base de dados é unificado, e as instâncias destes tipos podem ser persistentes (característica das bases de dados) ou transientes (característica das linguagens de programação).

O binding para uma determinada linguagem de programação mantém a sintaxe e a semântica da linguagem básica à qual é inserido. O binding é estruturado apenas como um subconjunto da linguagem de programação base, e portanto não altera a funcionalidade já existente. As expressões em OML e OQL podem ser combinadas com expressões da linguagem de programação base, e vice-versa.

Um aspecto importante no contexto de aplicações apoiadas em bases de dados é o suporte a persistência [Atkinson_94] [Cattell_94] [Elmasri_00]. Portanto, torna-se relevante que os bindings para linguagens de programação ofereçam esse suporte, uma vez que as linguagens de programação tratam apenas objetos transientes. O binding para a linguagem $\mathrm{C}++$ permite a criação de classes que podem ter instâncias persistentes ou transientes. Estas classes, chamadas persistence-capable classes, utilizam operadores sobrecarregados cujos argumentos definem o "tempo de vida" de um objeto, isto é, criam objetos persistentes ou transientes. O binding para a linguagem Java suporta persistência através da noção de "alcançabilidade", o que significa que quando uma transação é efetivada (committed), os objetos referenciados direta ou indiretamente por objetos persistentes tornam-se também persistentes. O binding para Smalltalk, que habilita o armazenamento de objetos Smalltalk, também trata persistência por "alcançabilidade" e os objetos "não alcançados" são coletados por um sistema de garbage collection. 


\subsubsection{SQL3}

SQL3 é um padrão importante para gerenciamento de dados orientados a objetos e relevante principalmente em sistemas de bases de dados relacionais estendidos[Cattell_94]. Entretanto, pode ter impacto sobre outras abordagens de arquiteturas de bases de dados, uma vez que o padrão SQL é largamente difundido e utilizado em sistemas de bases de dados. O padrão SQL3 é indicado para criar ou estender aplicações relacionais com suporte a objetos. Para tais aplicações o SQL3 é a abordagem mais simples e apropriada, se comparado com o ODMG [Barry_98b].

Caracterizado como SQL orientado a objetos [Eisenberg_99], SQL3 é uma linguagem de consulta relacional a objetos definida a partir da extensão e do aprimoramento da segunda geração do padrão SQL, conhecida como SQL2 ou SQL-92 [Date_97]. Logo, a definição do SQL3 inclui toda a linguagem SQL2 como um subconjunto. Além das características herdadas do SQL2, o SQL3 possui extensões que incluem um modelo de dados que permite a representação de informações para as quais o formato tabular relacional não é adequado. Outra extensão é a inclusão de características procedimentais que possibilitam criação, gerenciamento e consulta de objetos persistentes.

As subseções seguintes apresentam as características mais recentes introduzidas ao padrão SQL3 para suportar os requisitos da abordagem orientada a objetos, e fazer do SQL uma linguagem computacionalmente completa [Cattell_94]. Descrições mais detalhadas a respeito dessas e outras características do SQL3, e especificações sintáticas e semânticas da linguagem, como predicados, construtores, palavras-chave, regras e restrições para definição de cláusulas, entre outros, podem ser encontradas em [Date_97], [Eisenberg_99] e [SQL3_97].

\subsubsection{Tipos de Dados e Funções Definidos pelo Usuário}

O suporte a tipos e funções definidos pelo usuário, e conseqüente suporte a Tipos Abstratos de Dados (TADs), são considerados características fundamentais introduzidas ao padrão SQL3, pois são recursos de suporte à orientação a objetos [Cattell_94] [Eisenberg_99].

Os TADs na linguagem SQL3 especificam basicamente atributos e rotinas. Cada atributo pode ser de um tipo básico como INTEGER, de um tipo coleção como ARRAY, ou de um 
outro TAD definido pelo usuário. As rotinas podem ser procedimentos, métodos e funções que representam os aspectos de comportamento do TAD, ou seja, as operações válidas associadas ao mesmo. Assim como em linguagens de programação orientadas a objetos, as rotinas de um TAD em SQL3 podem ser sobrecarregadas.

O exemplo a seguir ilustra a definição do tipo Pessoa, com os atributos Nome, RG e Data_Nasc, e a rotina Idade:

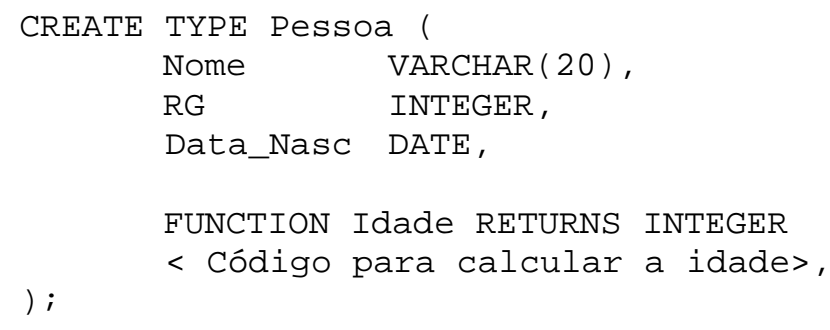

Todos os atributos e rotinas de um TAD são encapsulados, sendo que apenas aqueles declarados como PUBLIC são acessíveis fora da definição do TAD [SQL3_97]. No caso de sistemas de gerenciamento de dados orientados objetos, os atributos e as rotinas públicos de um TAD compõem a interface de acesso aos objetos criados como instâncias do TAD em questão.

Uma vez que o SQL3 oferece suporte ao conceito de objetos, torna-se necessário o suporte a identificadores únicos de objetos (OIds). Esta necessidade está diretamente associada ao relacionamento entre TADs e tabelas relacionais, pois embora a linguagem permita a utilização de TADs em declarações e cláusulas, o armazenamento efetivo de informações representadas como TADs requer a manipulação de tabelas relacionais [Cattell_94]. Para tanto, o SQL3 fornece um mecanismo de definição de tabelas chamadas "typed tables" [Eisenberg_99], cujas colunas são derivadas de atributos de um tipo estruturado. Cada coluna de uma tabela corresponde a um atributo do TAD, e cada linha representa uma instância com um OId único dentro da base de dados. As rotinas definidas para o TAD operam sobre as linhas da tabela. A cláusula abaixo ilustra a criação de uma typed table Pes associada ao TAD Pessoa definido anteriormente:

CREATE TABLE Pes OF Pessoa;

Os valores dos OIds são definidos a partir de um tipo especial chamado REF [Eisenberg_99], que é associado ao TAD. Os valores do tipo REF, derivados dos valores 
de um dos atributos do TAD, são os identificadores dos objetos. Desta forma, um valor de um tipo REF faz referência a apenas uma linha, e sempre à mesma, da typed table associada ao TAD, ou então não faz referência a mais nada. O exemplo seguinte ilustra a utilização do tipo REF, acrescentando ao TAD Pessoa uma declaração que determina que os OIds dos objetos do tipo Pessoa são derivados do atributo RG:

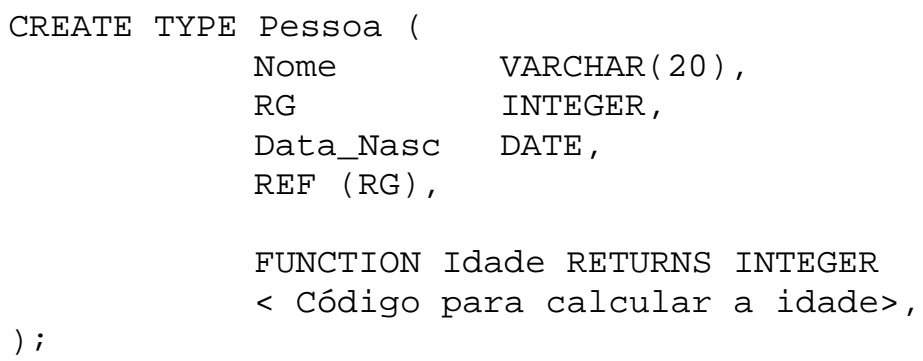

O padrão SQL3 suporta a noção de hierarquia, o que significa que TADs já definidos podem ser especializados em novos TADs (subtipos), compondo hierarquias de tipos. Os subtipos herdam dos supertipos todos os atributos e rotinas, embora possam incluir novos atributos e novas rotinas, como ilustrado no exemplo abaixo:

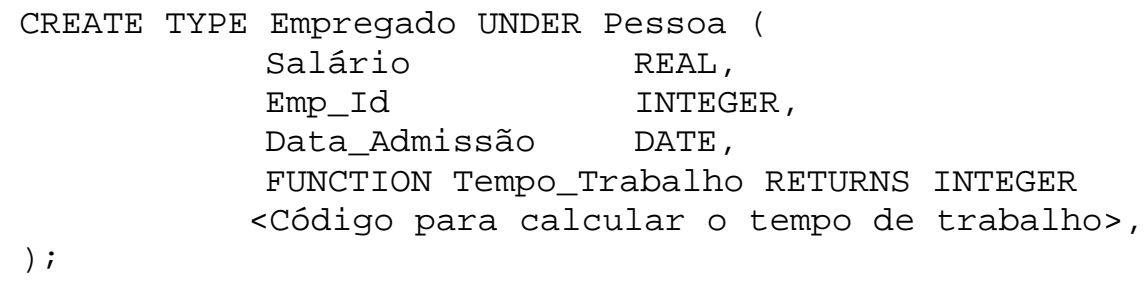

O tipo Empregado é um subtipo de Pessoa e possui, além dos atributos e rotinas de Pessoa, novos atributos (Salário, Emp_Id e Data_Admissão) e uma nova rotina (Tempo_Trabalho).

\subsubsection{Novos Tipos de Dados}

SQL3 possui quatro novos tipos de dados [Eisenberg_99]: LARGE OBJETC (LOB), BOOLEAN e os tipos compostos ARRAY e ROW.

O tipo LARGE OBJECT possui as variações CHARACTER LARGE OBJECT (CLOB) e BINARY LARGE OBJECT (BLOB), que representam respectivamente strings de caracteres e strings binárias de comprimentos variáveis. Ambas as variações possuem 
restrições que não permitem sua utilização como chave primária (PRIMARY KEY) e como chave estrangeira (FOREIGN KEY) [Eisenberg_99]. Além disso, as comparações entre valores do tipo LOB são restritas a testes de igualdade e não igualdade.

O tipo ARRAY permite o armazenamento de coleções de valores diretamente em uma coluna de uma tabela da base de dados. Por exemplo, a cláusula:

DIAS_DA_SEMANA VARCHAR (10) ARRAY [7]

armazena os nomes dos sete dias da semana diretamente em uma única linha e em uma única coluna de uma tabela da base de dados. Neste caso, embora a informação armazenada possa ser decomposta, pode-se dizer que o SQL3 não satisfaz a Primeira Forma Normal (1NF) [Elmasri_00], que define que um atributo de uma tupla deve assumir apenas valores atômicos, ou seja, armazenar coleção de valores em uma única coluna e em uma única linha é proibido pela $1 \mathrm{NF}$.

O tipo ROW é utilizado para armazenar valores estruturados em uma única coluna, como ilustrado pelo atributo Endereço nas cláusulas abaixo:

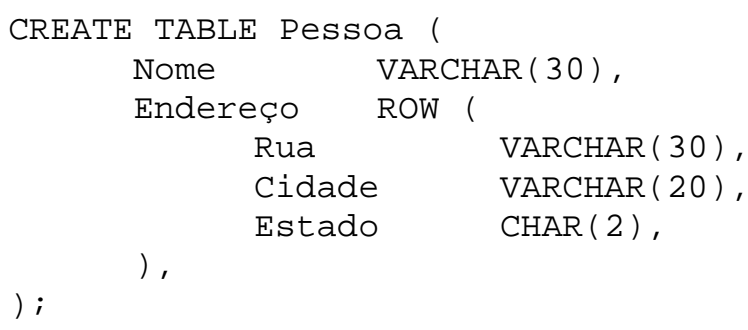

As considerações a respeito da $1 \mathrm{NF}$ para o tipo ARRAY também são válidas para o tipo ROW.

\subsubsection{Segurança Adicional}

O padrão SQL3 disponibiliza um recurso baseado em papéis (roles) definidos pelo usuário que permite que privilégios sejam concedidos indistintamente mediante identificadores de autorização e mediante papéis [Date_97] [Eisenberg_99]. Os papéis, por sua vez, também são privilégios concedidos a identificadores de autorização e a outros papéis. Este mecanismo aninhado pode simplificar o gerenciamento de segurança em um ambiente de base de dados. 


\subsubsection{Novos Aspectos Semânticos}

SQL3 incorpora alguns novos aspectos de comportamento, dentre os quais estão consultas recursivas, transações com savepoints e atualização de visões.

A consulta recursiva atende às aplicações para as quais o processamento recursivo é um requisito importante e necessário [Date_97]. Por exemplo, numa base de dados que armazena informações de pesquisas genealógicas, encontrar todos os ancestrais de uma pessoa é uma consulta comum que requer um processo recursivo. Esta consulta pode ser construída como no exemplo abaixo, em que Pai_De (Pai, Filho) é uma tabela que representa o relacionamento de paternidade. Ancestral_De é chamado de "nome da consulta" e integra os pares (Ancestral, Descendente) que resultam da consulta recursiva. A segunda parte da consulta seleciona, entre os pares (Ancestral, Descendente), todos os ancestrais de "Júlia".

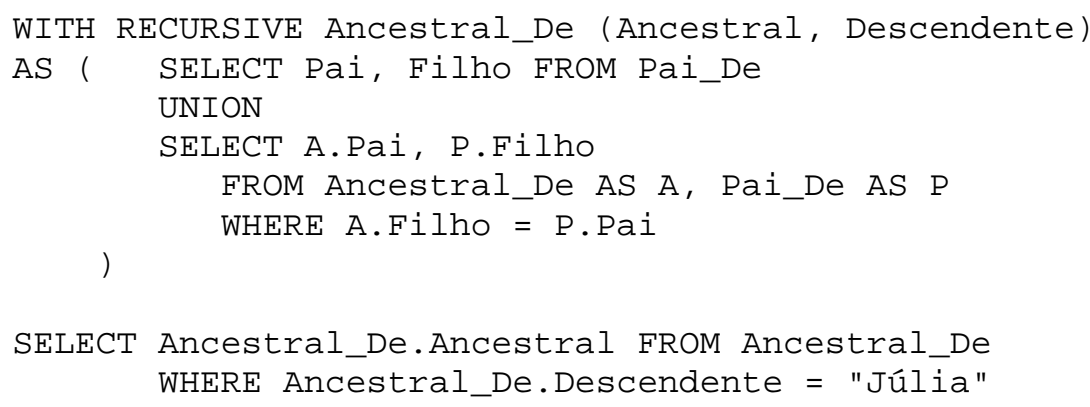

As transações com savepoints atuam como subtransações que garantem que apenas as ações realizadas a partir de um determinado ponto (savepoint) sejam afetadas por operações de "desfazer" (roll back). Isto evita que todas as ações de uma transação sejam desfeitas, preservando as atualizações efetuadas antes do savepoint especificado [Eisenberg_99].

O mecanismo de visões, utilizado em muitas aplicações, geralmente não permite operações de atualização em visões. O SQL3, entretanto, permite que dependências funcionais inerentes à aplicação determinem quais visões podem ser atualizadas e como as alterações são realizadas na base de dados [Eisenberg_99]. 


\subsubsection{Extensões Procedimentais}

SQL3 inclui novos construtores procedimentais, entre os quais estão declarações condicionais, como IF / THEN/ELSE e CASE, e declarações de repetições, como WHILE e FOR. Estes construtores contribuem para fazer do SQL3 uma linguagem computacionalmente completa.

\subsection{Considerações Finais}

Neste capítulo aborda os principais conceitos de Sistemas de Gerenciamento de Bases de Dados Orientados a Objetos. Em geral, os princípios de orientação a objetos fundamentam as características dos SGBDOOs e de seus componentes, bem como dos padrões especificados para auxiliar o desenvolvimento de aplicações portáveis apoiadas nestes sistemas.

A revisão conceitual apresentada neste capítulo representa o embasamento teórico inicial para o desenvolvimento do trabalho proposto. Em particular, as considerações a respeito da API dos SGBDOOs (seção 2.4) são de fundamental importância no contexto do trabalho, uma vez que este tem como objetivo principal definir uma API para um SGBDOO. O sistema SIRIUS, para o qual pretende-se criar uma API, é tratado no capítulo seguinte, onde são abordadas as características predominantes de alguns SGBDOOs clássicos. 


\section{Sistemas Orientados a Objetos}

\subsection{Introdução}

Os SGBDOOs oferecem o suporte apropriado a aplicações de âmbito técnico-científico, como as citadas no Capítulo 1. Tais aplicações abrangem diferentes áreas de conhecimento, entre as quais estão engenharia, medicina e inteligência artificial. No entanto, aplicações tradicionais voltadas para ambientes de negócios, usualmente apoiadas em SGBDs relacionais, também podem obter benefícios da tecnologia dos SGBDOOs [Cattell_94].

Vários SGBDOOs vêm sendo desenvolvidos com um objetivo em comum: integrar bases de dados e linguagens de programação orientadas a objetos para oferecer suporte adequado às exigências de aplicações não convencionais, ou seja, modelagem e tratamento adequado de objetos complexos, armazenamento e gerenciamento de dados em larga escala, extensibilidade, portabilidade, entre outras.

As seções seguintes descrevem os sistemas O2 e Jasmine, sintetizando as características de seus principais componentes, lembrando que não é objetivo deste trabalho fazer uma descrição completa e detalhada de tais sistemas, mas sim apresentar uma visão geral de cada um deles. Outros SGBDOOs são brevemente comentados na seção 3.5.

\subsection{Sistema 02}

O2 [Bancilhon_92] [Deux_90] [Deux_91] é um sistema comercial atualmente desenvolvido pela O2 Technology e comercializado pela Ardent Software, Inc. O O2 é adequado ao desenvolvimento de aplicações não convencionais, como sistemas de apoio à engenharia, sistemas geográficos e automação de escritórios, podendo também ser utilizado por aplicações tradicionais. 
O sistema $\mathrm{O} 2$ integra interface com o usuário, linguagem de programação e base de dados, utilizando o paradigma de orientação a objetos e mantendo a conformidade com padrões. Com isso, pretende aumentar a produtividade no processo de desenvolvimento de aplicações e melhorar a qualidade do produto final, em termos de aparência, performance, manutenibilidade e habilidade de customização.

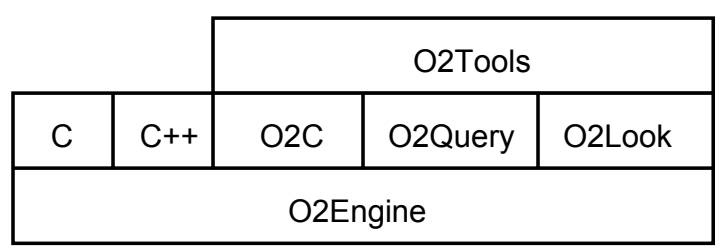

Figura 2 - Estrutura Funcional do Sistema 02

O O2 integra um conjunto de componentes que fazem dele um sistema de bases de dados e um sistema de programação orientado a objetos. A Figura 2 [Deux_91] ilustra a configuração funcional do $\mathrm{O} 2$, destacando o O2Engine - núcleo do sistema - e os dois tipos de interfaces (APIs) suportadas por este núcleo: as interfaces de linguagens para $\mathrm{C}$ e $\mathrm{C}++$, e o ambiente $\mathrm{O} 2$, composto por uma linguagem de objetos de $4^{\mathrm{a}}$ geração denominada $\mathrm{O} 2 \mathrm{C}$, uma linguagem de consulta O2Query (também chamada de O2SQL [Cattell_94]), um gerador de interfaces de usuário O2Look, e um ambiente gráfico de programação O2Tools, o qual inclui um debugger e um browser para esquema e base de dados. As subseções seguintes descrevem os elementos relevantes do $\mathrm{O} 2$ para o contexto deste trabalho.

\subsubsection{Arquitetura do Sistema}

O O2Engine é um engine de base de dados orientado a objetos, responsável pelo armazenamento de objetos complexos (estruturados e multimídia) e por funções de gerenciamento de disco, distribuição, gerenciamento de transações, concorrência, recuperação, segurança e administração de dados.

A arquitetura do O2Engine é organizada em três camadas principais, como ilustrado na Figura 3. O nível mais alto é o Gerenciador de Esquemas, cuja funcionalidade abrange a criação, acesso, atualização e a destruição de classes, métodos e nomes globais. Ainda nessa camada são manipulados os mecanismos de importação entre esquemas, verificação de consistência de esquemas e verificação de regras semânticas em hierarquias de tipos. 
Na camada intermediária está o Gerenciador de Objetos, responsável gerenciamento de objetos, trocas de mensagens, manipulação de valores estruturados e operações aplicadas sobre estes valores. O Gerenciador de Objetos implementa também o princípio da "alcançabilidade" para persistência de objetos, garbage collection para objetos não referenciados, gerenciamento de transações, estratégias de indexação e clustering baseadas em objetos complexos, e herança.

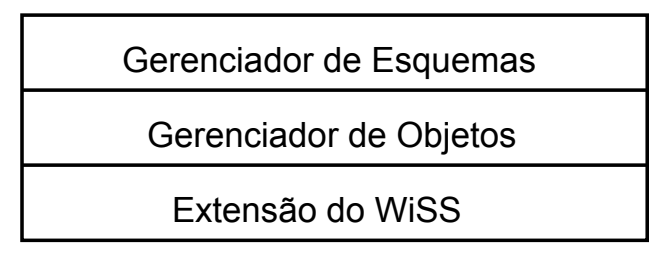

Figura 3 - Arquitetura do 02 Engine

A camada mais interna, também chamada de O2Store [Cattell_94], é uma extensão do WiSS (Wisconsin Storage System), que atua como o gerenciador de disco do O2. O WiSS provê funções de tratamento de estruturas persistentes, gerenciamento de disco e controle de concorrência. As extensões do WiSS original para o O2 incluem arquitetura cliente/servidor no nível do O2Store, recuperação de falhas e rollback, e suporte multithread para o servidor.

\subsubsection{Modelo de Dados e Linguagem O2C}

A linguagem $\mathrm{O} 2 \mathrm{C}$ - considerada uma linguagem de $4^{\mathrm{a}}$ geração por integrar programação, manipulação de base de dados e geração de interface de usuário - implementa todos os conceitos e construtores do modelo de dados do $\mathrm{O} 2$.

$\mathrm{O}$ modelo de dados e a linguagem $\mathrm{O} 2 \mathrm{C}$ suportam os tipos atômicos integer, real, character, string, boolean e bits, e tipos complexos definidos recursivamente através dos construtores tuple, list e set. As instâncias dos tipos são chamadas de valores.

No O2, o esquema da base de dados é definido por classes que descrevem a estrutura e o comportamento de um conjunto de objetos, identificados univocamente através de OIds. A parte estrutural de uma classe é definida por um tipo e o comportamento é representado por um conjunto de métodos. O exemplo a seguir ilustra a criação da classe Restaurante, com os atributos Nome, Menu e Cidade e o método Inserir_Novo_Prato. Os 
atributos Nome e Cidade são do tipo string e o atributo Menu é uma lista de tuplas formadas por Preço e Conteúdo. O método, assim como em linguagens de programação orientadas a objetos, é implementado fora da especificação da classe.

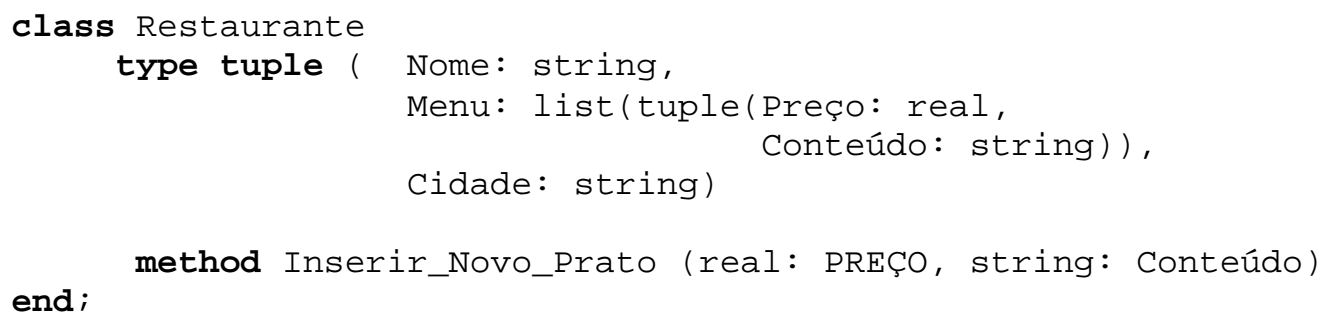

O O2 suporta o conceito de herança, simples e múltipla, permitindo que uma classe tenha seu tipo e seus métodos herdados de outras classes. A herança múltipla pode gerar eventuais colisões de nomes quando atributos ou métodos herdados de classes diferentes possuem o mesmo nome. Neste caso, os nomes conflitantes são explicitamente renomeados na subclasse (comando renaming). Novos atributos e métodos podem ser definidos para a subclasse, assim como tipos e métodos podem ser redefinidos localmente.

O tratamento à persistência segue o princípio da "alcançabilidade", onde um objeto tornase persistente se estiver ligado a um objeto raiz persistente através de um relacionamento de herança ou de composição (coleções). O conceito de encapsulamento é tratado no $\mathrm{O} 2$ em três níveis: encapsulamento de atributos e métodos numa classe, encapsulamento de um conjunto de classes no esquema e encapsulamento da base de dados. Os dois últimos tipos permitem reusabilidade, pois um esquema pode exportar um conjunto de classes para outro esquema, assim como uma aplicação rodando sobre uma base de dados em particular pode acessar outra base de dados apenas invocando um método que será executado na base "remota".

\subsubsection{Linguagem de Consulta}

A linguagem de consulta $\mathrm{O} 2 \mathrm{Query}$ é um subconjunto da $\mathrm{O} 2 \mathrm{C}$, mas pode ser utilizada como uma linguagem interativa independente ou pode ter seus comandos chamados dentro de programas $\mathrm{C}$ e $\mathrm{C}++$.

O2Query é uma linguagem SQL-like estendida para manipular valores e objetos complexos. Além disso, todos os tipos de dados, operadores e métodos são aceitáveis em uma consulta em O2Query. As consultas são especificadas basicamente em três partes: a 
parte do select define a estrutura do resultado; a parte do from introduz as classes de objetos, os conjuntos e listas sobre os quais a consulta será executada; e a parte where define o predicado que "filtra" o resultado. O exemplo a seguir ilustra uma consulta sobre objetos da classe Restaurante (definida na seção 3.2.2) que resulta em uma estrutura com as seguintes informações: nomes dos restaurantes de São Paulo onde pode-se comer por menos de 50 reais e as respectivas opções do menu, contendo os pratos e os preços.

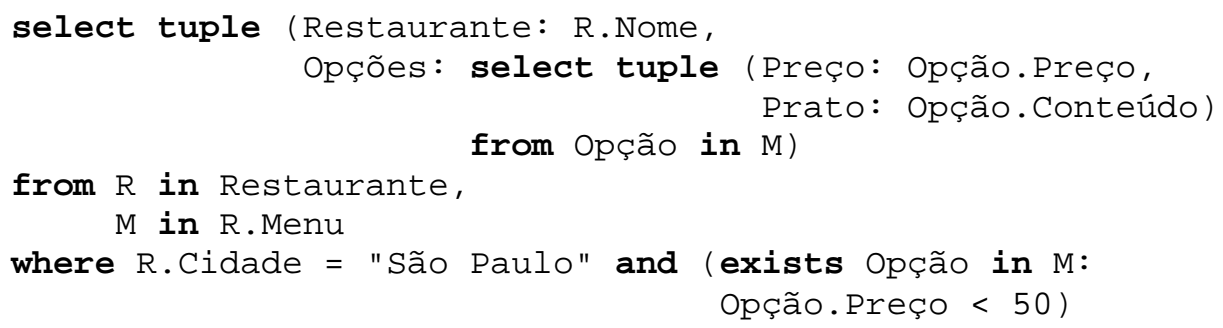

As linguagens $\mathrm{O} 2 \mathrm{Query}$ e $\mathrm{O} 2 \mathrm{C}$ constituem uma das formas de construção de aplicações e manipulação de dados, pois fazem parte da interface do ambiente O2. Por outro lado, aplicações também podem ser implementadas nas linguagens $\mathrm{C}$ e $\mathrm{C}++$, e conectadas ao $\mathrm{O} 2$ através das interfaces para linguagens de programação.

\subsubsection{Interfaces para Linguagens de Programação}

O sistema $\mathrm{O} 2$ suporta interfaces de programação para as linguagens $\mathrm{C}$ e $\mathrm{C}++$, viabilizando o desenvolvimento de aplicações nestas linguagens e a reutilização de aplicações existentes.

A integração de uma linguagem de programação $<\mathrm{LP}>$ e o $\mathrm{O} 2$ pode ocorrer de duas maneiras. Na primeira, o $\mathrm{O} 2$ exporta classes do esquema para o ambiente da linguagem de programação. $\mathrm{O}$ comando export to $<\mathbf{L P}>$ gera classes $<\mathrm{LP}>$ correspondentes às classes do esquema, permitindo que a aplicação manipule os dados do O2. A segunda abordagem, simétrica à primeira, permite que as classes sejam definidas na aplicação em linguagem $<\mathrm{LP}>$. As classes criadas na aplicação, assim como os objetos destas classes, podem tornar-se persistentes através do comando import from $<\mathbf{L P}>$, que gera no esquema $\mathrm{O} 2$ as classes correspondentes às classes especificadas em $<\mathrm{LP}>$.

O exemplo a seguir ilustra a utilização do comando export to $\mathbf{C + +}$, supondo que a aplicação C++ pretende utilizar a classe Restaurante definida anteriormente. No exemplo, a aplicação não precisa utilizar os métodos da classe, mas apenas o seu tipo. 
export class Restaurante type to $\mathbf{C + +}$

Este comando gera as seguintes declarações em $\mathrm{C}++$ :

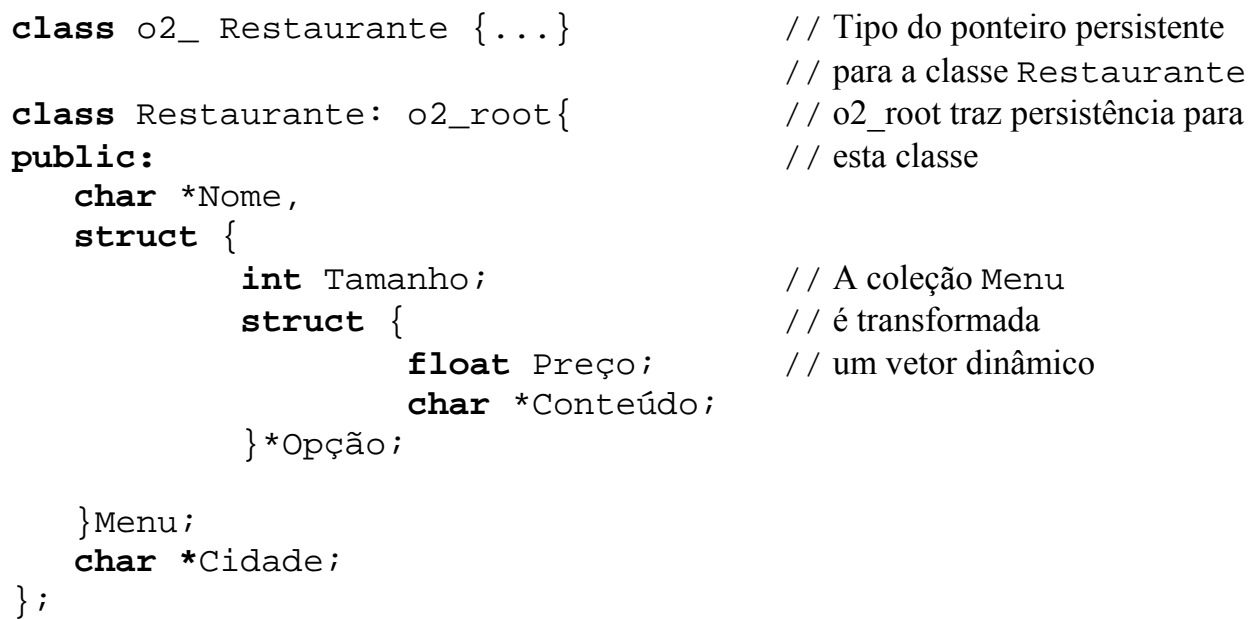

A interface para a linguagem $\mathrm{C}++$ incrementa o ambiente de desenvolvimento $\mathrm{C}++$ com quatro características adicionais para suportar a integração com o sistema O2:

- Ponteiros persistentes: permitem acesso transparente a qualquer objeto persistente. Um ponteiro persistente é pré-definido como um template que implementa a sintaxe e o comportamento de um ponteiro padrão da linguagem $\mathrm{C}++$.

- Coleções genéricas: provêem gerenciamento de coleções transientes e persistentes, como listas, conjuntos e vetores, pois permitem a definição de classes para os construtores de coleções do O2: set e list.

- Raízes persistentes: são objetos nomeados através dos quais objetos $\mathrm{C}++$ transientes podem tornar-se persistentes pelo princípio da "alcançabilidade".

- Suporte a bases de dados: inclui transações, indexação e O2Query embutido.

\subsection{Sistema Jasmine}

O sistema Jasmine [Ishikawa_93] [Ishikawa_96] [Jasmine_00], atualmente desenvolvido e comercializado pela Computer Associates, pretende atender às necessidades de aplicações não convencionais com ênfase em tarefas voltadas para engenharia, tais como gerenciamento de dados de projeto, suporte a CAD inteligente e gerenciamento de 
documentos de engenharia (textos, figuras, tabelas, entre outros). Dentre as características do Jasmine, algumas são relevantes para aplicações em engenharia, como facilidade de gerenciamento de restrições, facilidade de inclusão de regras de restrições, alimentação automática da base de dados e integração de esquemas. Além disso, o Jasmine oferece suporte ao desenvolvimento de aplicações multimídia, que envolvem gerenciamento de dados complexos.

As subseções seguintes apresentam uma visão geral da arquitetura, do modelo de dados e da linguagem de base de dados do sistema Jasmine.

\subsubsection{Arquitetura do Sistema}

O Jasmine possui uma estrutura em camadas que consiste de um nível de gerenciamento de objetos, um nível de gerenciamento de dados e uma base de dados relacional utilizada como repositório de dados. A Figura 4 [Ishikawa_96] ilustra a arquitetura do sistema, sobre a qual operam dois subsistemas predominantes: o subsistema de gerenciamento de dados e o subsistema de gerenciamento de objetos.

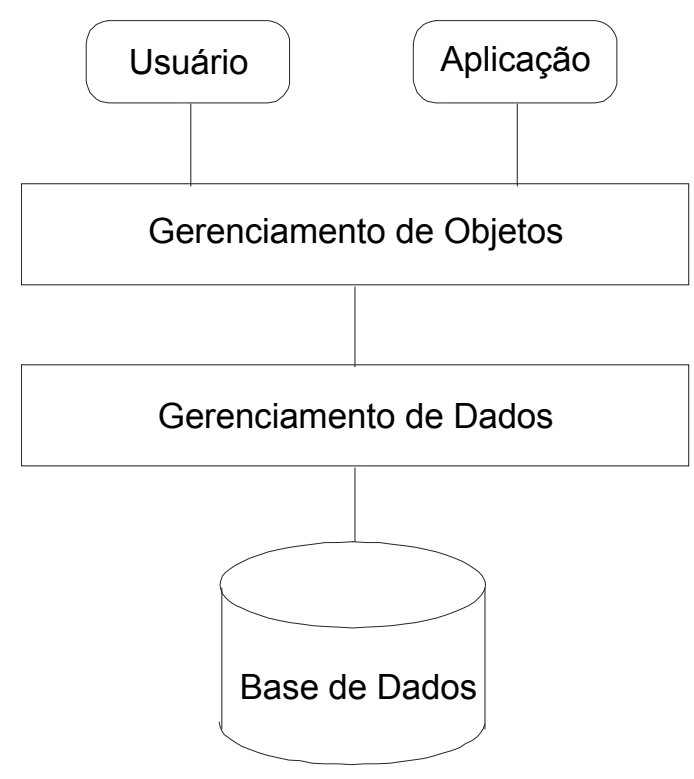

Figura 4 - Arquitetura do Sistema Jasmine

O subsistema de gerenciamento de dados é definido como um SGBD relacional estendido de propósito geral, pois utiliza a tecnologia relacional para o gerenciamento de dados. Esse subsistema possui métodos eficientes para armazenar e acessar objetos em memória secundária através das relações da base de dados relacional. Uma extensão à tecnologia relacional tradicional é o suporte a relações aninhadas, incorporado ao subsistema para 
No exemplo, a palavra chave mandatory indica que o atributo não pode receber valor nulo. Multiple indica atributo multi-valorado e enumerated indica início de uma lista de atributos definidos pelo programador. A palavra chave Db precede o nome da base de dados à qual a classe definida deve fazer parte e super indica quem é sua superclasse. A classe Composite, definida pelo sistema, é uma superclasse das classes que estão no nível mais alto da hierarquia de classes criada pelo usuário. No exemplo, a classe Pessoa não possui superclasse definida pelo usuário, ou seja, está no nível mais alto da hierarquia. Portanto, a superclasse de Pessoa é a classe Composite definida pelo sistema. Assume-se, para este exemplo, que a classe Cidade_Or, tipo do atributo Origem, foi previamente definida.

O exemplo abaixo ilustra uma possível instância da classe Pessoa:

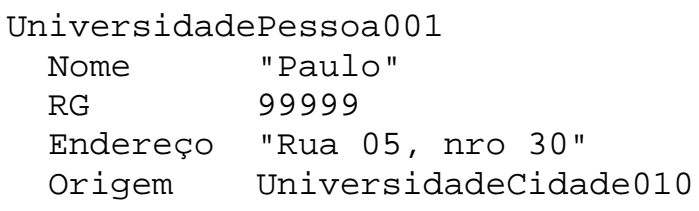

As classes são organizadas em uma hierarquia através de relacionamentos de generalização, oferecendo suporte a hierarquias de classes e herança múltipla. Em uma hierarquia de classes, qualquer classe pode ser instanciada diretamente, sendo que as instâncias de classes "não folhas" da hierarquia podem expressar conhecimento incompleto do domínio da aplicação. Por exemplo, se a classe Pessoa é especializada nas subclasses Estudante e Professor, as instâncias diretas da classe Pessoa denotam um conjunto de pessoas que a priori não são nem estudantes nem professores.

Uma classe pode ser interpretada como um conjunto de todas as suas instâncias diretas e de todas as instâncias de suas subclasses, o que caracteriza o conceito de classificação no modelo de dados do Jasmine. Em contrapartida, uma classe pode ser dividida em subclasses disjuntas, formando uma partição. Para a classe Pessoa, por exemplo, pode-se definir uma partição contendo as subclasses Adulto e Criança. Esta categorização pode ser especificada através de valores de algum atributo. Para o exemplo, um atributo 
Idade poderia determinar a semântica da partição. O conceito de categorização pode ser utilizado para otimização de consultas.

Finalmente, os atributos de um objeto podem estar associados a funções especializadas, chamadas demons, que atuam como mecanismos de tratamento de eventos e restrições. Os demons podem ser combinados, por exemplo, na implementação de bases de dados ativas.

\subsubsection{Linguagem de Base de Dados}

O sistema Jasmine possui uma linguagem de bases de dados, denominada Jasmine/C, que integra uma linguagem de programação de propósito geral (C) e uma linguagem de base da dados orientada a objetos. A Jasmine/C oferece suporte a dois tipos de acesso a objetos: acesso individual e acesso orientado a conjunto. O primeiro é baseado na manipulação de objetos através do envio de mensagens, permitindo atribuições de valores aos atributos e referências a valores de atributos. O segundo tipo de acesso, direcionado à base de dados, é implementado como consultas a objetos.

Uma expressão de consulta em Jasmine/C é dividida em duas partes: uma contendo uma expressão de objetos, ou uma lista de expressões, e outra contendo uma combinação lógica de predicados que comparam as expressões de objetos. Um consulta em uma classe retorna todas as instâncias da classe e de suas subclasses. As expressões de objetos, formadas predominantemente por nomes de classes seguidos de nomes de atributos, denotam os joins de objetos, que podem ser definidos implicitamente através de "caminhos" na expressão de objetos. O exemplo abaixo ilustra o join implícito em uma consulta em que pretende-se recuperar o nome da cidade de origem da pessoa cujo nome é Alice:

Pessoa.Cidade_Or.Nome where Pessoa.Nome == "Alice"

As expressões de objetos podem invocar demons que verificam restrições definidas pelo programador da aplicação. Além disso, métodos de classes e métodos definidos pelo sistema, como put, delete e print, também podem ser executados a partir de uma consulta. O tratamento a métodos definidos pelo sistema e métodos definidos pelo usuário é uniforme. $\mathrm{Na}$ consulta abaixo, por exemplo, o método put insere um novo valor para o conjunto de disciplinas cursadas pelo estudante Paulo:

Estudante.put ("Disciplinas", "ICC-II")

where Estudante. Nome == "Paulo" 
A linguagem de base de dados e o modelo de dados do Jasmine são baseados em um formalismo matemático que pode ser encontrado em [Ishikawa_93], onde descrições detalhadas a respeito do Jasmine e inúmeros exemplos são apresentados.

\subsection{Outros Sistemas}

Esta seção faz uma apresentação breve de outros sistemas de gerenciamento de bases de dados orientados a objetos.

ObjectStore [Lamb_91] é um SGBDOO que utiliza C++ como linguagem de programação de base de dados. O ObjectStore provê funções básicas de gerenciamento de objetos, manipulação de objetos complexos e coleções, e mecanismos de herança múltipla. Além de incorporar um browser de base de dados e uma ferramenta interativa para projetos de esquemas.

GemStone [Butterworth_91] possui uma linguagem de programação de bases de dados similar ao Smalltalk, chamada OPAL. Além da OPAL, este sistema possui interfaces para a linguagem $\mathrm{C}++$. O GemStone suporta uma arquitetura cliente-servidor, sobre a qual prevalecem dois processos: o Stone, responsável pelo gerenciamento de dados, e o Gem, responsável principalmente pela compilação da linguagem OPAL. O GemStone também oferece suporte a objetos complexos, serviços de garbage collection, evolução de esquemas e ferramentas de interface com o usuário.

Objectivity/DB [Cattell_94] integra uma interface de programação C++ com ênfase no SGBD, visando robustez e escalabilidade. O Objectivity/DB suporta uma arquitetura cliente-servidor e implementa transparência de operações sobre múltiplas bases de dados, esquemas, computadores, usuários, hardware, redes e sistemas operacionais heterogêneos. A interface de programação do Objectivity/DB inclui bibliotecas $\mathrm{C}$ e $\mathrm{C}++$ e suporte aos padrões SQL e ODMG.

POSTGRES [Stonebraker_91] é um sistema relacional estendido que utiliza uma base de dados INGRES como repositório de dados. Uma característica importante do POSTGRES é o mecanismo de no-overwrite, que considera operações de atualização como novas inserções, mantendo um histórico de dados anteriores. Este recurso viabiliza operações de 
time travel, que permitem que o usuário faça uma consulta histórica e obtenha dados válidos de acordo como o "tempo" especificado na consulta.

KROSS [Kim_96] é um sistema de base de dados espacial orientado a objetos que utiliza o ObjectStore como plataforma de implementação. O KROSS incorpora um modelo de dados baseado em assinatura espacial (SAS - spatial signature) que suporta os tipos de objetos espaciais e as operações correspondentes. A linguagem de consulta espacial orientada a objetos (SOQL - spatial object query language), além de manipular objetos espaciais, possui um mecanismo integrado para recuperação e apresentação gráfica de objetos espaciais. Sistemas de informações geográficas e sistemas de gerenciamento de imagens médicas são exemplos de aplicações baseadas em dados espaciais.

TriGS [Kappel_98] é um sistema de triggers implementado sobre o GemStone, inserindo conceitos ativos em um SGBDOO. O TriGS oferece suporte ao desenvolvimento de aplicações centradas em bases de dados ativas, permitindo a definição de regras associadas a eventos, condições e ações. São exemplos de tais aplicações: gerenciamento de fluxo de trabalho, CAM e aplicações multimídia.

SIRIUS é um SGBDOO que vem sendo desenvolvido pelo Grupo de Banco de Dados e Imagem (GBDI) do ICMC-USP. A pesquisa básica e a pesquisa tecnológica a cerca do desenvolvimento do SIRIUS têm como objetivo principal aplicar os resultados obtidos em atividades de desenvolvimento de sistemas centrados em bases de dados, voltados para aplicações não convencionais. Destacam-se sistemas de apoio à medicina e ambientes de armazenamento e distribuição de imagens.

\subsection{Considerações Finais}

Este capítulo discute uma pequena amostragem da variedade de SGBDOOs que podem ser encontrados na literatura. Em geral, estes sistemas diferem em relação à abordagem da arquitetura e às linguagens de programação e de consulta. As diferenças pertinentes às linguagens podem ser amenizadas com utilização de padrões, como o ODMG e o SQL3, apresentados na seção 2.6. Sistemas compatíveis com padrões de gerenciamento de objetos permitem o desenvolvimento de aplicações portáveis. 
Apesar das diferenças, os SGBDOOs comerciais e experimentais vêm sendo projetados e implementados visando tanto a contribuição no avanço da tecnologia de bases de dados orientadas a objetos quanto o suporte ao desenvolvimento de aplicações não convencionais voltadas para diferentes áreas de conhecimento.

O Sistema SIRIUS, em particular, é de grande interesse no contexto deste trabalho, cujo resultado principal é a definição da API para o Gerenciador de Objetos SIRIUS. Portanto, detalhes a respeito do Sistema SIRIUS serão apresentados nos capítulos seguintes, enfatizando o Modelo de Dados e Gerenciador de Objetos SIRIUS, componentes diretamente relacionados a este trabalho. 


\section{Modelo de Dados SIRIUS}

\subsection{Introdução}

O Modelo de Dados SIRIUS é um metamodelo orientado a objetos baseado em quatro abstrações: classificação, generalização, agregação e composição [Biajiz_96a] [Biajiz_96b]. A composição e a agregação são especializações da associação, como ilustrado na Figura 5.

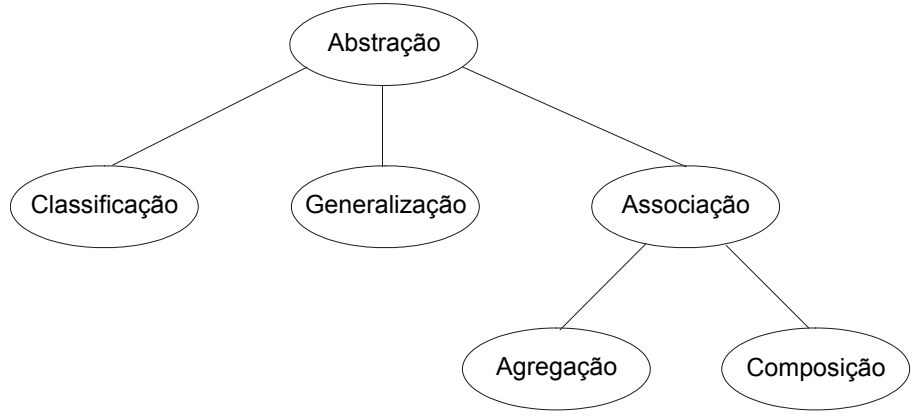

Figura 5 - Abstrações do modelo SIRIUS

Cada construtor semântico do modelo determina como uma ou mais abstrações são utilizadas e como se relacionam com as demais abstrações e com os demais construtores semânticos [Araujo_98a]. Os elementos sintáticos do SIRIUS, estruturados segundo as abstrações que o modelo suporta, são representados por objetos, atributos, características de atributos, estruturas de composição (colônias), estruturas de generalização, e seus respectivos tipos.

As abstrações do SIRIUS são consideradas em pares: classificação/instanciação, generalização/especialização, agregação/separação e composição/decomposição. A estrutura hierárquica de cada abstração permite a navegação em níveis abstratos ou de detalhe, e a utilização do objeto detalhe e do objeto abstrato numa modelagem ou num 
sistema. A Figura 6 ilustra o relacionamento entre um objeto detalhe e um objeto abstrato, onde um conjunto de objetos detalhe descreve um objeto abstrato, e um objeto abstrato sumariza as informações genéricas e comuns de um conjunto de objetos detalhe. As propriedades desse relacionamento são definidas pelas características da abstração.

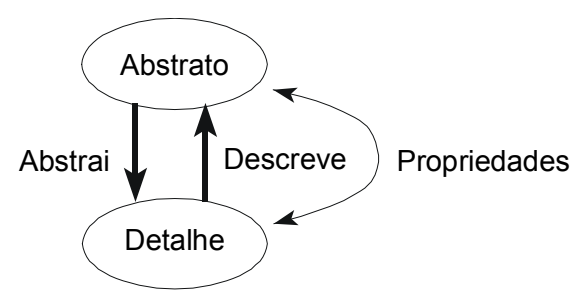

Figura 6 - Elementos de uma Abstração

A seção 4.2 descreve os conceitos principais do modelo SIRIUS, relacionados às abstrações de agregação, generalização e composição. Uma descrição mais detalhada da abstração de classificação é apresentada na seção 4.3, pois o suporte oferecido pelo SIRIUS ao conceito de classificação é mais abrangente e completo que o encontrado na literatura. Consequentemente, o suporte à abstração de classificação na API do Gerenciador SIRIUS é um dos principais resultados deste trabalho.

\subsection{Conceitos do Modelo SIRIUS}

\subsubsection{Abstração de Agregação}

A abstração de agregação ocorre de três maneiras distintas: agregação de atributos a objetos, agregação de atributos a atributos e agregação de objetos a objetos. A Figura 7 ilustra ocorrências da abstração de agregação.

Um objeto SIRIUS é definido como uma agregação de atributos, como ilustrado na Figura 7a. Cada atributo tem um tipo e um conjunto de valores que caracterizam o objeto. Por outro lado, cada de atributo está associado a uma característica que indica a funcionalidade e as operações que podem ser aplicadas ao atributo. O modelo SIRIUS define 15 características agrupadas em estáticas, dinâmicas, de interface e estruturais [Araujo_98a], como apresentado na Tabela 2. 


\begin{tabular}{|c|c|c|}
\hline Tipo de Característica & Característica & Símbolo \\
\hline \multirow[t]{3}{*}{ Estática } & texto & $\mathrm{Tx}$ \\
\hline & número & $\mathrm{Nu}$ \\
\hline & booleano & Bo \\
\hline \multirow[t]{2}{*}{ Dinâmica } & regra & $\mathrm{Rg}$ \\
\hline & procedimento & Pc \\
\hline \multirow[t]{5}{*}{ Interface } & visualização & Vs \\
\hline & som & So \\
\hline & partitura & $\mathrm{Pa}$ \\
\hline & imagem & $\operatorname{Im}$ \\
\hline & gráfico & Gr \\
\hline \multirow[t]{5}{*}{ Estrutural } & estrutura de dados & Ed \\
\hline & tempo & $\operatorname{Tm}$ \\
\hline & tupla & $\mathrm{Tp}$ \\
\hline & atributo de atributo & Aa \\
\hline & relacionamento & $\operatorname{Re}$ \\
\hline
\end{tabular}

Tabela 2 - Características de Atributos

A agregação de atributos a atributos define a formação de atributos com características tupla e atributo de atributo. A tupla é definida como um conjunto de atributos que associados formam um outro atributo. $\mathrm{O}$ atributo de atributo, por sua vez, possui um atributo principal, chamado de identificador, ao qual estão associados sub-atributos que adicionam informações relevantes ao atributo principal. A Figura $7 \mathbf{b}$ ilustra a tupla Endereço, formada pelos atributos Rua, Número e Cidade, e o atributo de atributo Passaporte, onde o atributo Nro Passaporte é o identificador da estrutura, e possui os sub-atributos Data de Expedição e Órgão Expedidor. 


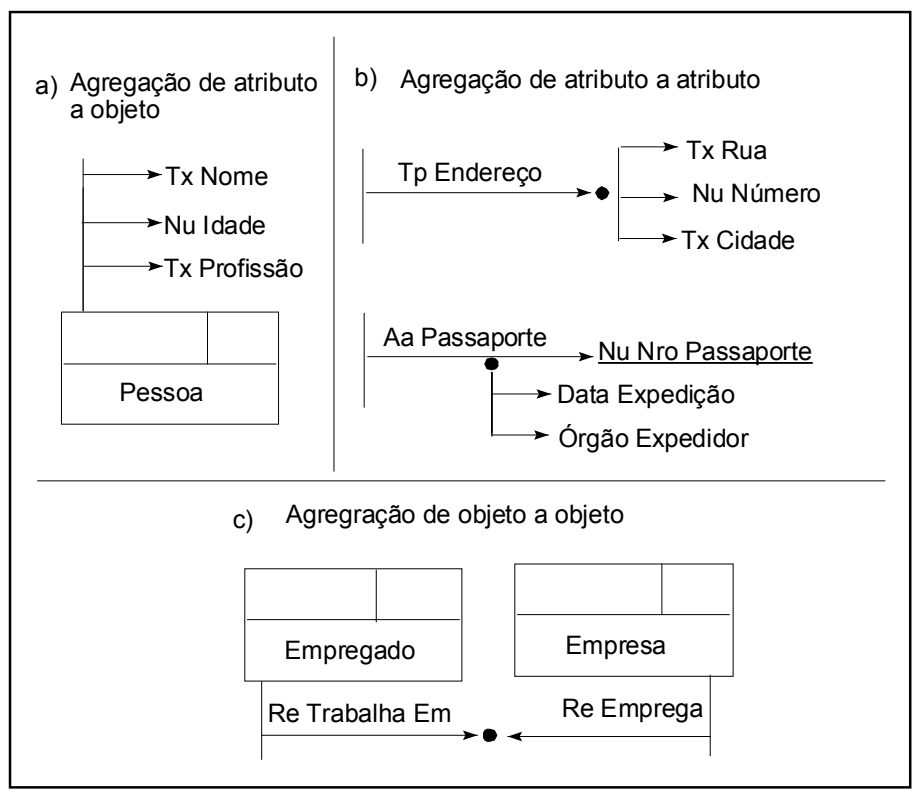

Figura 7 - Exemplo da Abstração de Agregação

A agregação de objetos a objetos ocorre através de atributos com característica relacionamento, como exemplificado na Figura 7c. Os atributos Trabalha Em e Emprega definem o relacionamento entre os objetos dos tipos Empregado e Empresa, respectivamente.

Quando um atributo é agregado a um objeto, algumas propriedades da abstração de agregação devem ser definidas, tais como a organização do atributo, ou seja, se a atributo é mono-valorado ou multi-valorado, e os limites inferior e superior, que determinam respectivamente o número mínimo e máximo de valores que podem ser assumidos pelo atributo.

\subsubsection{Abstração de Composição}

Os objetos em SIRIUS podem ser compostos por outros objetos, criando hierarquias de composição. Os elementos sintáticos colônia e tipo de colônia são as estruturas utilizadas para representar o conceito de composição.

Uma colônia é um conjunto de todos os objetos que compõem diretamente outro objeto, de acordo com um aspecto específico. Numa hierarquia de composição, o objeto abstrato, chamado de objeto composto, constringe uma colônia onde habitam os objetos detalhe, chamados de objetos parte. 
Numa representação gráfica, dois diagramas representam a ocorrência da composição [Araujo_98a]:

- Diagrama Hierárquico de Colônias (DHC) - representa a composição por tipo, definindo os tipos de colônia e os tipos dos objetos que vão constringir e habitar as colônias instâncias dos tipos de colônia definidos;

- Diagrama de Representação de Instâncias (DRI) - representa as colônias, os objetos que as habitam e os objetos que as constrigem.

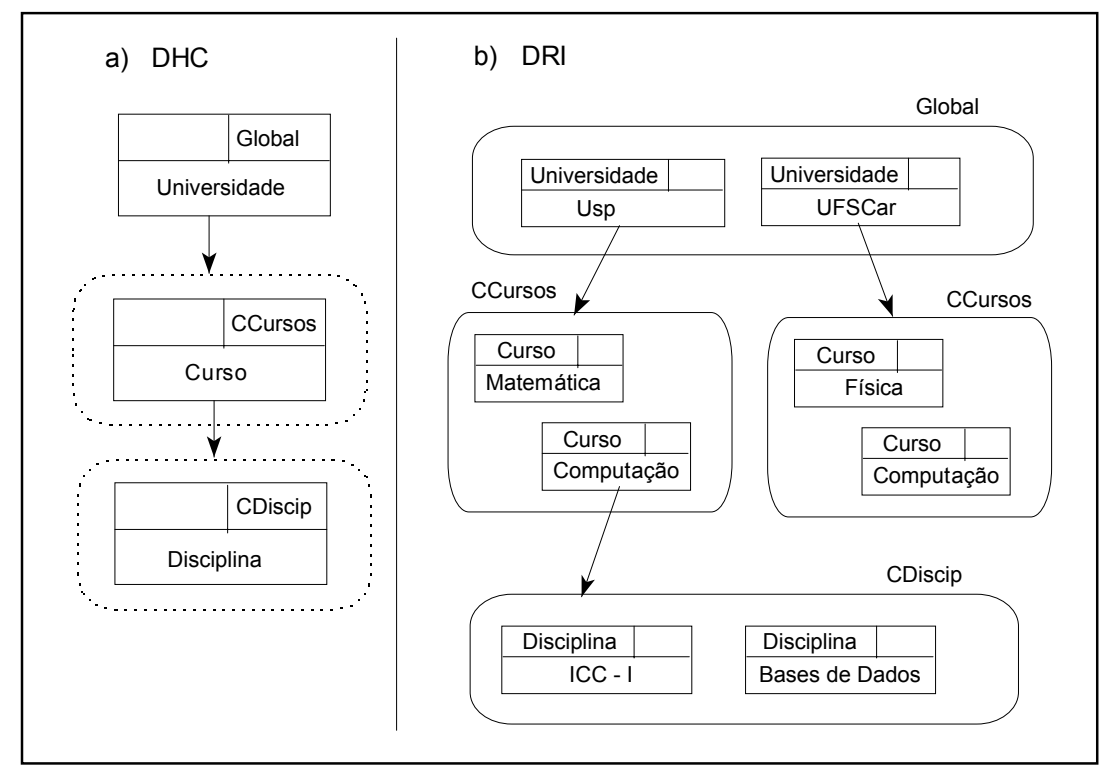

Figura 8 - Exemplo da Abstração de Composição

A Figura 8a ilustra um DHC. No exemplo, o tipo de objeto Universidade constringe o tipo de colônia CCursos. Em colônias do tipo CCursos vão habitar objetos do tipo Curso. Analogamente, o tipo de objeto Curso constringe o tipo de colônia CDiscip, e em colônias deste tipo vão habitar objetos do tipo Disciplina.

A Figura 8b ilustra um DRI, onde os objetos USP e UFSCar são objetos do tipo Universidade, e habitam uma colônia do tipo Global ${ }^{1}$. O objeto USP constringe uma colônia do tipo CCursos, como definido no DHC apresentado na Figura 8a. Nessa colônia habitam os objetos Computação e Matemática, do tipo Curso, que compõem o objeto USP. Da mesma forma, o objeto UF SCar constringe uma colônia do tipo CCursos,

\footnotetext{
${ }^{1} \mathrm{O}$ tipo de colônia Global e a colônia instância deste tipo são definidos pelo sistema. Na colônia do tipo Global habitam todos os objetos do tipo Meta Tipo, também definido pelo sistema.
} 
onde habitam os objetos que o compõem: Física e Computação, também do tipo Curso. O objeto Computação, que habita a colônia constrita por USP, constringe uma colônia do tipo CDiscip onde habitam os objetos ICC - I e Bases de Dados, do tipo Disciplina.

Por definição, um objeto habita exatamente uma colônia. No entanto, um objeto composto pode constringir várias colônias, desde que sejam de tipos diferentes [Ferreira_96].

\subsubsection{Abstração de Generalização}

A abstração de generalização é fundamental em modelos de dados orientados a objetos, pois através dela abstrai-se em um objeto genérico o comportamento e as propriedades de objetos específicos [Biajiz_96a]. Um tipo de objeto, chamado de sub-tipo ou tipo específico, pode especializar um outro tipo de objeto já existente, chamado de super-tipo ou tipo genérico, acrescentado detalhes pertinentes somente ao tipo de objeto específico, criando a hierarquia de generalização.

Um tipo de objeto é especializado segundo um critério de especialização, que pode ser definido pelo valor de um único atributo, num domínio discreto e pré-definido, ou através da avaliação de um predicado sobre os valores de um ou mais atributos. Além disso, duas restrições são aplicadas à especialização: a disjunção (D) ou sobreposição (S), e a participação total (T) ou parcial (D).

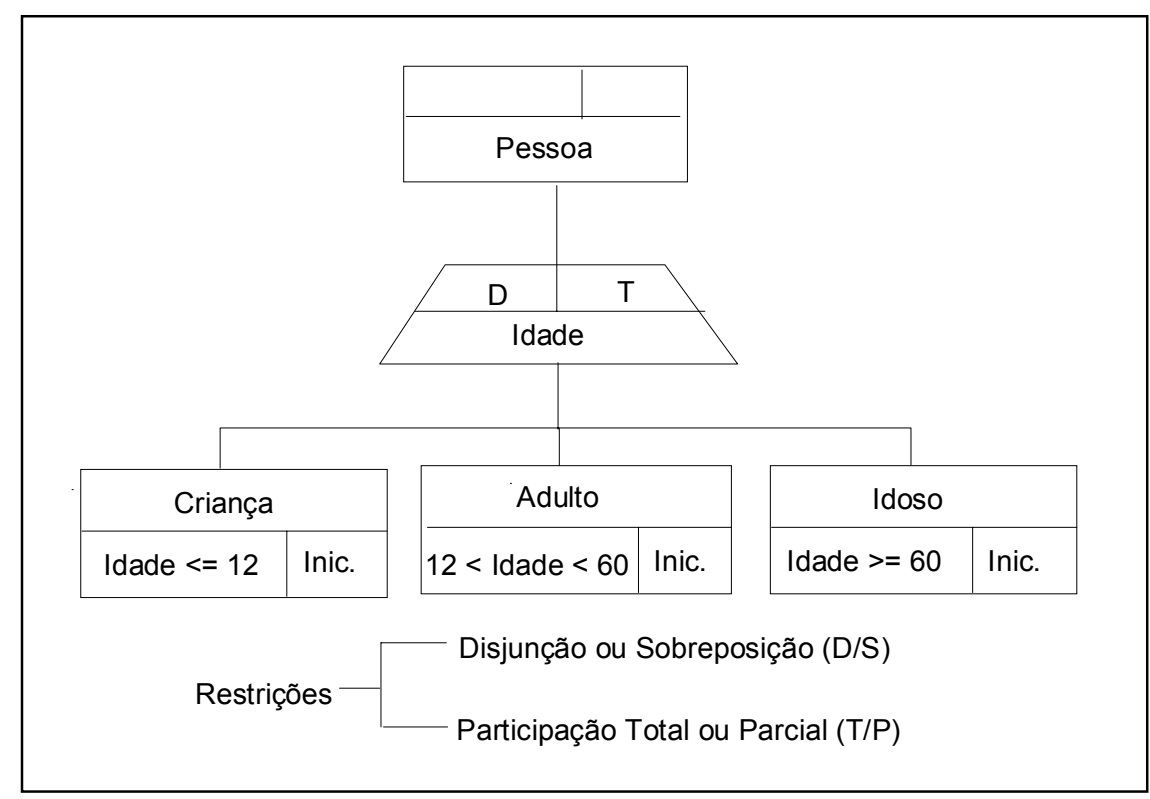

Figura 9 - Exemplo da Abstração de Generalização 
A Figura 9 exemplifica uma hierarquia de generalização, onde o super-tipo Pessoa é especializado nos sub-tipos Criança, Adulto e Idoso. O critério de especialização utilizado é a avaliação de predicados sobre o atributo Idade. Por exemplo, uma pessoa é do tipo específico Criança quando possui Idade $<=12$. A propriedade Inic. (Inicialização) define como os atributos de um objeto específico são inicializados quando o objeto é criado, e as restrições de disjunção (D) e participação total (T) completam a definição da hierarquia de generalização.

\subsection{Abstração de Classificação}

A Abstração de Classificação [Machado_00] é um conceito importante em sistemas de bases de dados, pois permite que os elementos de um esquema de dados sejam instanciados em uma base extensional. Entretanto, a classificação é utilizada em SGBDs de forma restrita, sendo usualmente tratada como um relacionamento implícito entre o esquema e a base extensional, pré-determinando o número de níveis da hierarquia de classificação.

Em modelos que não são caracterizados como metamodelos, como o ER, ER-X e OMT, a hierarquia de classificação possui apenas um nível, representado pelo relacionamento implícito entre tipo e instância. Em metamodelos, como o modelo relacional e o ODMG, os relacionamentos, também implícitos, entre meta tipo e tipo, e entre tipo e instância definem uma hierarquia de dois níveis.

O modelo SIRIUS, no entanto, oferece suporte a hierarquias de classificação de múltiplos níveis, representando a classificação explicitamente, através de um construtor semântico dedicado a representar objetos e tipos de objetos. Como a classificação é um conceito já presente em bases de dados, o novo construtor integra-se ao uso que vem sendo feito dessa abstração.

Os objetos, como citado anteriormente, são caracterizados através de atributos. O suporte à abstração de classificação divide os atributos em dois tipos: atributos de instanciação, que representam as propriedades e os métodos do objeto propriamente dito, e atributos de classificação, que caracterizam o objeto como um tipo, definindo os atributos das instâncias desse tipo. 
Os atributos de classificação de um tipo de objeto determinam as propriedades comuns de suas instâncias, que formam um conjunto de objetos estruturalmente idênticos. Logo, um tipo de objeto pode ser instanciado em um objeto, que por sua vez pode ser instanciado em outro objeto, e assim sucessivamente. Esse processo define a hierarquia de classificação de múltiplos níveis, onde o número máximo de níveis é determinado pela semântica da aplicação.

A Figura 10 apresenta uma representação do construtor da classificação. Um objeto é representado por um retângulo dividido por uma linha horizontal. Na parte inferior é colocado o nome do objeto e na parte superior, do lado esquerdo, é colocado o nome do tipo do objeto. No lado direito da parte superior é colocado o nome do tipo da colônia onde habitam as instâncias do objeto representado. Quando o campo do tipo de colônia é deixado em branco, subentende-se que as instâncias do objeto habitam uma colônia do tipo Global. Os atributos de classificação são representados acima do retângulo que representa o objeto, enquanto os atributos de instanciação são representados logo abaixo do mesmo.

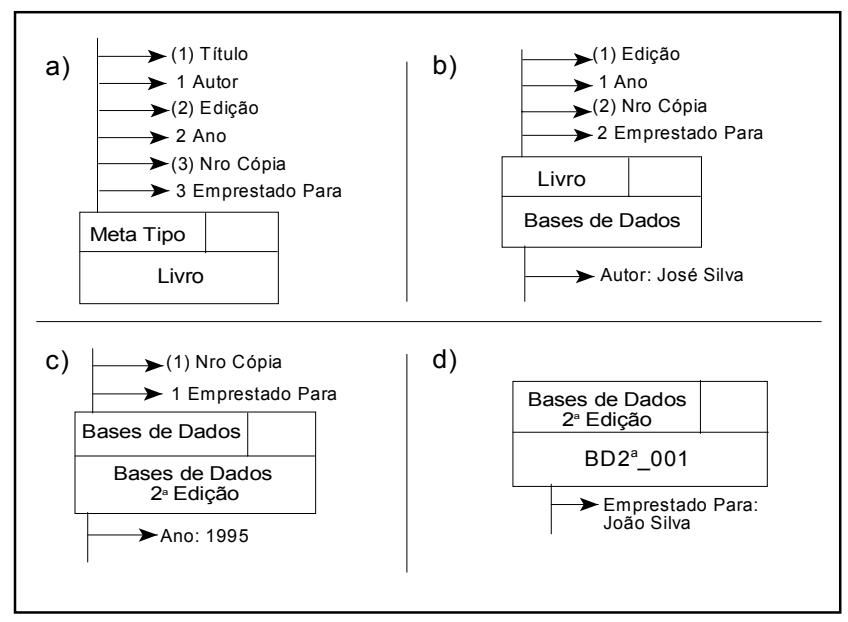

Figura 10 - Exemplo da Abstração de Classificação

Para exemplificar uma ocorrência da classificação numa situação real, será considerado um sistema de informação de uma biblioteca, onde cada título de livro pode ter várias edições e cada edição pode ter várias cópias. Isso significa que o conceito de Livro é instanciado em Título, Título é instanciado em Edição e Edição é instanciado em Cópia. Como Livro é instância de Meta-Tipo (definido pelo sistema), define-se uma hierarquia de quatro níveis, como ilustrado na Figura 10. As Figuras 10a, 10b, 10c e 10d representam, respectivamente, o objeto Livro como uma instância de Meta-Tipo, o título Bases de 
Dados como instância de Livro, Bases de Dados $2^{\text {a }}$ Edição como instância de Bases de Dados, e BD2 ${ }^{a} \_01$ como instância de Bases de Dados $2^{a}$ Edição.

Um requisito fundamental para o conceito de classificação em múltiplos níveis é um objeto do esquema da base de dados assumir os papéis de tipo e instância. Por exemplo, o objeto Bases de Dados é instância de Livro e tipo de Bases de Dados $2^{a}$ Edição.

Os atributos de classificação definem um "template" para instanciar um tipo de objeto, ou seja, definem as características estruturais e de comportamento das instâncias do tipo de objeto em cada nível da hierarquia de classificação e o número de níveis que podem ser criados a partir desse tipo. Na representação gráfica da classificação, o número que precede o atributo indica o nível onde o atributo será instanciado, tornando-se um atributo de instanciação.

No exemplo da Figura 10, o número 2 antes do atributo Ano do objeto Livro indica que este atributo será instanciado no segundo nível de instanciação, recebendo o valor 1995 como um atributo de instanciação do objeto Bases de Dados $2^{a}$ Edição. O número entre parênteses indica que o atributo é identificador das instâncias no respectivo nível. No exemplo, o atributo Título do objeto Livro identifica as instâncias do primeiro nível de instanciação de Livro. Portanto, Bases de Dados é o valor do atributo Título nessa instância de Livro.

A abstração de classificação envolve ainda conceitos como atributo fixo, atributo extra e valor default. Um atributo de classificação fixo de um tipo de objeto será um atributo fixo, de classificação ou de instanciação (dependendo do nível), das instâncias desse tipo, e assim sucessivamente por toda a hierarquia. Por exemplo, na Figura 10 o atributo Emprestado Para é um atributo fixo de nível 3, e portanto está presente em todos os níveis da hierarquia.

O suporte a atributo extra é um recurso importante para a classificação em múltiplos níveis. Os atributos extras permitem que novos atributos, tanto de classificação quanto de instanciação, sejam incluídos em qualquer nível da hierarquia. Deste modo, um atributo extra pode ser vinculado a um objeto mesmo que não esteja previsto em seu tipo. $\mathrm{Na}$ Figura 10a, todos os atributos de Livro são atributos extras, pois o objeto Meta-Tipo não tem esses atributos definidos. 
A Figura 11 apresenta uma extensão ao exemplo da Figura 10 para ilustrar o conceito de atributo extra utilizado num nível intermediário da hierarquia de classificação. Supondo que o livro Bases de Dados passe a ter um CD complementar a partir da $3^{\mathrm{a}}$ edição, e que esse CD possa ser emprestado separadamente, o objeto Bases de Dados $3^{\mathrm{a}}$ Edição passa a ter um atributo $C D$ Emprestado Para, que não existe em Bases de Dados $2^{a}$ Edição e que não foi previsto em Bases de Dados.

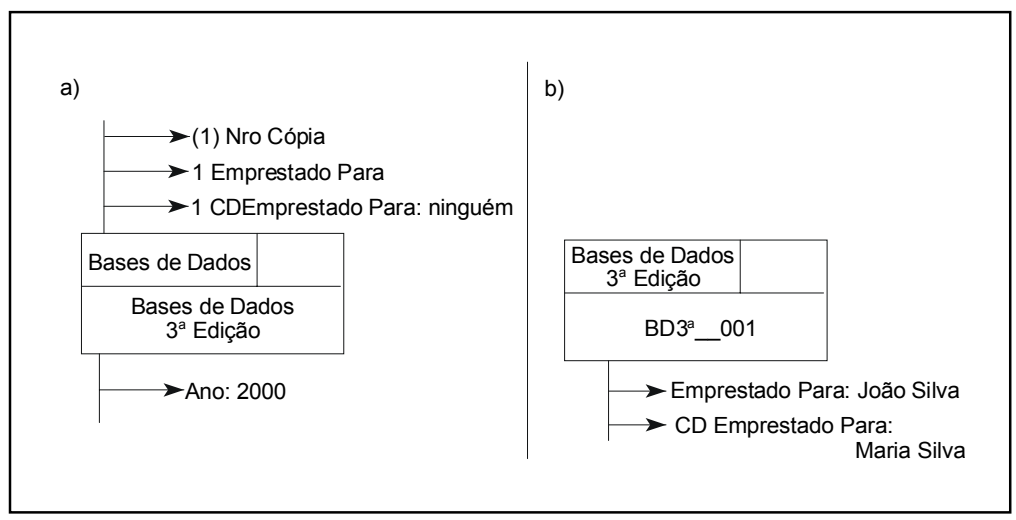

Figura 11 - Exemplo de atributo extra na hierarquia de classificação

Em 11a, o conceito de valor default é ilustrado através da atribuição do valor ninguém para o atributo de classificação $C D$ Emprestado Para, indicando que esse valor será atribuído a CD Emprestado Para quando Bases de Dados $3^{a}$ Edição for instanciado. Em 11b, um novo valor é atribuído a este atributo (Maria Silva), seguindo o princípio de que um valor default é "carimbado" ao atributo quando o tipo de objeto é instanciado, mas pode ser alterado nas instâncias individualmente, sem que isso afete o tipo de objeto ou outras instâncias. Da mesma forma, se um valor default é alterado num tipo de objeto, as instâncias já existentes não sofrem alteração alguma, pois o novo valor default só afetará as instâncias criadas após sua alteração. Note-se que valor default é diferente de valor herdado, presente na abstração de generalização. O valor herdado pelas instâncias de um sub-tipo não pode ser alterado, e se esse valor for modificado no supertipo, a alteração dever ser propagada por toda a hierarquia de generalização.

Algumas outras propriedades são definidas quando um atributo de classificação é criado, como por exemplo: determinar se o atributo é definido, indefinido ou nulo, ou seja, se o atributo deve assumir um valor, ou se pode permanecer sem valor definido ou assumir o valor nulo. 


\subsection{Considerações Finais}

Neste capítulo são apresentadas as principais características do modelo SIRIUS, enfatizando o suporte à abstração de classificação através de um construtor semântico dedicado a representar explicitamente o conceito de hierarquia de classificação em múltiplos níveis. Não é objetivo deste trabalho apresentar uma discussão exaustiva do SIRIUS, uma vez que descrições detalhadas de todos conceitos pertinentes ao modelo, tais como formalismo matemático, fundamento teórico, notação e exemplos podem ser encontrados em [Araujo_98a] [Biajiz_96a] [Ferreira_96] [Machado_00].

O capítulo seguinte discute como as abstrações aqui apresentadas são tratadas na API do Gerenciador SIRIUS. 


\section{API do Gerenciador SIRIUS}

\subsection{Introdução}

O sistema SIRIUS, como citado no Capítulo 3, vem sendo desenvolvido pelo Grupo de Banco de Dados e Imagens do ICMC-USP com o objetivo de oferecer suporte à aplicação de resultados das atividades de pesquisa científica do grupo.

A origem do sistema SIRIUS remota à construção do GErenciador de Objetos - GEO [Traina_91], cuja implementação teve como base os conceitos do modelo de dados MRO Modelo de Representação de Objetos [Biajiz_92] [Traina_92]. O sistema GEO/MRO foi criado como uma "bancada de experimentação" para o desenvolvimento de algoritmos e técnicas que contribuíssem para a criação de SGBDOOs eficientes e confiáveis. A experiência e o conhecimento adquiridos nesse processo levaram à definição do modelo SIRIUS, descrito no Capítulo 4, a partir do qual iniciou-se o desenvolvimento do sistema SIRIUS, mais especificamente do Gerenciador de Objetos SIRIUS, descrito na seção 5.2.

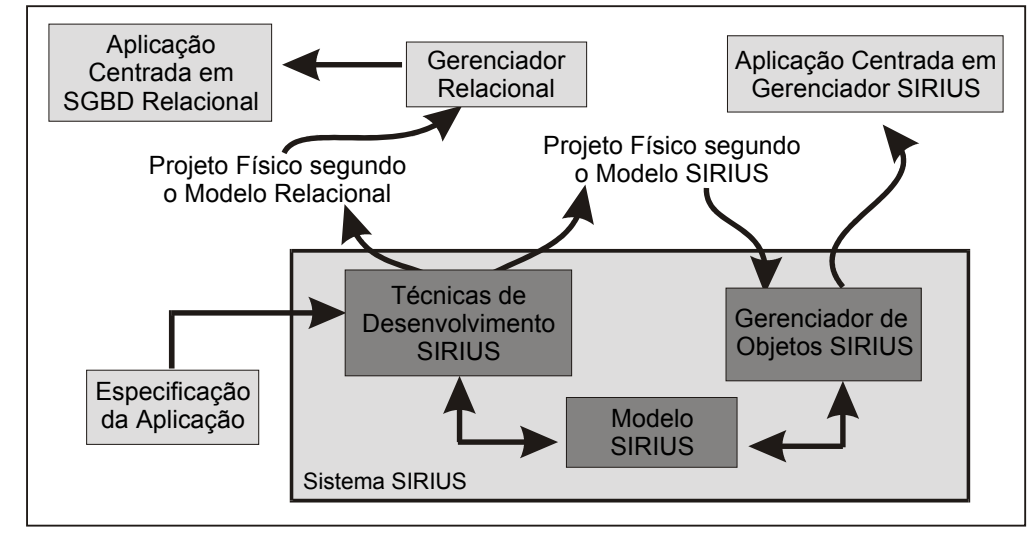

Figura 12 - Sistema SIRIUS

O sistema SIRIUS, ilustrado na Figura 12, consta ainda de um conjunto de Técnicas de Desenvolvimento a serem utilizadas nas fases de projeto lógico e físico de sistemas centrados em bases de dados. As Técnicas de Desenvolvimento SIRIUS encontram-se em fase inicial de desenvolvimento. O modelo SIRIUS, elemento central do sistema, foi 
concebido para suportar atividades de projeto de aplicações apoiadas em bases de dados e o Gerenciador SIRIUS vem sendo desenvolvido para suportar tais aplicações. É importante enfatizar que não se pretende que a implementação de aplicações projetadas através das Técnicas de Desenvolvimento SIRIUS fique restrita ao Gerenciador SIRIUS. Por outro lado, pretende-se que o SIRIUS possa oferecer suporte a aplicações em geral, independente da técnica de projeto utilizada.

O sistema, devido a suas características, constitui uma plataforma adequada ao desenvolvimento de uma interface de programação de aplicativos, que é o objetivo deste capítulo. Nesse sentido, a API foi construída visando emular um gerenciador de dados SIRIUS, tendo por suporte um gerenciador de dados relacional.

\subsection{Gerenciador de Objetos SIRIUS}

O gerenciador de objetos é essencial para o sistema SIRIUS, pois propicia o suporte necessário para desenvolvimento, teste e validação de algoritmos e técnicas de projeto. Como a disponibilidade de um gerenciador de objetos é de fundamental importância para a consolidação do sistema, duas versões do Gerenciador SIRIUS vêm sendo elaboradas: uma versão nativa e uma versão relacional. Ambas as versões são compostas por dois componentes principais: um Núcleo e um conjunto de Módulos Semânticos. Em qualquer uma de suas versões, o Gerenciador de Objetos SIRIUS possui uma interface de programação de aplicativos, chamada de API SIRIUS, responsável pela comunicação entre o gerenciador e aplicações centradas no modelo de dados SIRIUS.

A versão nativa é baseada em um núcleo desenvolvido especificamente para o suporte a gerenciadores de objetos, responsável por operações de alocação de espaço para objetos, gerenciamento de espaço em memória principal e memória secundária, transferência de objetos de e para memória principal, gerenciamento de identificadores de objetos, controle de transações, garantia de segurança física e controle de concorrência em registros [Valêncio_00].

A Figura 13 apresenta a arquitetura em camadas do núcleo nativo do gerenciador de objetos. A camada superior, o Subsistema de Gerenciamento de Atributos (SG-Atr), oferece suporte à manipulação de atributos estruturados (tuplas e listas), suporte a estruturas de índices sobre estes atributos, suporte a objetos extensos não estruturados 
(BLOBs) e objetos compostos. A camada intermediária, SG-Log, é responsável pela alocação, coesão e recuperação de espaços contínuos em registros físicos. $\mathrm{Na}$ camada inferior, o Subsistema de Gerenciamento de Transações realiza o controle das transações executadas durante a utilização do Gerenciador SIRIUS. Esta camada também é responsável pelas operações de controle de acesso e alocação de espaço físico em memória secundária.

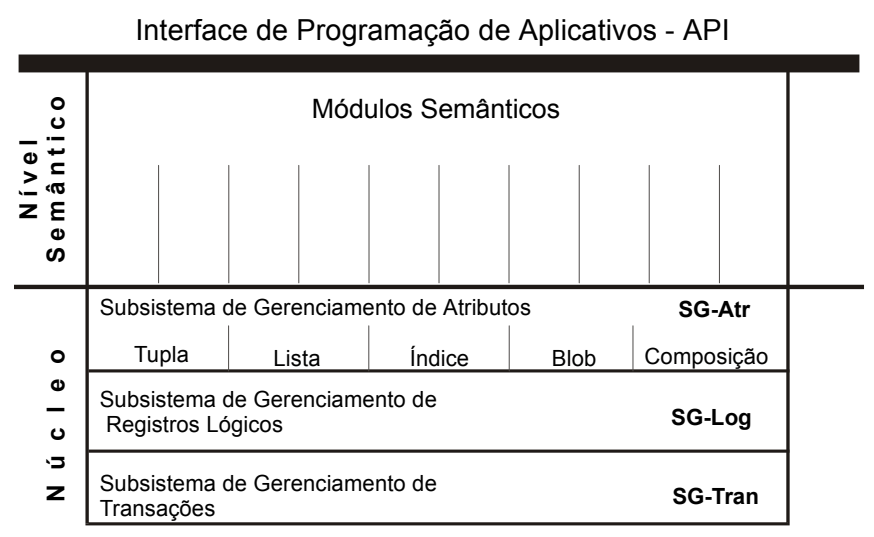

Figura 13 - Gerenciador SIRIUS com núcleo nativo

Os Módulos Semânticos, construídos sobre o núcleo do gerenciador, implementam a lógica de todos os construtores semânticos do modelo SIRIUS. A interface superior dos Módulos Semânticos constitui a interface de programação de aplicativos (API) do Gerenciador SIRIUS.

A versão nativa é eficiente e pode suportar os conceitos do modelo SIRIUS mais ampla e adequadamente, apresentando tempo de resposta muito satisfatório. Atualmente, existe um protótipo do gerenciador nativo [Valêncio_00], porém a implementação completa deste gerenciador, abrangendo todos os recursos do modelo SIRIUS, é uma tarefa complexa e requer ainda muito tempo de desenvolvimento.

O núcleo nativo do Gerenciador SIRIUS é genérico e independente do modelo de dados adotado, podendo ser utilizado para suportar os conceitos de outros modelos de dados orientados a objetos [Valêncio_00]. A semântica do modelo de dados é conhecida e tratada apenas no nível semântico do gerenciador de objetos. O núcleo é otimizado para o suporte a abstrações de objetos. Logo, o suporte a partir de modelos que não seguem o paradigma de orientação a objetos provavelmente não seria tão eficiente como o suporte dado por um núcleo especificamente construído para suportar as abstrações do modelo alvo. 
A versão sobre núcleo relacional possui a arquitetura apresentada na Figura 14, baseada em um núcleo que utiliza um gerenciador relacional padrão SQL. Essa versão oferece o suporte básico aos módulos semânticos do modelo SIRIUS e, embora não seja tão eficiente quanto a versão nativa, já possui um protótipo operacional, resultante deste trabalho. Um ponto importante a ser considerado aqui é que a técnica utilizada para a implementação realizada permite emular construções semânticas oriundas de um modelo orientado a objetos ( e suas respectivas abstrações) em um modelo muito mais simples, como é o caso do modelo relacional.

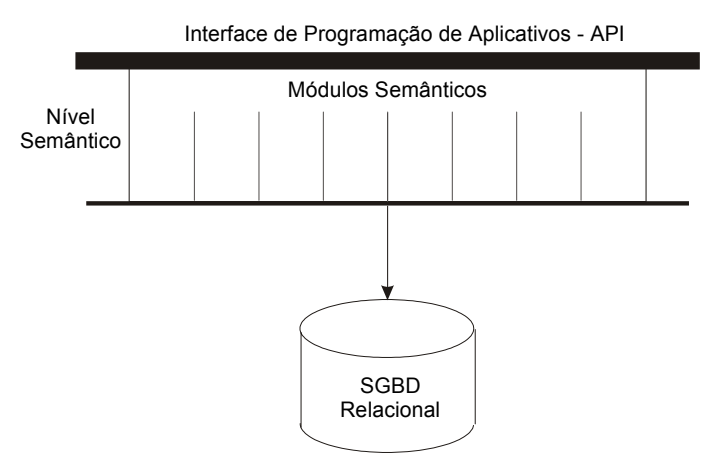

Figura 14 - Gerenciador SIRIUS com núcleo relacional

A versão relacional teve seu desenvolvimento iniciado através de uma ferramenta de representação e armazenagem de modelagens baseadas no modelo SIRIUS, utilizado um gerenciador relacional como repositório de dados. Esta ferramenta, chamada de $E^{2}$ SIRIUS (Editor de Esquemas SIRIUS) [Araujo_98a] [Araujo_98b], foi projetada para suportar tipos persistentes e tratamento homogêneo de objetos e tipos de objetos em tempo de execução. Este fator é primordial para a definição de hierarquias de classificação de múltiplos níveis, uma vez que a maioria das linguagens de programação tratam tipos apenas em tempo de compilação. Neste trabalho, o E ${ }^{2}$ SIRIUS foi reformulado, tornando-se um aplicativo de edição de modelagens que utiliza apenas as primitivas da API do Gerenciador SIRIUS para acessar a base de dados, em qualquer uma das versões do gerenciador. Todo o código de acesso direto à base de dados relacional desenvolvido para a versão original do Editor de Esquemas foi removido, e as cláusulas SQL contidas nesse código foram utilizadas como ponto de partida para o desenvolvimento da versão relacional do Gerenciador SIRIUS. A API definida para o Gerenciador SIRIUS, assim como o protótipo da versão relacional do gerenciador, são descritos nas seções seguintes. 
O que se pretende com a versão sobre núcleo relacional é disponibilizar uma "bancada experimental" para a elaboração de algoritmos, técnicas de desenvolvimento e extensões para suporte a aspectos ainda não tratados, possibilitando a definição de alternativas adequadas para uma implementação mais eficiente na versão nativa.

\subsection{API SIRIUS}

A API SIRIUS [Sousa_00] é compatível com as versões nativa e com núcleo relacional do Gerenciador SIRIUS. Como ilustrado nas Figura 13 e 14, uma API única está definida para ambas as versões do gerenciador de objetos, permitindo que aplicativos utilizem indistintamente qualquer uma das versões, sem que sejam necessárias alterações no código fonte da aplicação.

\subsubsection{Definição da API}

A API do Gerenciador de Objetos SIRIUS é definida como um conjunto de classes que, integradas, compõem os módulos semânticos do gerenciador. Cada uma das classes representa um ou mais elementos sintáticos do modelo SIRIUS.

Neste trabalho, foram implementadas classes representando os elementos objeto, tipo de objeto, atributo, colônia e tipo de colônia, como apresentado na Tabela 3.

\begin{tabular}{|l|l|}
\hline Elemento Sintático & Classe da API \\
\hline Objeto e Tipo de Objeto & SiriusObject \\
\hline Atributo & SiriusAttribute \\
\hline Colônia & SiriusColony \\
\hline Tipo de Colônia & SiriusColonyType \\
\hline
\end{tabular}

Tabela 3 - Correspondência entre Elemento Sintático e Classe da API

O modelo SIRIUS oferece suporte a 15 características de atributos [Araujo_98a], como descrito no Capítulo 4. As particularidades de cada característica são tratadas na API através de classes derivadas da classe SiriusAttribute, devendo ser definida uma classe para cada característica. No escopo deste trabalho, foram criadas classes específicas 
para as características Texto, Número e Atributo de Atributo. A Tabela 4 apresenta as classes correspondentes às características citadas acima.

\begin{tabular}{|l|l|}
\hline Característica de Atributo & Classe da API \\
\hline \hline Texto & SiriusAttribText \\
\hline Número & SiriusAttribNumber \\
\hline Atributo de Atributo & SiriusAttribAttrib \\
\hline
\end{tabular}

Tabela 4 - Correspondência entre Característica de Atributo e Classe da API

A API oferece suporte à consulta e à recuperação de conjuntos de objetos, atributos e colônias, assim como de seus respectivos tipos. Os critérios de busca que podem ser utilizados numa consulta são simples e diretos, destacando-se busca de objetos por tipo e por colônia que habitam, busca de objetos por igualdade de valor de atributo, busca de atributos de um objeto e busca de colônias por tipo. Uma primitiva de busca seleciona todos os objetos que satisfazem o critério de busca e armazena seus OIds numa estrutura interna à API. Como a interface desenvolvida destina-se ao uso em programação (em linguagem $\mathrm{C}$ ou $\mathrm{C}++$ ), o paradigma adotado é o navegacional. $\mathrm{O}$ conjunto de objetos recuperados é percorrido por um cursor, e os objetos são passados um a um para a aplicação. A Tabela 5 apresenta as classes criadas para consultas que manipulam conjuntos.

\begin{tabular}{|l|l|}
\hline Elementos Recuperados & Classe da API \\
\hline Objetos e Tipos de Objeto & SiriusObjectCursor \\
\hline Atributos & SiriusAttributeCursor \\
\hline Colônias e Tipos de Colônia & SiriusColonyCursor \\
\hline
\end{tabular}

Tabela 5 - Correspondência entre Conjunto Recuperado e Classe da API

As classes definidas para a API compõem alguns dos módulos semânticos do Gerenciador SIRIUS: Módulo Objeto, Módulo Atributo Texto, Módulo Atributo Número, Módulo Atributo de Atributo e Módulo Colônia. Esses módulos implementam a semântica das 
abstrações de classificação, composição e agregação (agregação de atributo a objeto e agregação de atributo a atributo). A composição de cada um dos módulos semânticos é apresentada na Tabela 6.

\begin{tabular}{|l|l|}
\hline Módulo Semântico & Classes da API \\
\hline \hline Módulo Objeto & $\begin{array}{l}\text { SiriusObject } \\
\text { SiriusObjectCursor }\end{array}$ \\
\hline Módulo Atributo Texto & $\begin{array}{l}\text { SiriusAttribute } \\
\text { SiriusAttribText } \\
\text { SiriusAttributeCursor }\end{array}$ \\
\hline Módulo Atributo Número & $\begin{array}{l}\text { SiriusAttribute } \\
\text { SiriusAttribNumber } \\
\text { SiriusAttributeCursor }\end{array}$ \\
\hline Módulo Atributo de Atributo & $\begin{array}{l}\text { SiriusAttribute } \\
\text { SiriusAttribAttrib } \\
\text { SiriusAttributeCursor }\end{array}$ \\
\hline Módulo Colônia & $\begin{array}{l}\text { SiriusColony } \\
\text { SiriusColonyType } \\
\text { SiriusColonyCursor }\end{array}$ \\
\hline
\end{tabular}

Tabela 6 - Composição dos Módulos Semânticos

A classe Siriusobject é a principal classe da API, e portanto constitui a base para as demais. As instâncias ou objetos dessa classe são representações em memória de objetos de uma base de dados SIRIUS. Para que o uso do termo "objeto" não fique confuso, os objetos da base SIRIUS serão chamados de objetos-sirius, e os objetos ou instâncias da classe Siriusobject criados em memória serão chamados de sobrestantes ${ }^{1}$ objeto.

É importante ressaltar que criar um sobrestante objeto através do construtor da classe Siriusobject não implica em criar um objeto-sirius. Quando um sobrestante objeto é criado, sua estrutura interna é inicializada de forma a preparar o sobrestante para a criação de um novo objeto-sirius (método Createobject), ou para a leitura de um objeto-sirius armazenado na base de dados (método Readob ject).

\footnotetext{
${ }^{1} \mathrm{O}$ termo sobrestante é utilizado com o mesmo significado do termo handler
} 
A operação de criação de objetos-sirius é ortogonal para tipos e instâncias, o que permite que a aplicação crie, da mesma maneira, tipos e instâncias, em tempo de execução. As demais operações implementadas nas classes SiriusObject e SiriusObjectCursor também são ortogonais para tipos e instâncias, permitindo que objeto-sirius, tipos ou não, sejam manipulados através de um mesmo conjunto de métodos. Esse tratamento homogêneo de tipos e instâncias é imprescindível para o suporte à classificação em múltiplos níveis, onde tipos e instâncias existem e podem ser criados em tempo de execução. Consequentemente, operações que usualmente são separadas em DDL e DML são unificadas num conjunto único de comandos.

Todo novo objeto-sirius é criado, por default, como transiente, podendo ser declarado explicitamente como persistente através do método SetAsPersistent. Quando lido da base para a memória, o objeto-sirius é automaticamente declarado persistente. Embora objetos-sirius transientes sejam manipulados de maneira semelhante a objetos-sirius persistentes, somente objetos-sirius persistentes possuem OIds, gerados automaticamente pelo Gerenciador SIRIUS quando o objeto-sirius é declarado persistente.

Uma aplicação que utiliza a API SIRIUS pode acessar um objeto-sirius armazenado na base através de seu OId ou através do seu nome e do nome de seu tipo. O método Readobject é sobrecarregado, permitindo as duas formas de acesso citadas acima. O acesso a objetos-sirius é restrito a colônias abertas, isto é, a aplicação somente tem acesso a objetos-sirius que habitam suas colônias abertas. A classe Siriuscolony possui o método OpenColony, que explicitamente abre uma colônia para a aplicação. Uma instância da classe SiriusColony, chamada de sobrestante colônia, representa em memória as informações de uma colônia definida na base de dados. Cada colônia é acessada pela aplicação através do nome de seu tipo e do OId do objeto-sirius que a constringe. Assim como na classe SiriusObject, criar um sobrestante colônia não significa criar uma colônia, pois a classe Siriuscolony também possui um método dedicado a essa operação: Createcolony.

A classe SiriusColonytype oferece suporte à criação da hierarquia de tipos da abstração de composição, definida através do DHC, descrito no Capítulo 4. A aplicação tem acesso às informações de um tipo de colônia através de seu nome. Os tipos de colônia 
são representados em memória por instâncias da classe SiriusColonyType, chamadas sobrestantes tipo de colônia.

A classe SiriusAttribute destina-se ao tratamento de atributos quando não se conhece, a priori, a característica do atributo. Os métodos dessa classe têm como funcionalidade principal o acesso a informações do esquema associadas às abstrações de classificação e agregação. Por exemplo, os métodos GetclassificationInfo e GetAggregationInfo recuperam, respectivamente, as propriedades da classificação e de agregação, como descritas no Capítulo 4. As classes derivadas de SiriusAttribute são utilizadas para a manipulação de atributos cujas características são conhecidas, e portanto oferecem o suporte adequado aos valores dos atributos.

As instâncias da classe SiriusAttribute e de suas derivadas são chamadas de sobrestantes atributo. Ao contrário do que ocorre nas demais classes, a criação de um sobrestante atributo implica na criação de um atributo. No entanto, o atributo só pode ser vinculado ao objeto-sirius através do método AddAttribute da classe Siriusobject.

Existe ainda a classe SIRIUS, que disponibiliza um conjunto de métodos para iniciar e finalizar uma conexão com a base de dados, e para iniciar e finalizar (commit ou abort) transações.

O tratamento de erros é realizado através da classe SiriusError, que utiliza uma abordagem semelhante ao tratamento de exceções oferecido pela biblioteca padrão $\mathrm{C}++$ (exception handling). Nessa abordagem, a aplicação pode verificar a ocorrência de erros por blocos de comando, utilizando por exemplo comandos try e catch da linguagem $\mathrm{C}++$.

O exemplo a seguir ilustra como os métodos da API podem ser utilizados para manipular informações modeladas a partir do modelo SIRIUS e armazenadas numa base de dados SIRIUS. A Figura 15 exemplifica uma modelagem de objetos que utiliza a notação gráfica adotada para o modelo de dados em questão. Em 15a, o DHC define que o tipo de objetosirius Biblioteca constringe o tipo de colônia $\mathrm{CBibl}$, em cujas instâncias (colônias) vão habitar objetos-sirius dos tipos Livro e Periódico. Em 15b, o objeto-sirius Prof. Achille Bassi, do tipo Biblioteca, constringe uma colônia do tipo CBibl onde habitam os objetos-sirius Transactions in Computer Science, Computer Networks e 3rd Edition, dos tipos Periódico, Livro e Computer Networks, 
respectivamente. A Figura 15c ilustra duas hierarquias de classificação: uma de dois níveis, composta por Biblioteca e Prof. Achille Bassi, e outra de três níveis, criada pelos objetos-sirius Livro, Computer Networks e 3rd Edition.

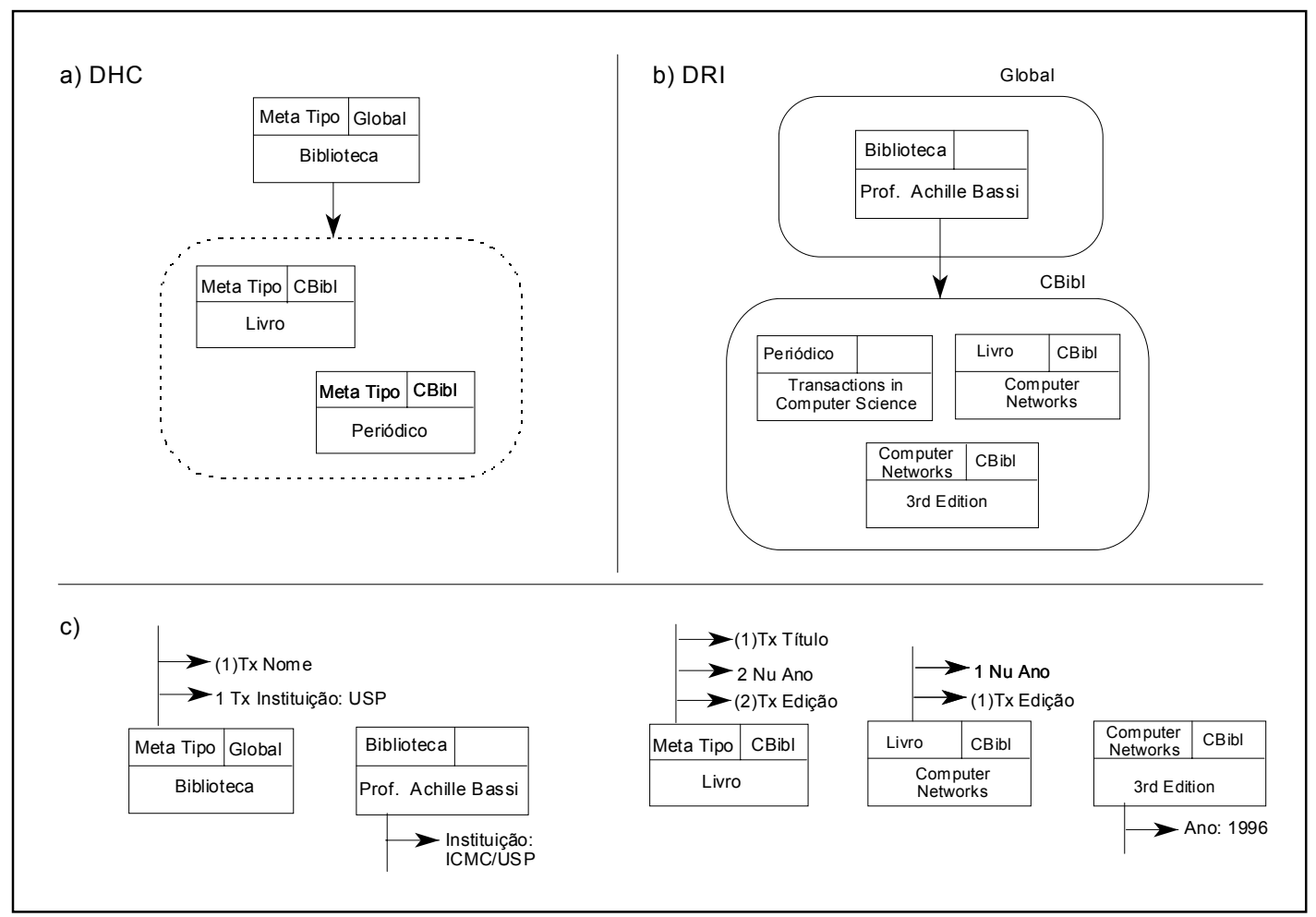

Figura 15 - Exemplo de Modelagem SIRIUS

O objeto-sirius Biblioteca é do tipo Meta Tipo e habita a colônia do tipo Global, que está sempre aberta para a aplicação. Portanto, Biblioteca pode ser o primeiro objetosirius a ser criado. Na criação de Biblioteca, METATYPE e GLOBAl são palavras prédefinidas na API para o Meta Tipo (que é tipo de Biblioteca) e para o tipo de colônia Global (que é o tipo de colônia onde vão habitar as instâncias de Biblioteca). O método SetAsPersistent torna o objeto-sirius persistente e retorna o OId gerado. $\mathrm{O}$ tipo de dado SOID é definido na API para armazenar os OIds dos objetos-sirius da base de dados. Note-se que todos os tipos definidos na API têm seus nomes iniciados pela letra S, de SIRIUS.

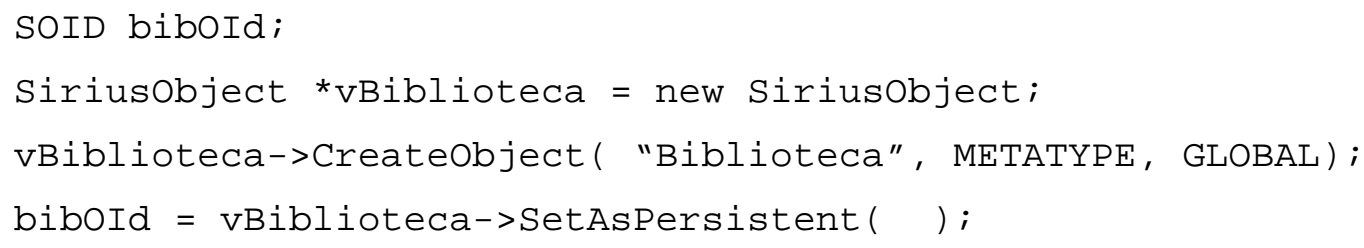


O atributo Nome é criado como atributo fixo identificador no nível de instanciação 1, mono-valorado, definido e sem valor default. O método AddAttribute vincula o atributo ao objeto-sirius Biblioteca. Para tratar as propriedades de classificação e agregação, a API possui palavras pré-definidas escritas em letras maiúsculas, como IDENTIFIER, DEFINED, FIX, entre outras. Todos os termos e tipos definidos na API e exportados para as aplicações são descritos em Anexo.

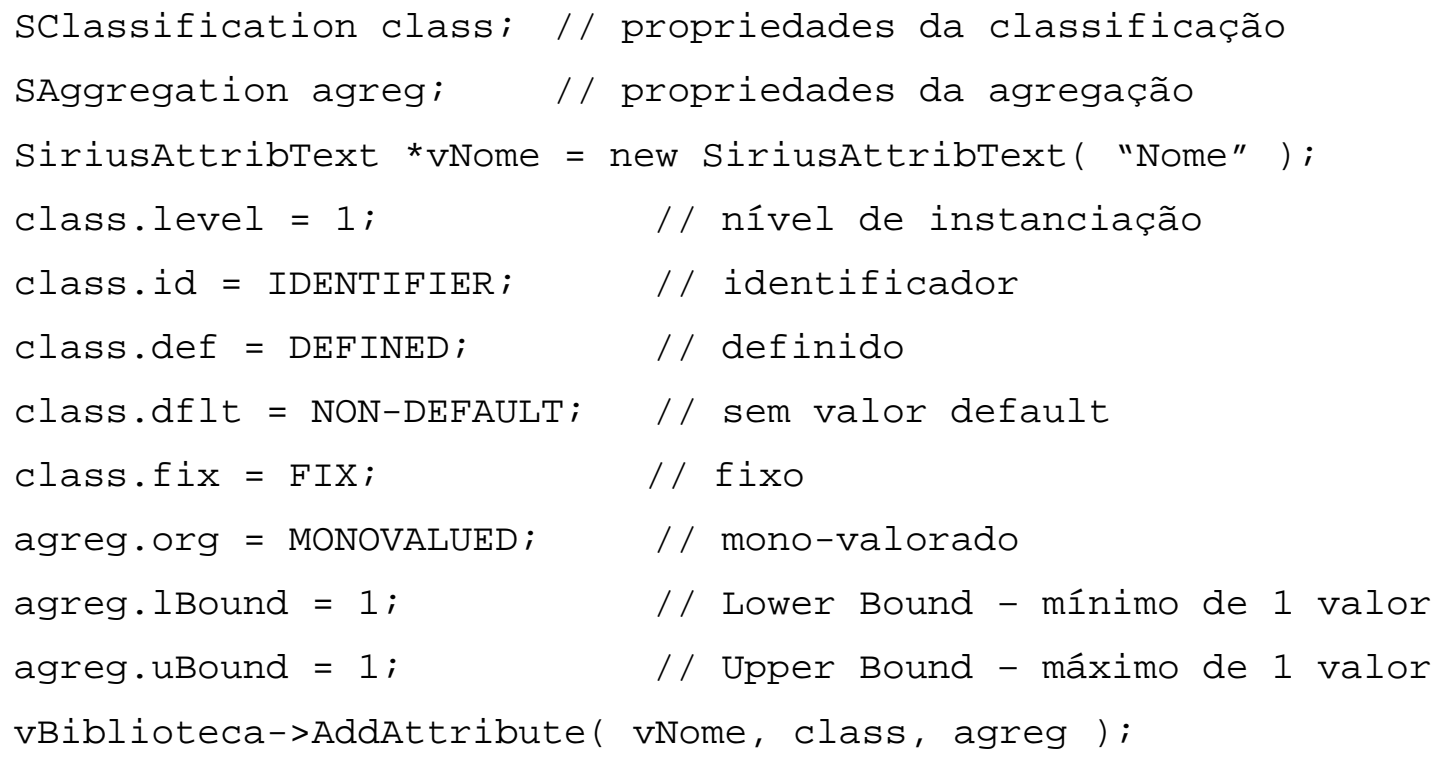

O atributo Instituição é criado como atributo fixo, não identificador, de nível de instanciação 1, mono-valorado, definido e com valor default. O método setvalue insere o valor USP para o atributo.

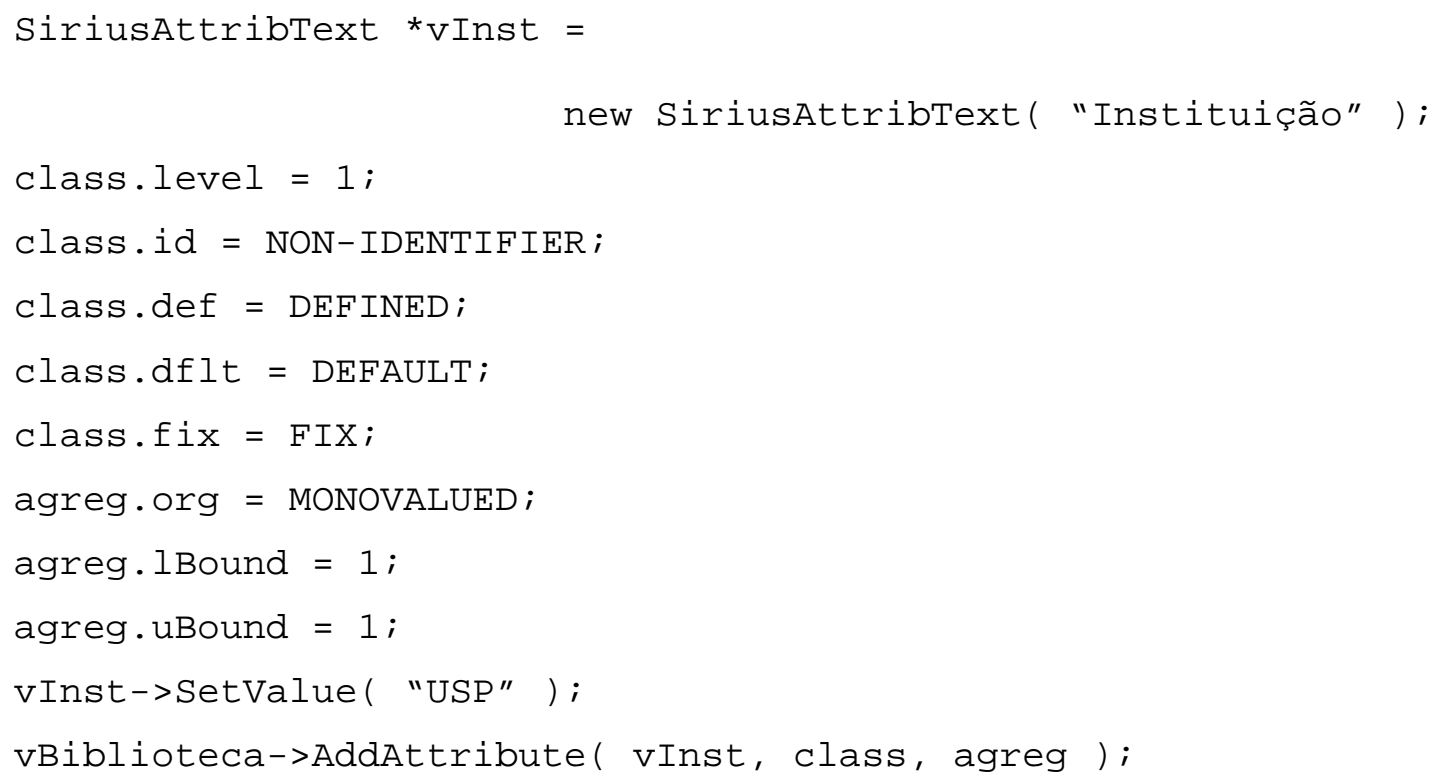


O objeto-sirius Prof. Achille Bassi, do tipo Biblioteca, habita a colônia do tipo Global. Este objeto-sirius está no último nível da hierarquia, ou seja, não possui instâncias, e portanto não possui tipo de colônia definido para instâncias. Neste caso, o método Createobject é chamado apenas com os parâmetros de nome e tipo do objetosirius. Os atributos definidos em Biblioteca são criados implicitamente para sua instância. As propriedades de classificação e agregação são preservadas, alterando-se apenas o nível de instanciação, que é decrementado. O valor default USP pode ser alterado em Prof. Achille Bassi, como ilustrado na modelagem. Para tanto, o método GetAttribute habilita o acesso ao atributo Instituição através do sobrestante vAttrib, e o método UpdateValue altera o valor default para ICMC-USP. Note-se que mesmo antes do objeto-sirius ser declarado como persistente, é possível manipular os valores dos atributos. Como citado anteriormente, objetos-sirius transientes são tratados de maneira semelhante a objetos-sirius persistentes. Algumas operações, entretanto, estão restritas a objetos-sirius persistentes, como criação e remoção de atributos.

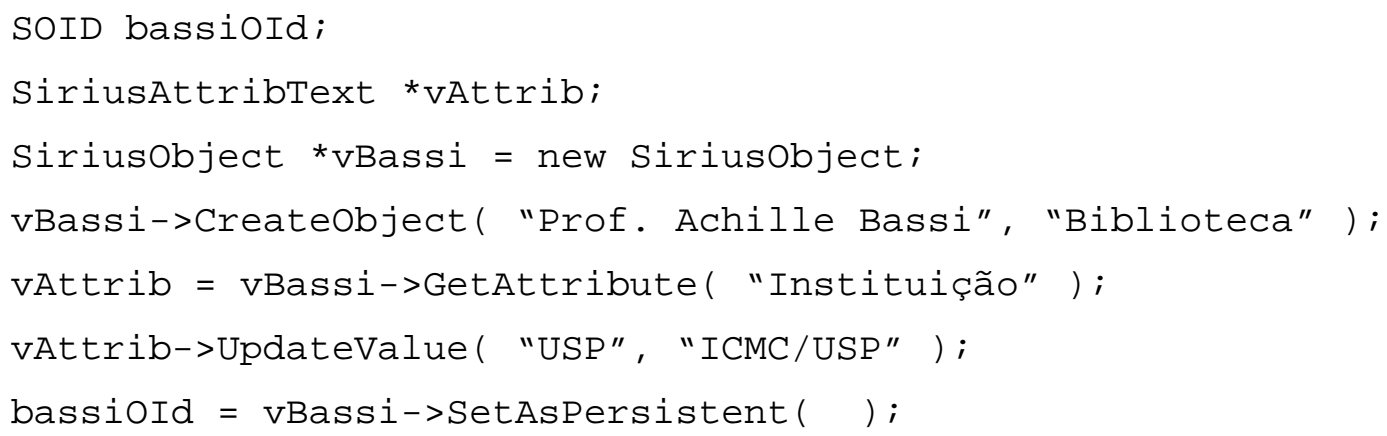

O passo seguinte é definir o tipo de colônia $\mathrm{CBibl}$, constrito pelo objeto-sirius Biblioteca, cujo OId é biboId (gerado no início do exemplo).

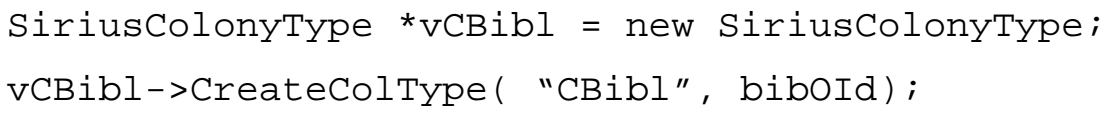

Criado o tipo de colônia $\mathrm{CBibl}$, é possível criar uma colônia deste tipo constrita pelo objeto-sirius Prof. Achille Bassi, representado no sobrestante vBassi.

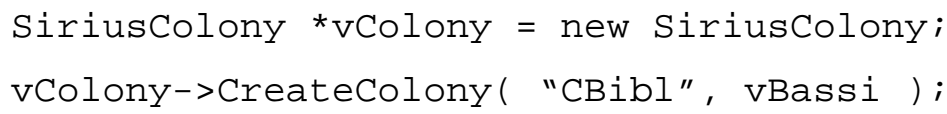


delete vColony;

A linha de código delete vColony invoca o método destrutor da classe Siriuscolony, que apenas libera o espaço em memória anteriormente alocado para o sobrestante colônia, não tendo efeito algum sobre a colônia já criada na base de dados. Os destrutores das demais classes atuam da mesma forma, havendo uma pequena diferença no destrutor da classe SiriusObject, já que se um sobrestante objeto for removido, o objeto-sirius correspondente só existirá na base se for persistente. As classes da API definem métodos específicos para a remoção de elementos da base SIRIUS, como por exemplo, Deleteobject da classe Siriusobject.

Retornando ao exemplo da modelagem, o objeto-sirius Livro, cujo tipo é Meta Tipo, habita a colônia do tipo Global e define $\mathrm{CBibl}$ como o tipo de colônia onde vão habitar suas instâncias. De maneira análoga à criação de Biblioteca, as linhas de código a seguir criam o objeto-sirius Livro.

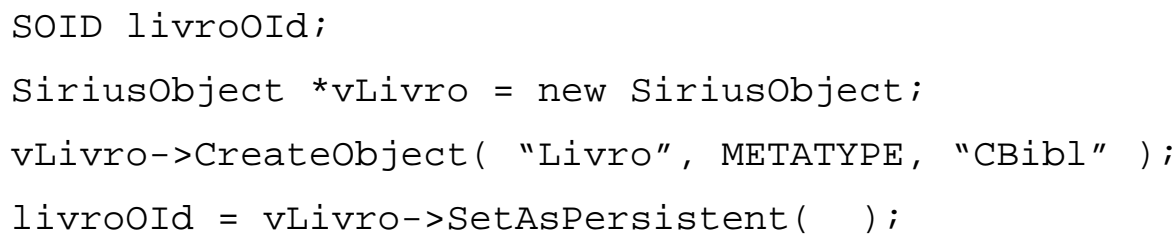

O atributo Título é criado como atributo fixo identificador no nível de instanciação 1, mono-valorado, definido e sem valor default.

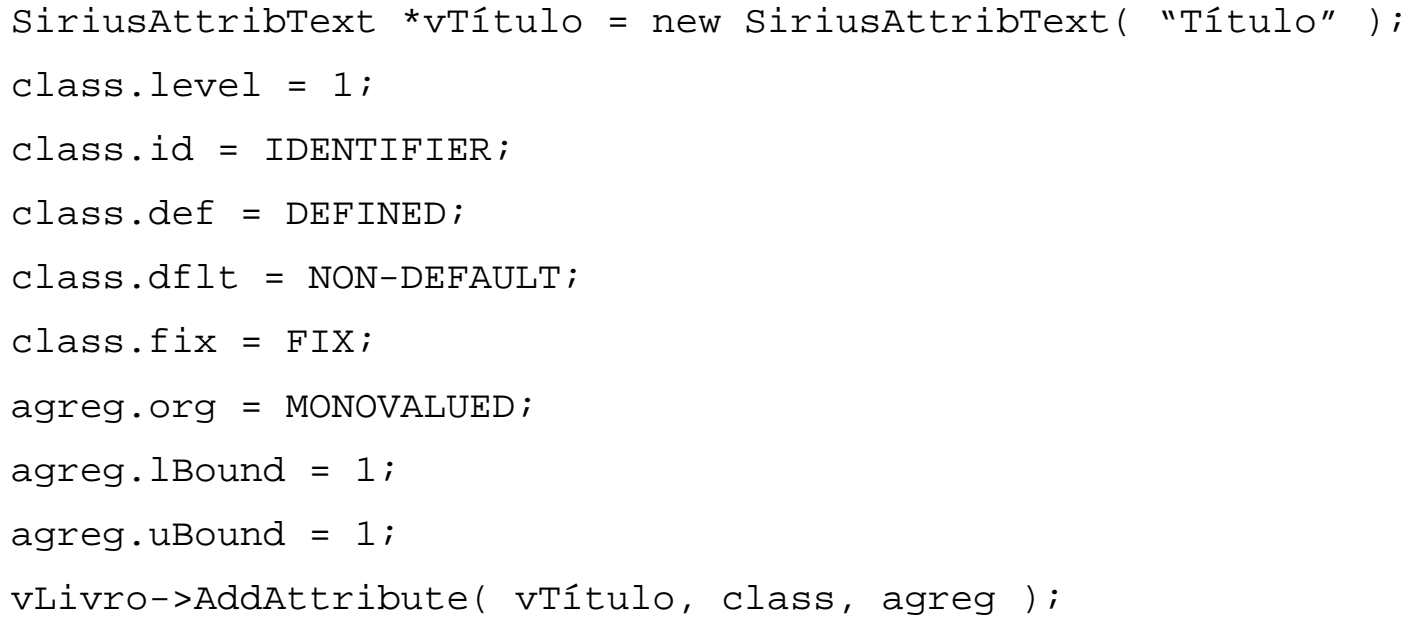


O atributo Edição é criado como atributo fixo identificador no nível de instanciação 2, mono-valorado, definido e sem valor default.

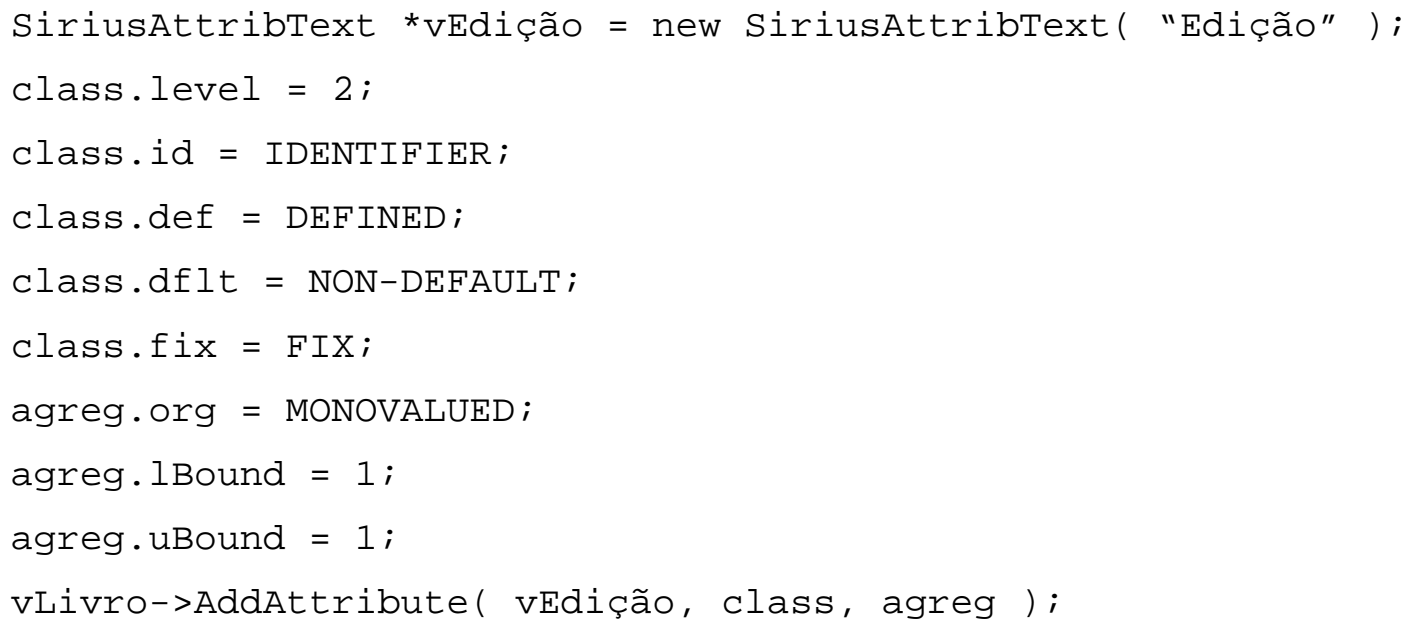

O atributo Ano é criado como atributo fixo, não identificador, de nível de instanciação 2 , mono-valorado, definido e sem valor default.

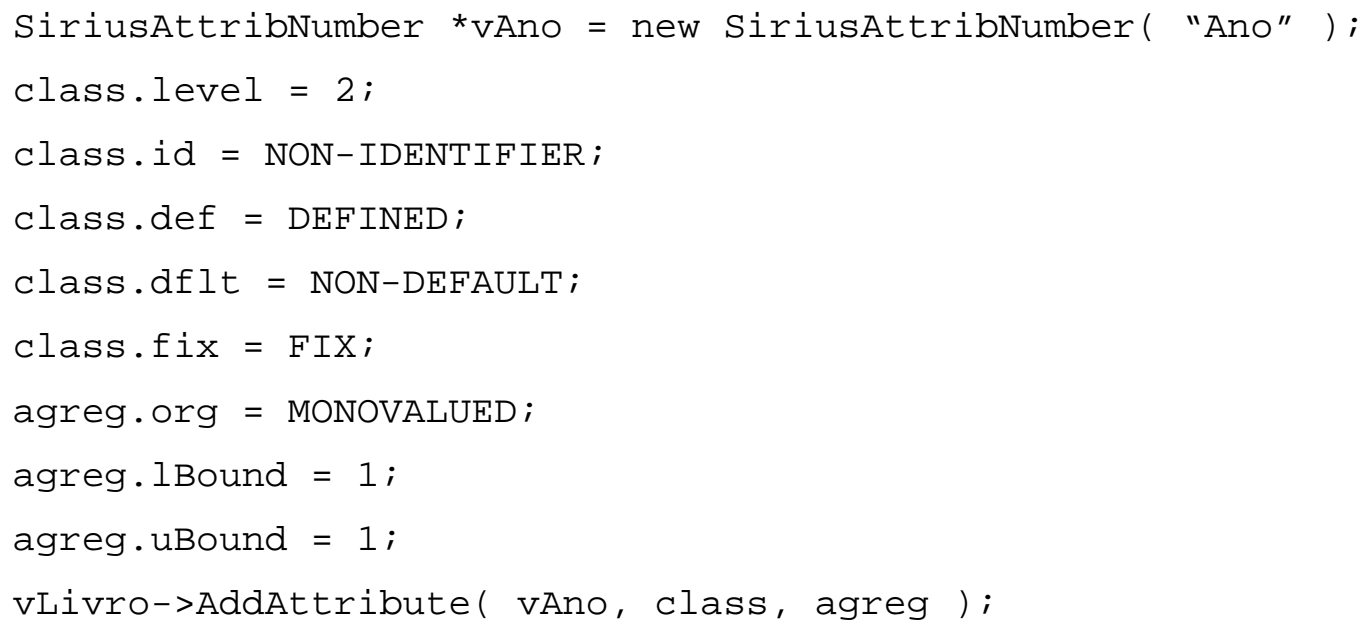

Para criar as instâncias de Livro é preciso abrir uma colônia do tipo CBibl. O método OpenColony abre a colônia criada anteriormente.

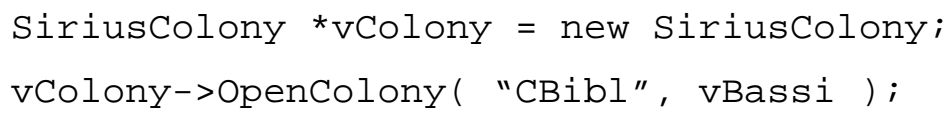

As linhas de código seguintes criam os objetos-sirius Computer Networks e 3rd Edition. Os comandos try e catch ilustram a utilização da classe SiriusError. 


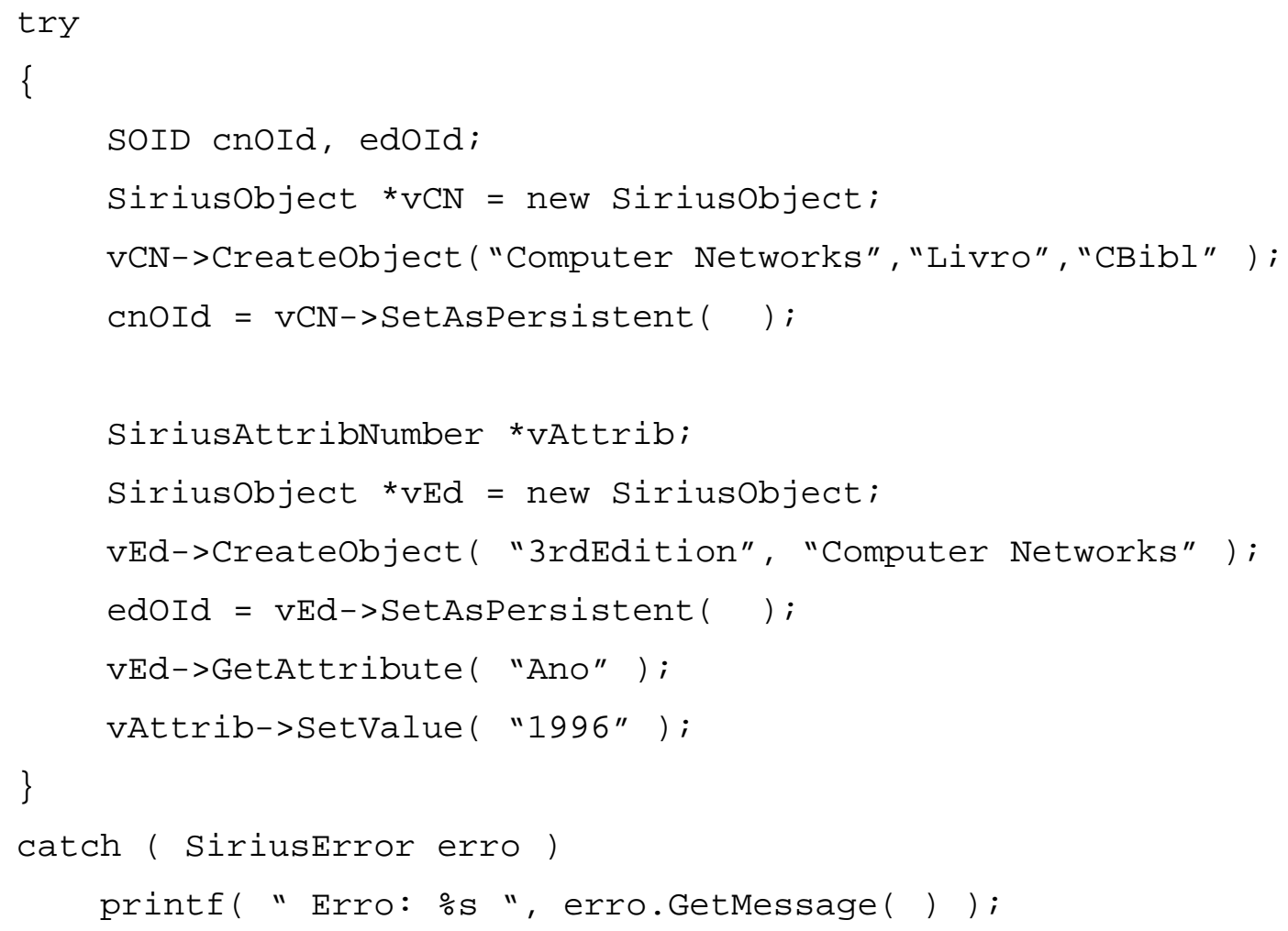

Para exemplificar a utilização de métodos de consulta, dois tipos de busca podem ser considerados:

"Buscar todos os títulos de livros da biblioteca Prof. Achille Bassi". Como as instâncias de Livro habitam colônias do tipo CBibl, é necessário abrir a colônia constrita por Prof. Achille Bassi, pois como já foi dito anteriormente, os métodos da API só têm acesso a objetos-sirius de colônias abertas para a aplicação. Quando a aplicação requisita que uma colônia seja aberta, o método openColony fecha qualquer outra colônia do mesmo tipo que estiver aberta, pois SIRIUS define que apenas uma colônia de cada tipo pode estar aberta simultaneamente para a aplicação.

O método Searchobject é sobrecarregado na classe e faz a busca segundo o critério especificado nos parâmetros. Todos os OIds recuperados na consulta são armazenados e percorridos através do cursor controlado no método Endofobjects. O método Getob ject retorna para a aplicação o OId apontado pelo cursor.

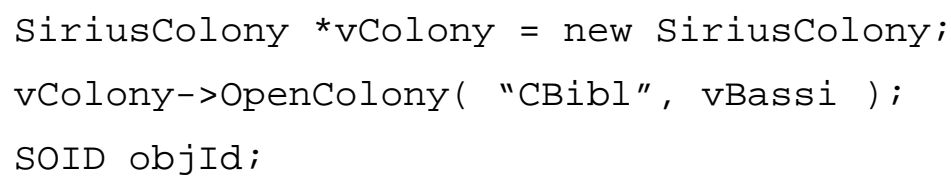




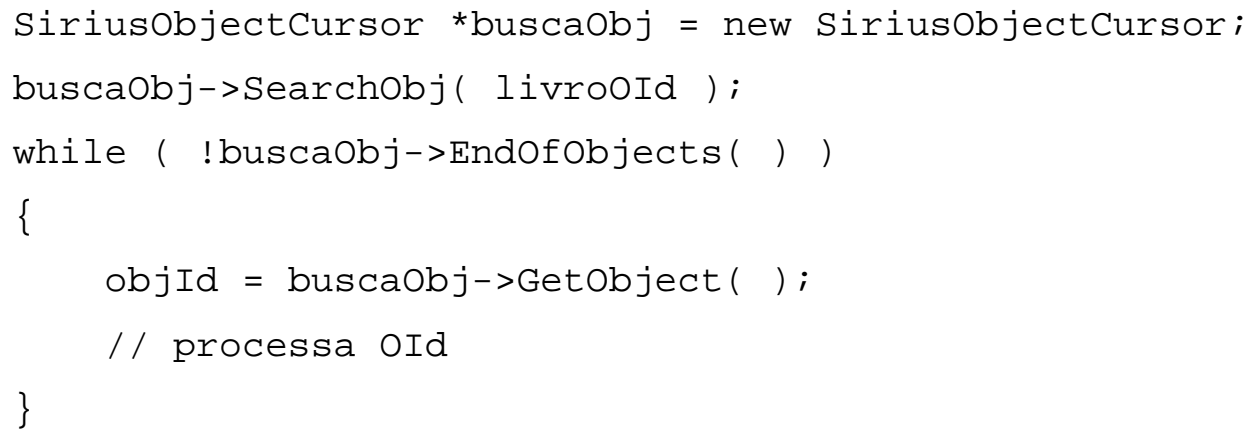

"Buscar todos os atributos do objeto-sirius Computer Network". O método SearchAttribute armazena os atributos do objeto-sirius em sobrestantes atributo, cujas referências são retornadas para a aplicação através do método GetAttribute. O método GetName retorna o nome do atributo.

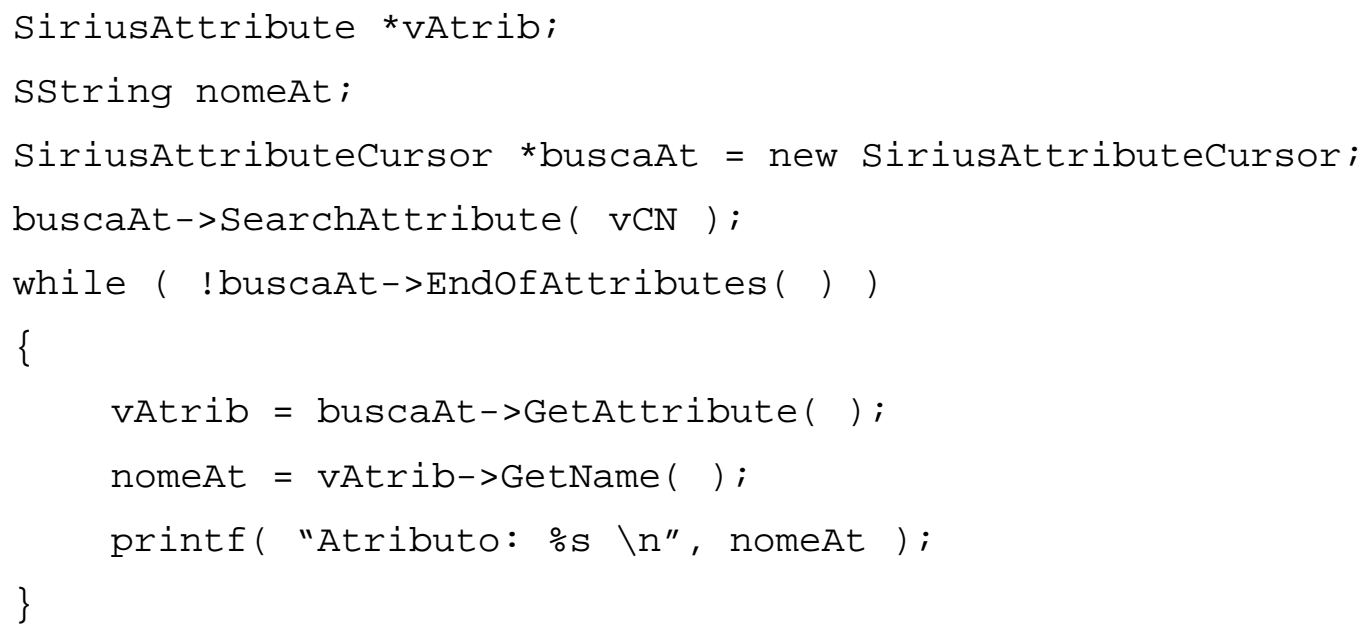

Na seção 2.4, foram discutidas algumas características consideradas fundamentais na API de um SGBDOO. A Tabela 1 apresentou uma comparação entre APIs de alguns SGBDOOs e do padrão ODBC. A Tabela 7 utiliza o mesmo conjunto de características e mostra se a API SIRIUS suporta ( $\mathrm{S}$ ) ou não ( $\mathrm{N}$ ) cada uma delas. O símbolo * refere-se a uma observação a ser feita a respeito da característica. A quarta coluna da tabela descreve como a característica é suportada na API SIRIUS. Para as características tratadas explicitamente através de métodos da API, são apresentados o(s) nome(s) do(s) método(s) e o nome da classe correspondente. 


\begin{tabular}{|c|c|c|c|}
\hline & & SIRIUS & \\
\hline \multirow[b]{2}{*}{ Interface } & Startup & $\mathrm{S}$ & $\begin{array}{l}\text { Classe: SIRIUS } \\
\text { Método: Connect( ... ) }\end{array}$ \\
\hline & Shutdown & $\mathrm{S}$ & $\begin{array}{l}\text { Classe: SIRIUS } \\
\text { Método: Disconnect( ... ) }\end{array}$ \\
\hline \multirow{3}{*}{ Sistema } & Início de Transação & $\mathrm{S}$ & $\begin{array}{l}\text { Classe: SIRIUS } \\
\text { Método: BeginTransaction( ... ) }\end{array}$ \\
\hline & Commit de Transação & $\mathrm{S}$ & $\begin{array}{l}\text { Classe: SIRIUS } \\
\text { Método: CommitTransaction( ... ) }\end{array}$ \\
\hline & Abort de Transação & $\mathrm{S}$ & $\begin{array}{l}\text { Classe: SIRIUS } \\
\text { Método: AbortTransaction( ... ) }\end{array}$ \\
\hline \multirow[t]{3}{*}{ Interface } & Alocação/Desalocação & $\mathrm{S}$ & $\begin{array}{l}\text { Classe: SiriusObject } \\
\text { Métodos: SiriusObject( } \ldots \text { ) } \\
\\
\sim \text { SiriusObject }(\ldots)\end{array}$ \\
\hline & Atribuição/Comparação & $\mathrm{S}$ & $\begin{array}{l}\text { "a atribuição e comparação de referências é suportada } \\
\text { através dos operadores de atribuiçãao }(=) \text { e } \\
\text { comparação }(==) \text { da linguagem } C++ \text { " }\end{array}$ \\
\hline & Persistência & $\mathrm{S}$ & $\begin{array}{l}\text { Classe: SiriusObject } \\
\text { Método: SetAsPersistent(... ) }\end{array}$ \\
\hline \multirow{2}{*}{ Objetos } & Modificação & $\mathrm{S}$ & $\begin{array}{l}\text { "a verificação de modificação é realizada } \\
\text { implicitamente pelo sistema" }\end{array}$ \\
\hline & Recuperação & $\mathrm{S}$ & $\begin{array}{l}\text { Classe: SiriusObject } \\
\text { Método: ReadObject( ... ) }\end{array}$ \\
\hline \multirow{5}{*}{ Outras } & Transações Elaboradas & * & \\
\hline & Grupos de Objetos & $*$ & \\
\hline & Versões Anteriores & $*$ & \\
\hline & Locks em Objetos & $*$ & \\
\hline & Nomeação de Objetos & & $\begin{array}{l}\text { "os objetos possuem um identificador, ou nome, } \\
\text { definido pelo usuário como o valor do atributo } \\
\text { identificador" }\end{array}$ \\
\hline
\end{tabular}

Tabela 7 - Características de API no Gerenciador SIRIUS 


\section{Observação:}

* Características não previstas na API, pois ainda não foi definido o suporte a cada uma delas no Gerenciador de Objetos SIRIUS.

\subsubsection{Implementação da API}

As classes definidas para a API SIRIUS, com exceção da classe SiriusAttribAttrib, foram implementadas como uma DLL que exporta os métodos públicos destas classes para a aplicação. A implementação da API compõe um conjunto de módulos semânticos para a versão com núcleo relacional do Gerenciador de Objetos SIRIUS. A Figura 16 ilustra a estrutura implementada.

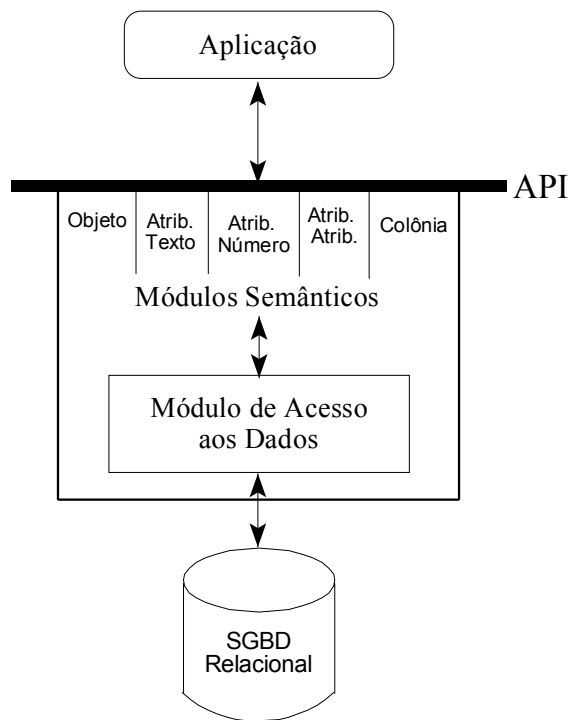

Figura 16 - Estrutura de implementação da API

Um gerenciador de base de dados relacional é utilizado como núcleo da versão relacional do Gerenciador SIRIUS. Acima do SGBD relacional, a camada semântica é dividida em duas sub-camadas principais: um conjunto de Módulos Semânticos e um Módulo Acesso aos Dados. Os Módulos Semânticos Objeto, Atributo Texto, Atributo Número, Atributo de Atributo e Colônia implementam grande parte dos conceitos e da semântica do modelo de dados SIRIUS. O Módulo de Acesso aos Dados implementa todo o código de acesso ao gerenciador relacional. Essa divisão na camada semântica tem por objetivo isolar todo o acesso à base no Módulo de Acesso aos Dados, facilitando assim a manutenção do código de tratamento dos dados e a migração de um gerenciador relacional para outro, uma vez que o Módulo de Acesso aos Dados concentra todo o código que está suscetível a alterações decorrentes do processo de migração. 
O conjunto de cláusulas SQL que permitem o acesso aos dados armazenados na base relacional, na versão da API sobre núcleo relacional, foi gerado a partir das cláusulas SQL criadas para a versão original do $E^{2}$ SIRIUS, como citado na seção 5.2. Algumas dessas cláusulas foram alteradas para otimizar algumas operações, mas a essência da estrutura de tabelas definida no $E^{2}$ SIRIUS foi mantida [Araujo_98a].

A classe Siriusobject, como citado na seção anterior, é a principal classe da API. Os membros privados de um sobrestante objeto armazenam as informações relevantes do objeto-sirius armazenado na base de dados. A Figura 17 ilustra a estrutura de um sobrestante objeto, composto pelo OId (OID) e o nome do objeto-sirius (Name), o OId de seu tipo (Type), o nome da colônia onde o objeto-sirius habita (Colony), o nome do tipo de colônia onde habitam suas instâncias (InstCol), e uma lista dos atributos do objeto-sirius representado. A lista divide os atributos por característica, onde cada atributo é representado por um sobrestante atributo da classe apropriada. Em cada sobrestante atributo é armazenado o identificador (AtId) e o nome do atributo (AtName), e o(s) valor(es) assumido(s) por esse atributo.

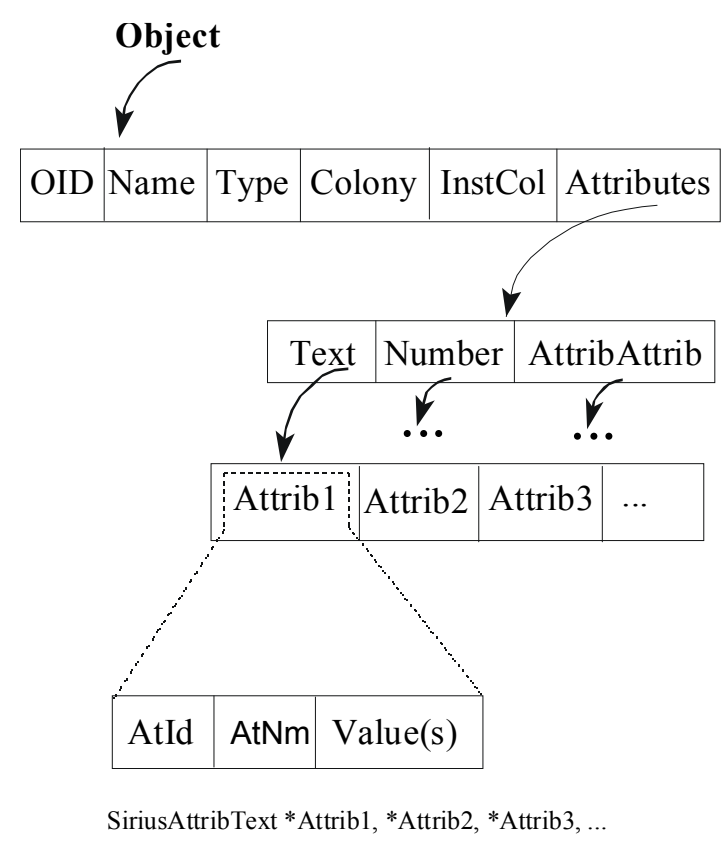

Figura 17 - Estrutura do sobrestante objeto

O OId de um objeto-sirius é implementado de maneiras diferentes nas versões nativa e relacional do Gerenciador SIRIUS, pois o conceito de OId, característico do paradigma de orientação a objetos, foi emulado num ambiente relacional. Entretanto, a estrutura de representação do OId utilizada na API é compatível com ambas as versões do gerenciador. 
O OId é composto por dois campos: um campo address e um campo counter. Na versão nativa, address armazena do endereço lógico do objeto-sirius e counter armazena o número de vezes que esse endereço foi utilizado por objetos-sirius diferentes, mantendo assim duas propriedades importantes do OId: a unicidade e a não reutilização do mesmo durante toda a existência da base de dados [Valêncio_00]. Na versão relacional, o campo address perde o sentido, e portanto é mantido com valor 0 (zero); o campo counter é gerado automaticamente pelo gerenciador para objetos-sirius "declarados" persistentes, mantendo as propriedades citadas acima.

Assim como os objetos-sirius, atributos, colônias e tipos de colônia também possuem códigos identificadores únicos, gerados pelo gerenciador. Entretanto, a aplicação tem acesso somente aos OIds dos objetos-sirius; os atributos são identificados através de seus nomes; uma colônia é identificada através do nome de seu tipo e do OId do objeto-sirius que a constringe, e o tipo de colônia é identificado por seu nome.

O sobrestante objeto possui ainda um flag indicando se o objeto-sirius é persistente ou transiente e, se for transiente, um flag indicando se valores de atributos foram adicionados, removidos ou alterados, pois quando "declarado" persistente, o objeto-sirius representado no sobrestante objeto deverá ser criado na base de dados assim como definido no sobrestante. Quando um objeto-sirius de um determinado tipo é criado no sobrestante objeto, toda a estrutura do sobrestante é criada independentemente do novo objeto-sirius ser persistente ou transiente. Se, por exemplo, o tipo em questão possuir valor default para algum atributo, o novo objeto-sirius também possuirá esse valor para o atributo. Porém, se esse valor for alterado enquanto o objeto-sirius for transiente, essa alteração deverá ser mantida quando o objeto-sirius tornar-se persistente e for criado na base de dados.

As classes que manipulam conjuntos, ou seja, as classes siriusobjectCursor, SiriusAttributeCursor e SiriusColonyCursor, são estruturadas como listas dinâmicas encadeadas, e armazenam respectivamente OIds, nomes de atributos e estruturas de identificação de colônias, compostas pelo nome do tipo da colônia e OId do objetosirius que a constringe. Estas listas são criadas para armazenar os resultados de consultas na base de dados, como por exemplo: a requisição "buscar todos os objetos-sirius de um determinado tipo" resulta numa lista dos OIds de todos os objetos-sirius recuperados na consulta em questão. As listas possuem um ponteiro, aqui chamado de cursor, que percorre 
todos os seus elementos, permitindo que a aplicação recupere um a um todos os elementos resultantes da consulta.

Como um sobrestante é uma representação em memória de um elemento de uma base SIRIUS, seria possível criar uma base de dados transiente completa no espaço de memória da aplicação, ou seja, definir em memória hierarquias de tipos correspondentes a cada uma das abstrações e criar instâncias para "alimentar" essa base transiente em memória, independentemente dessas informações tornarem-se ou não persistentes posteriormente. Entretanto, o suporte a esse conceito aumentaria significativamente a complexidade da implementação dos métodos da API, tornado-se inviável no contexto deste trabalho.

Para efeito de demonstração, o conceito descrito acima foi implementado para a hierarquia da abstração de classificação, com a seguinte restrição: todo objeto-sirius, persistente ou transiente, é instância de um tipo persistente. Assim, visualizando a hierarquia de classificação como uma árvore, onde o nó raiz é representado pelo Meta Tipo, todos os nós folha podem ser transientes, enquanto os intermediários são obrigatoriamente persistentes. Considerando então os nós intermediários como os tipos definidos na base de dados, pode-se "alimentar" toda a base na memória da aplicação. Para tanto, um conjunto de métodos da classe siriusobject trata objetos-sirius transientes e persistentes de maneira ortogonal. Assim, é possível criar quantos objetos-sirius transientes quantos forem necessários, desde que sejam de tipos persistentes. Para objetos-sirius transientes, assim como para persistentes, é possível consultar informações como tipo, colônia onde habita, tipo de colônia das instâncias e atributos. Valores de atributos podem ser inseridos, removidos ou alterados em objetos-sirius transientes, mas há restrições quanto às operações de inserção e remoção de atributos, que somente podem ser efetuadas para objetos-sirius persistentes.

As atividades de implementação das classes da API foram realizadas em ambiente Windows, utilizando a ferramenta de desenvolvimento Inprise/Borland $C++$ Builder. $\mathrm{O}$ gerenciador relacional InterBase (Inprise/Borland) foi utilizado como núcleo da versão relacional do Gerenciador de Objetos SIRIUS. As cláusulas SQL de acesso à base de dados seguem o padrão SQL, e portanto tornam a versão relacional do Gerenciador SIRIUS independente do SGBD relacional utilizado como núcleo. 


\subsection{Considerações Finais}

Este capítulo descreve o Gerenciador de Objetos SIRIUS, apresentando a arquitetura e as principais características de cada uma de suas versões: a versão com núcleo nativo e a versão com núcleo relacional. Ambas as versões do gerenciador possuem uma API única, chamada de API SIRIUS, que permite que aplicações utilizem qualquer uma das versões sem alterações em código fonte.

A API SIRIUS oferece suporte às abstrações de classificação, composição e agregação, destacando-se o tratamento homogêneo de tipos e instâncias inerente à hierarquia de classificação em múltiplos níveis. Este capítulo apresenta ainda diversos exemplos para ilustrar a utilização de alguns métodos da API. 


\section{Editor de Esquemas SIRIUS}

\subsection{Introdução}

O E ${ }^{2}$ Sirius [Araujo_98a] [Araujo_98b], embora tenha sido criado com base no modelo SIRIUS, foi desenvolvido com a finalidade de demonstrar principalmente o suporte a atributos extras e a hierarquias de classificação em múltiplos níveis, utilizando um conjunto único de comandos para o tratamento de tipos e instâncias em tempo de execução.

A versão original do $E^{2}$ Sirius incorpora um conjunto de operações de acesso direto a uma base de dados relacional. Neste trabalho, o $E^{2}$ Sirius foi re-implementado, e suas operações passaram a utilizar apenas as primitivas da API desenvolvida. Este capítulo pretende apresentar a nova abordagem de implementação do Editor de Esquemas, demonstrando que a API pode ser utilizada na criação de um utilitário de bases de dados genérico, como é o $E^{2}$ Sirius, e portanto é válida para o desenvolvimento de aplicações em geral centradas em um gerenciador de dados orientado a objetos.

\subsection{Descrição do $E^{2}$ Sirius}

O $E^{2}$ Sirius é composto por um conjunto de formulários gráficos agrupados em subconjuntos que tratam separadamente as abstrações de classificação, agregação, composição e generalização. Os formulários estão interligados, representando o relacionamento entre as abstrações, que coexistem numa modelagem. Os formulários do editor constituem a interface com o usuário, permitindo uma representação coerente e completa de informações de acordo com os conceitos propostos no modelo SIRIUS.

O formulário Object, apresentado na Figura 18, representa o ponto de partida para a definição de hierarquias das abstrações de dados, e portanto é o mais complexo do 
utilitário. Nesse formulário, o interador Object, composto pelos campos object Name, Object Type e Instances Colony Type definem, respectivamente, o nome do objeto, seu tipo e o tipo da colônia onde habitam as suas instâncias. Para criar um objeto, o usuário escolhe seu tipo dentre os disponíveis em object Type. Quando a base de dados é criada, existe apenas o tipo Meta Tipo, definido pelo sistema. Logo, o primeiro objeto criado deve ter esse tipo, iniciando a hierarquia de classificação. Os próximos objetos a serem criados podem ser de qualquer tipo disponível, ressaltando que um objeto é considerado tipo quando sua definição inclui atributos de classificação, como descrito no Capítulo 4.

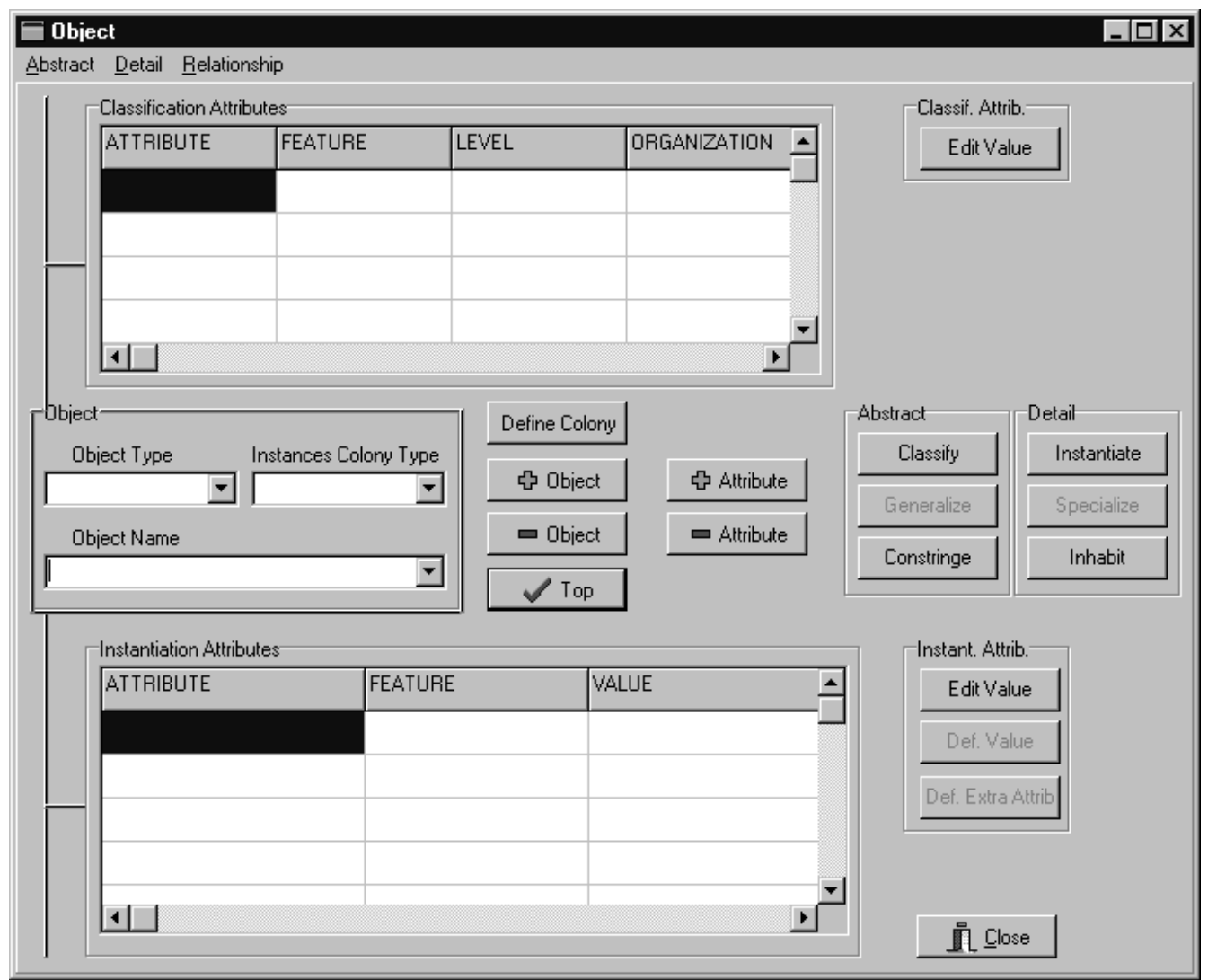

Figura 18 - Formulário Object do E' 2 SIRIUS

Os OIds dos objetos, gerados automaticamente pelo sistema, compartilham um mesmo domínio e são utilizados internamente por operações suportadas pelo editor, de maneira que todo comando pode ser indistintamente aplicado a objetos e tipos de objetos. $\mathrm{O}$ $E^{2}$ Sirius não apresenta diferença alguma no tratamento de tipos e instâncias, sendo que o mesmo formulário permite a criação e visualização de objetos e tipos de objetos em qualquer nível da hierarquia de classificação. Os botões Classify e Instantiate permitem a navegação por toda a hierarquia. 
A abstração de agregação é tratada por um subconjunto de formulários acionados através dos botões + Attribute e - Attribute, que disponibilizam respectivamente as operações: de criação de atributos para o objeto, definindo propriedades de classificação e agregação; e de remoção de atributos do objeto. A atribuição de valores default a atributos de classificação é feita através do botão Edit Value, no interador Classif. Attrib., enquanto a atribuição de valores a atributos de instanciação é realizada através do botão Edit Value no interador Instanc. Attrib.

A abstração de composição é representada através da informação definida no campo Instances Colony Type e de um subconjunto de formulários vinculados aos botões Define Colony, Constringe e Inhabit. A abstração de generalização é tratada por um subconjunto de formulários vinculados aos botões Generalize e Specialize.

O Editor de Esquemas possui um conjunto de regras que garantem restrições de integridade e consistência, aplicadas principalmente a operações de edição que podem causar inconsistência na base de dados.

\subsection{Utilização da API no $E^{2}$ Sirius}

O Editor de Esquemas foi re-implementado utilizando apenas as primitivas da API desenvolvida neste trabalho, tornando-se um utilitário centrado num gerenciador de dados orientado a objetos. Como a emulação desse tipo de gerenciador foi desenvolvida com o cuidado de se preservar uma mesma interface para as versões relacional e nativa do Gerenciador SIRIUS, a nova versão do $\mathrm{E}^{2}$ Sirius pode utilizar, como utilitário, tanto a versão relacional quanto a versão nativa desse gerenciador.

A funcionalidade geral do Editor de Esquemas foi preservada na nova implementação, pois os conceitos inerentes às abstrações de dados que o editor suporta, com exceção da abstração de generalização, estão presentes na API. Entretanto, o código resultante é bem mais conciso e mais simples, pois todas as operações de acesso direto à base de dados emulando um ambiente orientado a objetos são feitas na API. Além disso, as operações específicas de verificação de consistência e de restrições de integridade referentes ao modelo de dados também são tratadas na API, deixando para o utilitário apenas a tarefa de verificar, se como resultado, houve ou não a ocorrência de erros. Além disso, a maioria dos 
trechos de código que envolvem uma lógica mais complexa ficaram implementados internamente à API.

Essa nova abordagem de implementação facilitou significativamente a atividade de desenvolvimento do editor, finalizado num tempo muito menor que a versão original, mesmo levando-se em consideração a experiência anteriormente adquirida com o desenvolvimento da mesma. Uma medida quantitativa desse ganho pode ser vista pelo número de linhas de código do editor: desconsiderando-se os módulos que não foram alterados por não haver sido criado na API o suporte necessário (como por exemplo o suporte à abstração de generalização), 6.389 linhas de código da versão original foram transformadas em 2.948 linhas na versão que utiliza a API. Uma vantagem importante dessa nova abordagem é a redução na complexidade da tarefa de manutenção e extensão do Editor de Esquemas.

Para ilustrar, são apresentados trechos de código da versão original e da versão utilizando a API para a mesma operação. A Figura 19 apresenta o código que efetua a criação de um novo objeto na versão original do editor, e a Figura 20 apresenta o código para a mesma operação na versão que utiliza a API. Note-se que no exemplo da versão original todas as funções utilizadas foram implementadas na própria ferramenta, enquanto no exemplo da versão utilizando a API são utilizados apenas métodos implementados nas classes da API, com exceção da função RefreshGrids, que refere-se apenas à interface com o usuário, e da macro SAFEDELETE, cuja lógica refere-se a restrições impostas pelo editor. 


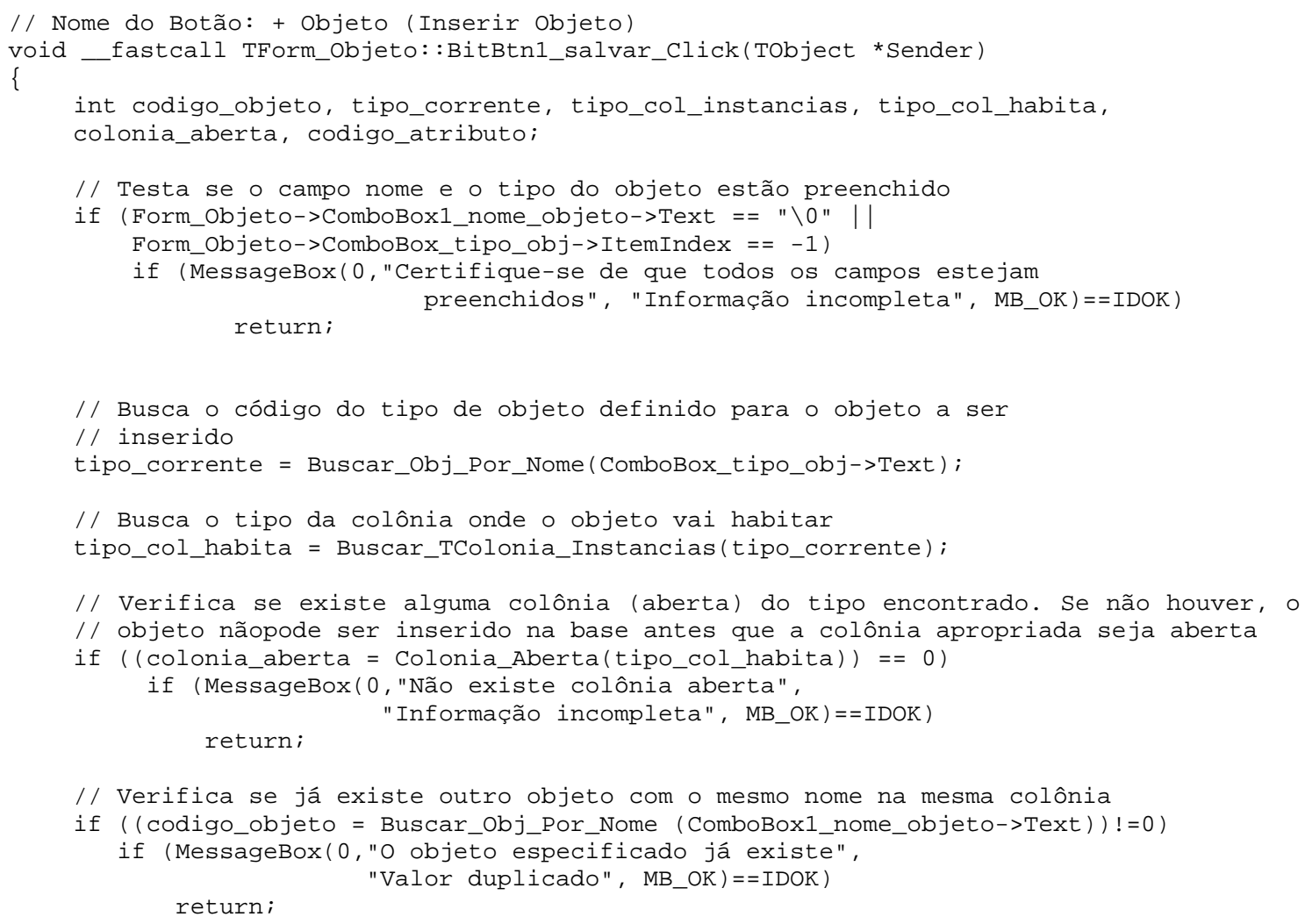

ModuloDado->Grid_Classificacao->Close () ;

ModuloDado->Grid_Classificacao->ParamByName ("Codigo")->AsInteger = codigo_objeto; ModuloDado->Grid_Classificacao->Open ();

Seta_Valor_Grid();

if (MessageBox (0,"Objeto armazenado na base", "Confirmação", MB_OK)==IDOK) return;

Figura 19 - Código no E²SIRIUS original 


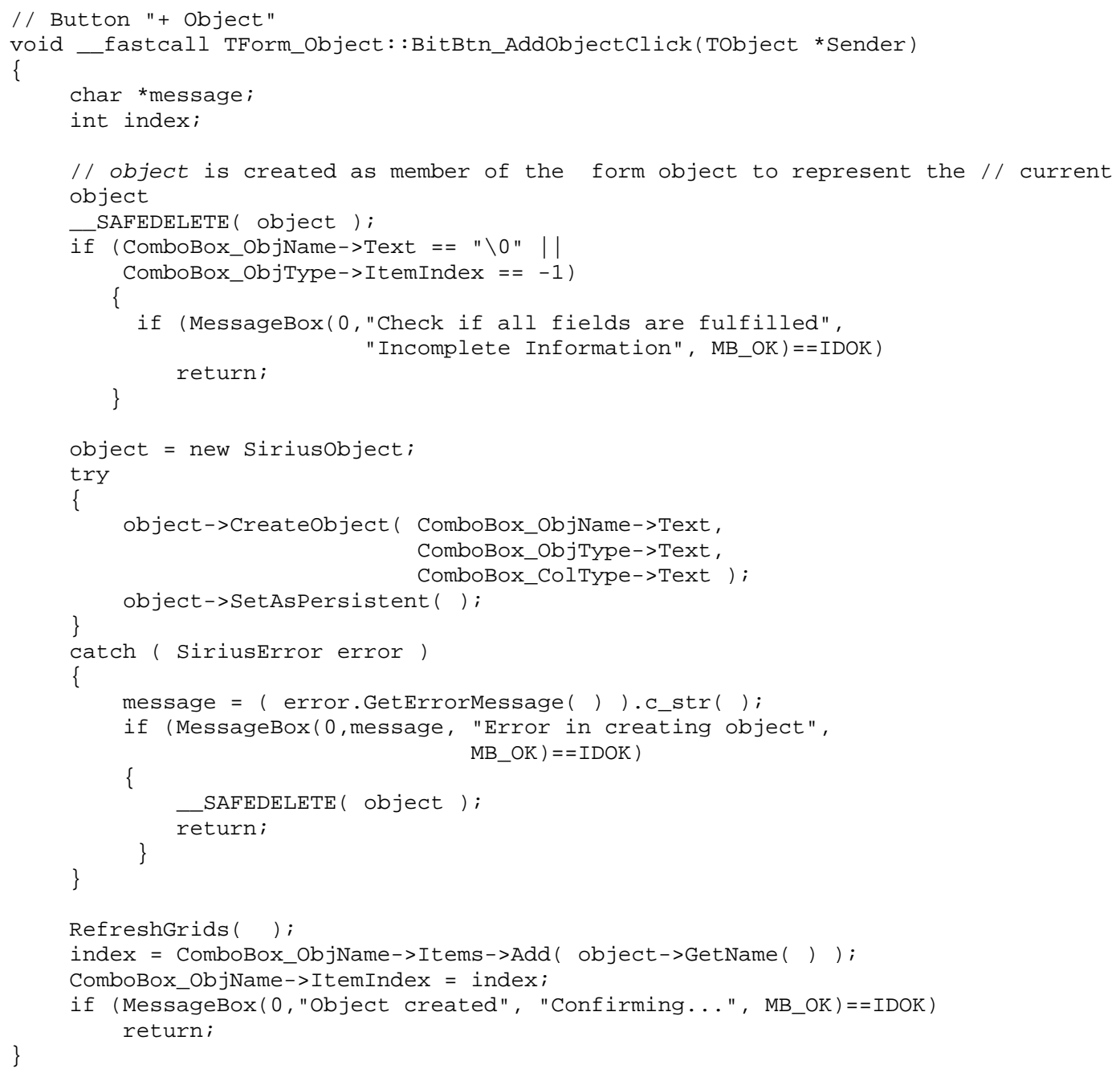

Figura 20 - Código no E²SIRIUS reformulado

O Editor de Esquemas foi re-implementado com o objetivo de validar a API definida neste trabalho, a qual comprovou ser um mecanismo consistente de desenvolvimento de aplicativos centrados num gerenciador de dados orientado a objetos. Foi demonstrado que a API pode ser utilizada para implementar um utilitário de bases de dados genérico e abrangente, oferecendo suporte consistente aos conceitos das abstrações de dados de um modelo orientado a objetos. Naturalmente, a API também pode ser utilizada no desenvolvimento de aplicações para a resolução de problemas mais específicos, e pode ser expandida para suportar tipos de dados complexos característicos de aplicações não convencionais, em diversas áreas de conhecimento. 


\subsection{Considerações Finais}

Este capítulo mostra a utilização da API desenvolvida neste trabalho na re-implementação de um Editor de Esquemas, cuja funcionalidade predominante é a edição de modelagens centradas num modelo de dados orientado a objetos baseado nas abstrações de classificação, agregação, composição e generalização.

O editor, desenvolvido originalmente como uma ferramenta cujas operações acessavam diretamente uma base de dados relacional, foi re-escrito para que seu código acessasse um gerenciador de base de dados orientado a objetos. A nova abordagem do Editor de Esquema utiliza apenas primitivas da API, cuja implementação sobre um gerenciador relacional emula um gerenciador de dados orientado a objetos.

A reformulação do editor demonstrou a consistência da API no suporte aos conceitos inerentes às abstrações de dados citadas acima, destacando o tratamento homogêneo a tipos e instâncias, o suporte a atributos extras e o suporte ao Meta Tipo (definido pelo sistema), imprescindíveis para a hierarquia de classificação em múltiplos níveis. 


\section{Conclusão}

\subsection{Considerações Iniciais}

Este trabalho descreve uma Interface de Programação de Aplicativos (Application Program Interface - API) desenvolvida para um gerenciador de dados orientado a objetos. A API resultante integra de maneira consistente os recursos básicos que devem estar presentes na API de um gerenciador de objetos, incluindo as operações de criação, remoção, atualização e consulta, e os recursos necessários ao suporte das características particulares de abstrações de dados tratadas em modelos de dados orientados a objetos.

O Modelo de Dados SIRIUS foi escolhido como alvo para a definição da API por tratar-se de um metamodelo semanticamente rico, e bem conhecido pelos membros do Grupo de Bases de Dados e Imagens (GBDI). Este modelo considera quatro abstrações de dados: classificação, agregação, generalização e composição. Um aspecto diferencial que motivou a utilização do SIRIUS foi o conceito de hierarquia em múltiplos níveis proposta para a abstração de classificação. Nesta abordagem, o modelo define um construtor semântico específico para representar a classificação no esquema de uma aplicação, onde o número de níveis da hierarquia é determinado de acordo com a realidade do problema a ser tratado. Portanto, objetos assumem indistintamente os papéis de tipos e instâncias manipulados através de um conjunto único de operações.

Os métodos que compõem a API foram implementados sobre um gerenciador relacional para emular um gerenciador de dados orientado a objetos. Os dados armazenados numa base relacional são tratados por uma camada semântica que implementa a lógica do modelo de objetos, tornado o "formato relacional" dos dados totalmente transparente para a aplicação. Como a base conceitual da criação da API foi o modelo SIRIUS, o gerenciador emulado foi desenvolvido como uma versão com núcleo relacional do Gerenciador de Objetos SIRIUS. 
A API, assim como o protótipo da versão com núcleo relacional do Gerenciador SIRIUS, foi validada através da reformulação do Editor de Esquemas SIRIUS, que passou a realizar toda a comunicação com a base de dados através dos métodos definidos na API [Araujo_98b]. O resultado obtido foi um código conciso, consistente e compatível com as necessidades do editor, ou seja, suporte à edição de modelagens centradas no modelo SIRIUS, alimentação da base de dados, consulta e atualização. A reformulação do editor demonstrou que a API oferece os recursos adequados ao desenvolvimento de uma ferramenta que incorpora as particularidades das abstrações de classificação, agregação, composição e generalização, como é o caso do Editor de Esquemas. Portanto, a API pode ser utilizada no desenvolvimento de aplicações cujas informações sejam representadas segundo as abstrações citadas acima.

Conclui-se que a API resultante deste trabalho atende aos requisitos considerados fundamentais no contexto ao qual está inserida:

incorpora a funcionalidade básica da API de um gerenciador de base de dados, disponibilizando operações de criação, remoção, atualização e consulta;

abrange os conceitos principais do modelo SIRIUS, destacando-se as abstrações de dados que o modelo suporta;

permite acesso ao esquema e manipulação de dados utilizando um mesmo conjunto de primitivas, unificando operações usualmente divididas em DDL e DML;

> é compatível com as versões com núcleo relacional e com núcleo nativo do gerenciador de objetos SIRIUS;

$>$ oferece suporte adequado à abstração de classificação com hierarquia em múltiplos níveis através do tratamento homogêneo de tipos e instâncias.

Este último requisito é particularmente significativo, pois demonstra (pela primeira vez na literatura, segundo o melhor de nosso conhecimento), de maneira prática, a utilização da abstração de classificação em um ambiente relacional, e a união dos subconjuntos DDL e DML de uma linguagem de consulta em apenas um conjunto de comandos [Machado_00]. 


\subsection{Contribuições Apresentadas}

Dentre as contribuições apresentadas por este trabalho, destacam-se:

definição de uma API consistente para um gerenciador de dados orientado a objetos, abrangendo os conceitos pertinentes às abstrações de dados suportadas por um metamodelo orientado a objetos baseado nas abstrações de classificação, generalização, associação e composição. Embora tenha sido definida a partir dos princípios do modelo SIRIUS, a API pode ser adaptada a qualquer modelo baseado em abstrações de dados, pois a semântica de cada abstração é definida e implementada através de um conjunto bem definido de métodos das classes que compõem os módulos semânticos da API. Numa aplicação imediata, a API poderá ser utilizada no desenvolvimento de ferramentas centradas no Gerenciador de Objetos SIRIUS, para o qual foi criada uma versão com núcleo relacional;

suporte à abstração de classificação, demonstrando como a hierarquia de tipos em múltiplos níveis, definida num modelo de dados, pode ser aplicada na prática através do tratamento homogêneo de tipos e instâncias num gerenciador orientado a objetos;

unificação de operações de uma linguagem de consulta normalmente divididas em DDL e DML num conjunto único de comandos, compatível com uma linguagem de programação orientada a objetos, permitindo a criação, remoção e manipulação de objetos e tipos de objetos em tempo de execução;

as contribuições citadas acima consolidam a abordagem diferencial dada à abstração de classificação no modelo de dados SIRIUS. A definição e implementação da API, e sua utilização no desenvolvimento de um utilitário como o Editor de Esquemas, comprovam a aplicabilidade do conceito de classificação em múltiplos níveis, através de um construtor semântico, na representação de informações do mundo real num sistema, incluindo modelagem de dados e suporte adequado num gerenciador de dados orientado a objetos; 
$>$ desenvolvimento de um gerenciador de dados orientado a objetos emulado, resultando num protótipo da versão com núcleo relacional do Gerenciador de Objetos SIRIUS. Esta versão será utilizada como um “ambiente experimental” para testes de algoritmos, técnicas de desenvolvimento e suporte a conceitos ainda não tratados, possibilitando a avaliação de alternativas de projeto e implementação para a versão nativa do gerenciador.

\subsection{Sugestões para Trabalhos Futuros}

Uma das motivações deste trabalho foi o de tornar disponível uma versão operacional de um gerenciador de dados apoiado no modelo SIRIUS. Esse objetivo foi cumprido, dentro das restrições típicas de um programa de mestrado, tais como prazos, delimitação acadêmica dos resultados (comparando com a disponibilidade completa de recursos úteis para a usabilidade diária da ferramenta-produto, mas que conceitualmente consistem na mera repetição de conceitos já tratados em outros aspectos da ferramenta). Dentro dessa perspectiva, uma continuação óbvia do trabalho consiste em se completar a ferramenta, com o suporte a todos os recursos do modelo SIRIUS. Essa tarefa é importante para permitir a utilização real da ferramenta em outros projetos em andamento no Grupo de Bases de Dados e Imagens do ICMC, e como uma ferramenta de divulgação desses conceitos entre outros grupos de pesquisa. Essa tarefa poderia, por exemplo, ser desenvolvida por alunos de Iniciação Científica, ou técnicos vinculados ao projeto.

Outra motivação deste trabalho foi explorar a idéia de que técnicas de implementação de conceitos voltados à orientação a objetos podem ser mais fácil e rapidamente implementados e testados num ambiente relacional do que num ambiente nativo. Obviamente, tal solução não leva a um desempenho tão bom quanto pode ser obtido no ambiente nativo, servindo assim como uma bancada de experimentação (ou prototipação) que não substitui a versão nativa, mas pode prover mais rapidamente parâmetros para a decisão sobre alternativas de implementação. Essa motivação pode agora ser explorada, e a API desenvolvida pode ser utilizada para a experimentação de novas técnicas de implementação de conceitos voltados à orientação a objetos.

Utilizando um editor com suporte completo ao modelo de dados, diversos tópicos de pesquisa tornam-se interessantes, e são descritos a seguir. 
Suporte a novos conceitos sem impacto em aplicações já existentes. Uma característica importante, associada ao uso de gerenciadores de dados é a chamada "Independência de Dados”. Essa característica, fortemente procurada nos primeiros modelos de dados (que seguem a especificação CODASYL), não é adequadamente tratada em gerenciadores relacionais. Modelos de dados orientados a objetos, por outro lado, têm sido citados como melhores plataformas para enfatizar essa característica. Temos visto que na prática, a extensão de um banco de dados em um empreendimento para suportar um novo conceito leva à inclusão de novos dados e procedimentos em muitas das tabelas já existentes, e à necessidade de modificações nos processos correspondentes a diversos aplicativos. A inclusão de uma nova camada, como a que suporta o SIRIUS, em um empreendimento já existente causa menos impacto à arquitetura do sistema de informação do empreendimento, pois é definida através de suas próprias relações e procedimentos, causando um impacto menor (ou mesmo nulo) nas aplicações existentes. Por outro lado, como um novo conceito provavelmente deve ser mais facilmente desenvolvido utilizando um modelo de dados semanticamente mais rico, a solução natural é que ele seja incorporado não diretamente pelo modelo relacional, mas através de uma ferramenta como a API aqui desenvolvida.

Suporte a imagens. Este tópico é em parte decorrente do anterior, considerando ser o suporte a imagens um novo conceito a ser suportado. Nesse caso, uma aplicação (nova ou já existente) irá se referenciar a imagens em qualquer parte (relação) onde a lógica do empreendimento indicar o uso de imagens. Se o suporte a imagens tiver que ser tratado fora do gerenciador, como é a situação atualmente, não um, mas diversos atributos, com suas respectivas restrições e procedimentos têm que ser incluídos em cada parte onde imagem deva ser suportada. Por exemplo, se um suporte a busca por conteúdo deve ser empregado, os métodos de acesso a características de imagens ("features") e os atributos resultantes devem ser inseridos e replicados em cada lugar onde uma imagem deve ser armazenada. Utilizando a API desenvolvida, um atributo imagem é inserido como um identificador para o SIRIUS, assim um único atributo estabelece a ligação da aplicação com qualquer suporte a imagens que venha a ser construído sobre SIRIUS (como é o caso atualmente, em que diversos projetos do GBDI vêm desenvolvendo uma estrutura de suporte a imagens em SIRIUS).

Desenvolvimento e suporte de novas técnicas de indexação. Este tópico leva em conta que a maioria dos gerenciadores relacionais existentes são arquiteturas fechadas, tornando 
inexeqüível a sua utilização com estruturas de indexação não suportadas nativamente pelo gerenciador. Através da API, qualquer atributo que deva ser incluído numa estrutura de indexação pode ser tratado por esta interface. A partir daí, a estrutura de indexação pode ser incluída como parte da funcionalidade da API, ou pode ser ativada como um módulo externo à própria API, que assim atua apenas como uma "ponte" entre os atributos a serem indexados (colocados na estrutura de dados da aplicação) e os métodos de indexação supridos pela aplicação.

Desenvolvimento de uma linguagem de consulta textual. Da mesma maneira que a API pode dar suporte a um editor de esquemas para o modelo SIRIUS, ela pode dar suporte a uma linguagem de consulta textual "SQL-like". No entanto, como SIRIUS provê muitos recursos além dos suportados por SQL, uma linguagem consistente deve ser projetada, em particular provendo recursos para a existência de um mecanismo de otimização e permitindo o desenvolvimento de um bom otimizador de consultas. 


\section{Referências Bibliográficas}

[Araujo_98a] Araujo, M. R. B. - "Representação de Construtores Semânticos em SIRIUS e Suporte através de um Editor de Esquemas”, Dissertação de Mestrado - ICMC - USP, São Carlos, 1998.

[Araujo_98b] Araujo, M. R. B.; Traina Jr, C.; Biajiz, M.; Machado, E. P. - "Editor de Esquemas com Suporte para Hierarquias de Classificação”, Anais do XIII Simpósio Brasileiro de Banco de Dados, pp. 135 - 149, Maringá, Outubro 1998.

[Atkinson_94] Atkinson, M. et al. - "The Object-Oriented Database System Manifesto", Readings in Database System, edited by M. Stonebraker, Morgan Kaufmann Publishers, pp. 946 - 954, 1994, Second Edition.

[Bancilhon_92] Bancilhon, F.; Delobel, L.; Kanellakis, P. - "Building an Object-Oriented Database System, The Story of O2”, Morgan Kaufmann, 1992.

[Barry_98a] Barry, D. - "There's an ODMG Database in Your Future”, Database Programming \& Design, pp. 66, April 1998. Disponível on line em http://www.odmg.org.

[Barry_98b] Barry, D. - "If You Want Better Answers...", Database Programming \& Design, pp. 72, July 1998. Disponível on line em http://www.odmg.org.

[Bertino_91] Bertino, E.; Martino, L. - "Object-Oriented Database Management Systems: Concepts and Issues”, Computer IEEE, vol. 24, no. 4, pp. 33 - 47, April 1991.

[Bertino_92] Bertino, E.; Negri, M.; Pelagatti, G.; Sbattella, L. - "Object-Oriented Query Languages: The Notion and the Issues", IEEE Transactions on Knowledge and Data Engineering, vol. 4, no. 3, pp. 223 - 237, June 1992.

[Biajiz_92] Biajiz, M. - "Uma Atualização do Modelo de Representação de Objetos e Uma Abordagem Formal”, Dissertação de Mestrado - ICMC -USP, São Carlos, Julho 1992.

[Biajiz_96a] Biajiz, M. - "Representação de Modelos de Dados Orientados a Objetos através de Parametrização de Abstrações", Tese de Doutorado - IFSC - USP, São Carlos, Setembro 1996.

[Biajiz_96b] Biajiz, M.; Traina Jr., C.; Vieira, M. T. P. - "SIRIUS - Modelo de Dados Orientado a Objetos Baseado em Abstrações de Dados”, Anais do XI Simpósio Brasileiro de Banco de Dados, pp. 338 - 352, São Carlos, Outubro 1996.

[Butterworth_91] Butterworth, P.; Otis, A.; Stein, J. - "The GemStone Object Database Management System", Communications of the ACM, vol. 34, no. 10, pp. 64 - 77, October 1991.

[Cattell_94] Cattell, R. G. G. - "Object Data Management-Object-Oriented and Extended Relational Database Systems”, Addison - Wesley, 1994. 
[Cattell_95] Cattell, R. G. G. - “Object Databases and Standards”, Lecture Notes in Computer Science, no. 940, pp. 1 - 11, 1995.

[Cattell_97] Cattell, R. G. G. et al. - "The Object Database Standard: ODMG 2.0", Morgan Kaufmann Publishers, 1997.

[Chan_94] Chan, D. K. C.; Trinder, P. W. ; Welland, R. C. - "Evaluating Object-Oriented Query Languages”, The Computer Journal, vol. 37, no. 10, pp. 858 - 872, 1994.

[Date_97] Date, C. J.; Darwen, H. - "A Guide to The SQL Standard”, Addison-Wesley, 1997, Fourth Edition.

[Deux_90] Deux, O. et al. - "The Story of O2”, IEEE Transactions on Knowledge and Data Engineering, vol. 2, no. 1, pp. 91 - 108, March 1990.

[Deux_91] Deux, O. et al. - "The O2 System”, Communications of the ACM, vol. 34, no. 10, pp. 34 - 49, October 1991.

[Eisenberg_98] Eisenberg, A.; Melton, J. - "Standards In Practice”, SIGMOD Record, vol. 27, no. 3, pp. 53 - 58, September 1998.

[Eisenberg_99] Eisenberg, A.; Melton, J. - "SQL:1999, formerly known as SQL3", SIGMOD Record, vol. 28, no. 1, pp. 131 - 138, March 1999.

[Elmasri_00] Elmasri, R.; Navathe, S. B. - "Fundamentals of Database Systems", Addison Wesley, 2000, Third Edition.

[Ferreira_96] Ferreira, J. E.; Traina Jr., C. - "Controle de Compartilhamento e Acesso em GBDOOO Baseado em Composição de Objetos”, Anais do XI Simpósio Brasileiro de Banco de Dados, pp. 143 - 157, São Carlos - SP, Outubro 1996.

[Fishman_89] Fishman, D. H. et al. - "Overview of the Iris DBMS", Object-Oriented Concepts, Databases and Applications, edited by W. Kim and F. H. Lochovsky, ACM Press, pp. 219 - 250, 1989.

[Ishikawa_93] Ishikawa, H. et al. - "The Model, Language and Implementation of an Object-Oriented Multimedia Knowledge Base Management System”, ACM Transactions on Database Systems, vol. 18, no. 1, pp. 1 - 50, March 1993.

[Ishikawa_96] Ishikawa, H.; Yamane, Y.; Izumida, Y.; Kawato, N. - "An Object-Oriented Database System Jasmine: Implementation, Application, and Extension”, IEEE Transactions on Knowledge and Data Engineering, vol. 8, no. 2, pp. 285 - 340, April 1996.

[Jasmine_00] "Jasmine ${ }_{i i}$ " - Computer Associates, http://www.cai.com/products/jasmine.htm, acessado em Novembro 2000.

[Kappel_98] Kappel, G.; Retschitzegger, W. - "The TriGS Active Object-Oriented Database System - An Overview”, SIGMOD Record, vol. 27, no. 3, pp. 36 - 41, September 1998. 
[Kim_96] Kim, Y. H. et al. - "The Object-Oriented Design of KROSS: An Object-Oriented Spatial Database System”, Lecture Notes in Computer Science, no. 1134, pp. 603 612, 1996.

[Lamb_91] Lamb, C. et al. - "The ObjectStore Database System”, Communications of the ACM, vol. 34, no. 10, pp. 50 - 63, October 1991.

[Machado_00] Machado, E. P.; Traina Jr., C.; Araujo, M. R. B. - "Classification Abstraction: an intrinsic element in Database Systems", In proceedings of First Biennial Conference on Advances in Information Systems (ADVIS 2000) - Lecture Notes in Computer Science, vol. 1909, Turkey, October 2000.

[Nierstrasz_89] Nierstrasz, O. - "A Survey of Object-Oriented Concepts”, Object-Oriented Concepts, Databases, and Applications, edited by W. Kim and F. H. Lochovsky, ACM Press, pp. 3 - 21, 1989.

[Perez_91] Perez, E. - “A strawman reference model for an application program interface to an Object-Oriented Database”, Computer Standards \& Interfaces, vol. 13, pp. 123 $138,1991$.

[ODBC_00a] "ODBC Guide”, http://www.cs.hut.fi/ las/odbc.htm, acessado em Novembro 2000.

[ODBC_00b] “Open Database Connectivity”, http://www.microsoft.com/data/odbc, acessado em Novembro 2000.

[ODMG_00] “Object Database Management Group”, http://www.odmg.org, acessado em Novembro 2000.

[Sousa_00] Sousa, E. P. M.; Traina Jr., C. - "Interface de Programação de Aplicativos para o Gerenciador de Objetos SIRIUS”, Relatório Técnico a ser publicado, ICMC USP, Dezembro 2000.

[SQL3_97] "SQL3 Object Model", http://ww.objs.com/x3h7.sql3.htm, acessado em 05/07/99.

[Stonebraker_91] Stonebraker, M.; Kemnitz, G. - "The POSTGRES Next-Generation Database Management System", Communications of the ACM, vol. 34, no. 10, pp. 78 92, October 1991.

[Traina_91] Traina Jr., C. - "GEO: Um Sistema de Gerenciamento de Bases de Dados Orientado a Objetos - Estado atual de Desenvolvimento e Implementação”, VI Simpósio Brasileiro de Banco de Dados, pp. 193 - 207, Manaus, Maio 1991.

[Traina_92] Traina Jr., C. - "Um Modelo de Representação de Objetos", Notas Internas no. 104, ICMC-USP, São Carlos, Fevereiro 1992.

[Traina_93b] Traina Jr., C.; Camolesi Jr., L. - "Primitivas do Núcleo do Gerenciador de Esquemas de Dados no Modelo MRO*”, Relatório Técnico no. 010, ICMC-USP, São Carlos, Maio 1993. 
[Valêncio_00] Valêncio, C. R. - "Núcleo Gerenciador de Objetos: Compatibilizando Eficiência e Flexibilidade”, Tese de Doutorado - IFSC - USP, Setembro 2000.

[Wilkinson_90] Wilkinson, K.; Lyngbaek, P.; Hasan, W. - "The Iris Architecture and Implementation", IEEE Transactions on Knowledge and Data Engineering, vol. 2, no. 1, pp. 63 - 75, March 1990.

[Zand_95] Zand, M.; Collins, V.; Caviness, D. - "A Survey of Current Object-Oriented Databases", The Database for Advances in Information System, vol. 26, no. 34, pp. 14 - 29, February 1995. 
Anexo:

API do Gerenciador de Objetos SIRIUS 


\section{Descrição das Classes da API}

Obs: na descrição das classes, os tipos de dado dos parâmetros e dos retornos dos métodos são colocados em negrito. Os tipos definidos na API são descritos no final do Anexo, onde são feitas as observações necessárias pertinentes a cada tipo.

\section{Classe SiriusObject}

Uma instância da classe SiriusObject, chamada de sobrestante objeto, é uma representação em memória de um objeto armazenado na base de dados.

\begin{tabular}{|l|l||}
\hline Método: & SiriusObject ( ) \\
\hline Descrição: & $\begin{array}{l}\text { Construtor da classe: cria um sobrestante objeto vazio, permitindo a } \\
\text { criação de um novo objeto ou a recuperação de um objeto armazenado } \\
\text { na base de dados }\end{array}$ \\
\hline Parâmetros: & $\begin{array}{l}\text { Cria os sobrestantes } v \text { Person e vJohn: } \\
\text { Siriusobject }{ }^{*} \text { verson }=\text { new Siriusobject; } \\
\text { Siriusobject *vJohn }=\text { new Siriusobject; }\end{array}$ \\
\hline Exemplos:
\end{tabular}

\begin{tabular}{|l|l|}
\hline Método: & S SiriusObject ( ) \\
\hline Descrição: & $\begin{array}{l}\text { Destrutor da classe - libera o espaço em memória alocado para o } \\
\text { sobrestante objeto. Se o objeto representado no sobrestante for } \\
\text { persistente, o destrutor não tem efeito algum sobre o objeto armazenado } \\
\text { na base de dados. }\end{array}$ \\
\hline
\end{tabular}

\begin{tabular}{|l|l|}
\hline Método: & $\begin{array}{l}\text { void CreateObject ( SString objectName, SString typeName, } \\
\text { SString colTypeName = "I0") }\end{array}$ \\
\hline Descrição: & $\begin{array}{l}\text { Cria um objeto temporário, que pode ser explicitamente declarado como } \\
\text { persistente através do método SetAs Persistent. }\end{array}$ \\
\hline Parâmetros: & $\begin{array}{l}\text { Parâmetros de entrada: } \\
\text { objectName - nome do objeto a ser criado } \\
\text { typeName - nome do tipo do objeto } \\
\text { colTypeName - nome do tipo de colônia onde habitam as instâncias do } \\
\text { objeto criado. Default: colTypeName == "I0" }\end{array}$ \\
\hline Exemplos: & $\begin{array}{l}\text { Cria no sobrestante } v \text { Person o objeto Person, cujo tipo é METATYPE } \\
\text { (tipo pré-definido do sistema). As instâncias de Person habitam colônias } \\
\text { do tipo GLOBAL (tipo de colônia pré-definido do sistema): } \\
\text { vPerson->Createobject ( "Person", METATYPE, GLOBAL) ; } \\
\text { Cria no sobrestante vJohn o objeto John, cujo tipo é Person: } \\
\text { vJohn->CreateObject ("John", "Person") ; }\end{array}$ \\
\hline \hline
\end{tabular}

\begin{tabular}{||l|l|}
\hline Método: & SOID SetAsPersistent ( ) \\
\hline Descrição: & Torna o objeto persistente e retorna o OId criado para esse objeto \\
\hline Parâmetros: & $\begin{array}{l}\text { Retorno: } \\
\text { SOID - OId do objeto persistente }\end{array}$ \\
\hline Exemplos: & $\begin{array}{l}\text { Torna persistentes os objetos Person e John, respectivamente } \\
\text { representados nos sobrestantes } v \text { Person } \text { e John: } \\
\text { SOID personId }=\text { vPerson->SetAsPersistent ( ) ; } \\
\text { SOID johnId }=\text { vJohn->SetAsPersistent ( ); }\end{array}$ \\
\hline
\end{tabular}




\begin{tabular}{|l|l||}
\hline Método: & bool IsPersistent ( ) \\
\hline Descrição: & Verifica se o objeto é persistente ou não \\
\hline Parâmetros: & $\begin{array}{l}\text { Retorno: } \\
\text { true - objeto persistente } \\
\text { false - objeto transiente }\end{array}$ \\
\hline Exemplos: & $\begin{array}{l}\text { Verifica se o objeto Person, representado no sobrestante vPerson é } \\
\text { persistente: } \\
\text { bool persistent }=\text { vPerson->IsPersistent ( ) ; } \\
\begin{array}{l}\text { Resultado: } \\
\text { persistent }==\text { true; }\end{array}\end{array}$ \\
\hline
\end{tabular}

\begin{tabular}{|l|l|}
\hline Método: & void ReadObject ( SOID object ) \\
\hline Descrição: & Recupera um objeto armazenado na base de dados \\
\hline Parâmetros: & $\begin{array}{l}\text { Parâmetro de entrada: } \\
\text { object } \text { - OId do objeto a ser lido }\end{array}$ \\
\hline Exemplos: & $\begin{array}{l}\text { Cria um sobrestante } \text { OObject } \text { e traz para este sobrestante as informações } \\
\text { do objeto de código } \text { objectId } \text { armazenado na base de dados: } \\
\text { Siriusobject *vobject }=\text { new Siriusobject ; } \\
\text { vobject->Readobject ( object Id ) ; }\end{array}$ \\
\hline
\end{tabular}

\begin{tabular}{||l|l||}
\hline Método: & $\begin{array}{c}\text { void ReadObject ( SString objectName, } \\
\text { SString typeName = METATYPE ) }\end{array}$ \\
\hline Descrição: & Recupera um objeto armazenado na base de dados \\
\hline Parâmetros: & $\begin{array}{l}\text { Parâmetros de entrada: } \\
\text { objectName - nome do objeto a ser lido } \\
\text { typeName - nome do tipo do objeto. Default: METATYPE }\end{array}$ \\
\hline Exemplos: & $\begin{array}{l}\text { Cria um sobrestante } v \text { Paul } \text { e traz para este sobrestante as informações do } \\
\text { objeto Paul, do tipo Person, armazenado na base de dados: } \\
\text { SiriusObject *vPaul = new Siriusobject; ; } \\
\text { vPaul->Readobject ( "Paul", "Person" ); }\end{array}$ \\
\hline
\end{tabular}

\begin{tabular}{|l|l||}
\hline Método: & void DeleteObject ( ) \\
\hline Descrição: & Remove da base de dados o objeto representado no sobrestante \\
\hline Parâmetros: & $\begin{array}{l}\text { Remove da base o objeto Paul, representado no sobrestante vPaul: } \\
\text { vPaul->DeleteObject ( ); }\end{array}$ \\
\hline Exemplos:
\end{tabular}




\begin{tabular}{|c|c|}
\hline Método: & $\begin{array}{l}\text { void AddAttribute ( SiriusAttribute *attribute, } \\
\text { SClassification classInfo, SAggregation aggregInfo ) }\end{array}$ \\
\hline Descrição: & $\begin{array}{l}\text { Associa ao objeto um atributo previamente criado através da classe } \\
\text { correspondente à característica do atributo. Atributos somente podem ser } \\
\text { associados a objetos persistentes. }\end{array}$ \\
\hline Parâmetros: & $\begin{array}{l}\text { Parâmetros de entrada: } \\
\text { attribute - referência para um sobrestante atributo correspondente à } \\
\text { característica do atributo a ser associado ao objeto } \\
\text { classInfo - propriedades da abstração de classificação } \\
\text { aggregInfo - propriedades da abstração de agregação }\end{array}$ \\
\hline Exemplos: & 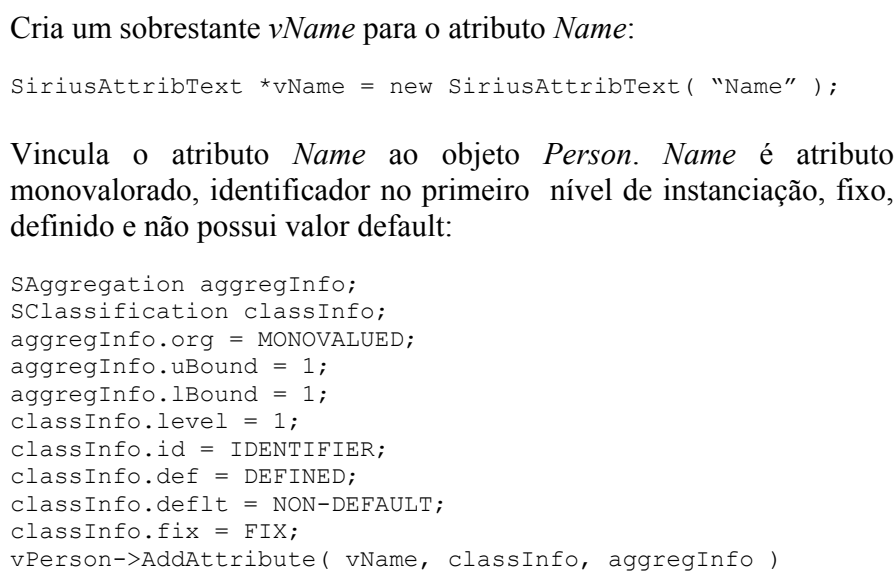 \\
\hline
\end{tabular}

\begin{tabular}{||l|l|}
\hline Método: & void DeleteAttribute ( SString attribName ) \\
\hline Descrição: & Remove um atributo do objeto \\
\hline Parâmetros: & $\begin{array}{l}\text { Parâmetro de entrada: } \\
\text { attribName - nome do atributo a ser removido }\end{array}$ \\
\hline Exemplos: & $\begin{array}{l}\text { Remove o atributo Address do objeto Person } \\
\text { vPerson->DeleteAttribute( "Address" ); }\end{array}$ \\
\hline
\end{tabular}

\begin{tabular}{|l|l|}
\hline Método: & SiriusAttribute* GetIdAttribute ( SLevel level ) \\
\hline Descrição: & $\begin{array}{l}\text { Acessa o atributo identificador do objeto num determinado nível de } \\
\text { instanciação }\end{array}$ \\
\hline Parâmetros: & $\begin{array}{l}\text { Parâmetro de entrada: } \\
\text { level - nível de instanciação do atributo identificador a ser manipulado } \\
\text { Retorno: } \\
\text { SiriusAttribute* - referência para o sobrestante do atributo identificador }\end{array}$ \\
\hline Exemplos: & $\begin{array}{l}\text { Recupera o atributo identificador do objeto Person no nível 1 de } \\
\text { instanciação: } \\
\text { SiriusAttribute *vId; } \\
\text { vId }=\text { vPerson->GetIdAttribute( 1 ); }\end{array}$ \\
\hline
\end{tabular}




\begin{tabular}{|c|c|}
\hline Método: & SiriusAttribute* GetAttribute ( SString attribName ) \\
\hline Descrição: & Acessa um atributo do objeto \\
\hline Parâmetros: & $\begin{array}{l}\text { Parâmetro de entrada: } \\
\text { attribName - nome do atributo a ser manipulado } \\
\text { Retorno: } \\
\text { SiriusAttribute* - referência para o sobrestante do atributo }\end{array}$ \\
\hline Exemplos: & $\begin{array}{l}\text { Recupera o atributo Age do objeto Paul. vAge é uma referência para o } \\
\text { sobrestante que representa o atributo Age: } \\
\text { SiriusAttribNumber *vAge; } \\
\text { vAge = (SiriusAttribNumber*) vPaul->GetAttribute( "Age" ); } \\
\text { O atributo Age pode ser manipulado através dos métodos da classe } \\
\text { SiriusAttribNumber (específica para a característica Número): } \\
\text { vAge->SetValue( "20" ); } \\
\text { SNumberValue value = vAge->GetValue( ); } \\
\text { Resultado: } \\
\text { value }==20\end{array}$ \\
\hline
\end{tabular}

\begin{tabular}{|l|l||}
\hline Método: & SString GetColonyType ( ) \\
\hline Descrição: & $\begin{array}{l}\text { Recupera o nome do tipo da colônia onde habitam as instâncias do } \\
\text { objeto, de acordo com o Diagrama Hierárquico de Colônias }\end{array}$ \\
\hline Parâmetros: & $\begin{array}{l}\text { Retorno: } \\
\text { SString - nome do tipo de colônia }\end{array}$ \\
\hline Exemplos: & $\begin{array}{l}\text { Recupera o nome do tipo de colônia onde habitam as instâncias do } \\
\text { objeto Person, representado no sobrestante } v \text { Person } \\
\text { SString typeName = vPerson->GetColonyType ( ); } \\
\text { printf ( "os", typeName.c_str( ) ); } \\
\text { Resultado: } \\
\text { typeName }==\text { GLOBAL }\end{array}$ \\
\hline
\end{tabular}

\begin{tabular}{|l|l||}
\hline Método: & SString GetName ( ) \\
\hline Descrição: & Recupera o nome do objeto. \\
\hline Parâmetros: & $\begin{array}{l}\text { Retorno: } \\
\text { SString - nome do objeto }\end{array}$ \\
\hline Exemplos: & $\begin{array}{l}\text { Recupera o nome do objeto representado no sobrestante vPerson: } \\
\text { SString objName = vPerson->GetName ( ) ; } \\
\text { Resultado: } \\
\text { objName }==\text { Person }\end{array}$ \\
\hline
\end{tabular}




\begin{tabular}{||l|l||}
\hline Método: & SString GetColony ( SOID *ctrObject ) \\
\hline Descrição: & $\begin{array}{l}\text { Recupera a colônia onde o objeto habita, de acordo com o DRI. A } \\
\text { colônia é identificada pelo nome de seu tipo e pelo OId do objeto que a } \\
\text { constringe. }\end{array}$ \\
\hline Parâmetros: & $\begin{array}{l}\text { Parâmetro de Retorno: } \\
\text { ctrObject - OId do objeto que constringe a colônia recuperada } \\
\text { Retorno: } \\
\text { SString - nome do tipo da colônia recuperada }\end{array}$ \\
\hline Exemplos: & $\begin{array}{l}\text { Recupera a colônia que onde habita o objeto Person, representado no } \\
\text { sobrestante } v \text { Person: } \\
\text { SOID obj; } \\
\text { SString colony }=\text { vPerson->GetColony ( \&obj ) ; } \\
\begin{array}{l}\text { Resultado: } \\
\text { colony }==\text { GLOBAL } \\
\text { Obs: neste exemplo, o valor de obj não é alterado porque o tipo de } \\
\text { objeto Meta Tipo, que constringe a colônia do tipo Global, não pode ter } \\
\text { seu OId manipulado pela aplicação. }\end{array}\end{array}$ \\
\hline
\end{tabular}

\begin{tabular}{|l|l|}
\hline Método: & SOID GetType ( ) \\
\hline Descrição: & Recupera OId do tipo do objeto representado no sobrestante \\
\hline Parâmetros: & $\begin{array}{l}\text { Retorno: } \\
\text { SOID - OId do tipo do objeto }\end{array}$ \\
\hline Exemplos: & $\begin{array}{l}\text { Recupera o OId do tipo do objeto representado no sobrestante } v \text { Person: } \\
\text { SOID typeOId }=\text { vPerson->GetType ( ); }\end{array}$ \\
\hline
\end{tabular}

\begin{tabular}{|l|l||}
\hline Método: & SOID GetOId ( ) \\
\hline Descrição: & Recupera o OId do objeto representado no sobrestante \\
\hline Parâmetros: & $\begin{array}{l}\text { Retorno: } \\
\text { SOID - OId do objeto }\end{array}$ \\
\hline Exemplos: & $\begin{array}{l}\text { Recupera o OId do objeto representado no sobrestante } v \text { Person: } \\
\text { SOID OId }=\text { vPerson->GetoId ( ); }\end{array}$ \\
\hline
\end{tabular}

\begin{tabular}{||l|l|}
\hline Método: & bool operator== ( SiriusObject\& ) \\
\hline Descrição: & Verifica se dois sobrestantes objeto representam o mesmo objeto \\
\hline Parâmetros: & $\begin{array}{l}\text { Verifica se } v \text { John e vPerson representam o mesmo objeto da base de } \\
\text { dados: } \\
\text { if (vJohn }==\text { vPerson })\{\ldots\} ;\end{array}$ \\
\hline Exemplos: $\ldots\}$,
\end{tabular}




\section{Classe SiriusObjectCursor}

Uma instância da classe SiriusObjectCursor, chamada de sobrestante cursor objeto, armazena os OIds de um conjunto de objetos da base de dados recuperados numa consulta, segundo algum critério.

\begin{tabular}{|l|l||}
\hline Método: & SiriusObjectCursor ( ) \\
\hline Descrição: & $\begin{array}{l}\text { Construtor da classe: cria uma estrutura para armazenar um conjunto de } \\
\text { OIds de objetos que satisfazem um critério de busca numa consulta. O } \\
\text { conjunto de OIds é percorrido através de cursores definidos para esta } \\
\text { estrutura. }\end{array}$ \\
\hline Parâmetros: & SiriusObjectCursor *VResult = new SiriusObjectCursor; \\
\hline Exemplos: & L
\end{tabular}

\begin{tabular}{|c|c|}
\hline Método: & void SearchObject ( SOID typeOId ) \\
\hline Descrição: & $\begin{array}{l}\text { Busca por tipo: seleciona, em colônias abertas, os objetos de um } \\
\text { determinado tipo }\end{array}$ \\
\hline Parâmetros: & $\begin{array}{l}\text { Parâmetro de entrada: } \\
\text { typeOId - OId do tipo de objeto }\end{array}$ \\
\hline Exemplos: & $\begin{array}{l}\text { Busca todos os objetos do tipo Person: } \\
\text { SOID personOId; } \\
\text { Siriusobject *verson = new SiriusObject; } \\
\text { vPerson->Readobject ( "Person", METATYPE ); } \\
\text { personOId = vPerson->GetOId ( ); } \\
\text { vResult->Searchobject ( personOId); }\end{array}$ \\
\hline
\end{tabular}

\begin{tabular}{|l|l|}
\hline Método: & void SearchObject ( int isType $=0$ ) \\
\hline Descrição: & Busca por colônias abertas: seleciona os objetos das as colônias abertas \\
\hline Parâmetros: & $\begin{array}{l}\text { Parâmetros de entrada: } \\
\text { isType - define um critério de seleção dos objetos das colônias: } \\
\text { isType }=0 \text { (default) - seleção de todos os objetos, tipos ou não } \\
\text { isType }=1 \text { - seleção de objetos que são tipos }\end{array}$ \\
\hline Exemplos: & $\begin{array}{l}\text { Busca todos os objetos das colônias abertas: } \\
\text { vResult->Searchobject ( ) ; }\end{array}$ \\
\hline
\end{tabular}

\begin{tabular}{|l|l|}
\hline Método: & $\begin{array}{l}\text { void SearchObject ( SOID typeOId, SString attribName, } \\
\text { SData value ) }\end{array}$ \\
\hline Descrição: & $\begin{array}{l}\text { Busca por valor: seleciona, em colônias abertas, os objetos de um } \\
\text { determinado tipo que possuem um valor específico para um atributo }\end{array}$ \\
\hline Parâmetros: & $\begin{array}{l}\text { Parâmetros de entrada: } \\
\text { typeOId - OId do tipo de objeto } \\
\text { attribName - nome do atributo } \\
\text { value - valor a ser procurado }\end{array}$ \\
\hline Exemplos: & $\begin{array}{l}\text { Busca os objetos do tipo Person que possuem o valor "doctor" para o } \\
\text { atributo Profession: } \\
\text { vResult->Searchobject ( personId, "Profession", "doctor" ) ; }\end{array}$ \\
\hline
\end{tabular}




\begin{tabular}{|c|c|}
\hline Método: & void SearchObject ( SiriusColony *colony, int isType $=0$ ) \\
\hline Descrição: & Busca por colônia: seleciona os objetos de uma colônia \\
\hline Parâmetros: & $\begin{array}{l}\text { Parâmetros de entrada: } \\
\text { colony - referência para a colônia aberta onde deve ser feita a busca } \\
\text { isType - define um critério de seleção dos objetos da colônia: } \\
\text { isType }=0 \text { (default) - seleção de todos os objetos, tipos ou não } \\
\text { isType }=1 \text { - seleção de objetos que são tipos }\end{array}$ \\
\hline Exemplos: & $\begin{array}{l}\text { Busca todos os objetos na colônia do tipo Countries, constrita pelo } \\
\text { objeto Europe, representado no sobrestante vEurope: } \\
\text { SiriusColony *vEuroCountries = new SiriusColony; } \\
\text { vEuroCountries->OpenColony ("Countries", vEurope); } \\
\text { vResult->Searchobject ( vEuroCountries); } \\
\text { Seleciona apenas os objetos que são tipos: } \\
\text { vResult->Searchobject (vEuroCountries, 1); }\end{array}$ \\
\hline
\end{tabular}

\begin{tabular}{|l|l|}
\hline Método: & SOID GetObject ( ) \\
\hline Descrição: & $\begin{array}{l}\text { Retorna o OId apontado pelo cursor interno que manipula o conjunto de } \\
\text { OIds recuperados numa consulta anterior. O cursor passa a apontar o } \\
\text { próximo elemento do conjunto. }\end{array}$ \\
\hline Parâmetros: & $\begin{array}{l}\text { Retorno: } \\
\text { SOID - OId do objeto }\end{array}$ \\
\hline Exemplos: & SOID object $=$ vResult->Getobject ( ); \\
\hline
\end{tabular}

\begin{tabular}{|l|l|}
\hline Método: & bool EndOfObjects( ) \\
\hline Descrição: & $\begin{array}{l}\text { Verifica se o cursor está no fim do conjunto de OIds recuperados na } \\
\text { consulta }\end{array}$ \\
\hline Parâmetros: & $\begin{array}{l}\text { Retorno: } \\
1 \text { - todos os OIds foram percorridos } \\
\text { - ainda existem OIds a serem percorridos }\end{array}$ \\
\hline Exemplos: & $\begin{array}{l}\text { Busca todos os objetos do tipo Person, cujo OId é personId, e percorre } \\
\text { todo o conjunto de OIds selecionados, processando-os um a um: } \\
\text { soID object; } \\
\text { vResult->Searchobject ( personoId ) ; } \\
\text { while ( !vResult->Endofobjects ( ) ) } \\
\text { i object = vResult->Getobject ( ); } \\
\text { ?.... }\end{array}$ \\
\hline
\end{tabular}

\begin{tabular}{|l|l|}
\hline Método: & $\sim$ SiriusObjectCursor ( ) \\
\hline Descrição: & Destrutor da classe \\
\hline
\end{tabular}




\section{Classe SiriusAttribute}

Uma instância da classe SiriusAttribute, chamada de sobrestante atributo, é uma representação em memória de um atributo vinculado a um objeto armazenado na base de dados e representado num sobrestante objeto.

\begin{tabular}{|l|l||}
\hline Método: & SiriusAttribute ( ) \\
\hline Descrição: & Construtor da classe: cria um sobrestante atributo vazio. \\
\hline
\end{tabular}

\begin{tabular}{|c|c|}
\hline Método: & $\sim$ SiriusAttribute ( ) \\
\hline Descrição: & $\begin{array}{l}\text { Destrutor da classe - libera o espaço em memória alocado para o } \\
\text { sobrestante atributo, não tendo efeito algum sobre o atributo armazenado } \\
\text { na base de dados. }\end{array}$ \\
\hline
\end{tabular}

\begin{tabular}{|c|c|}
\hline Método: & SFeature GetFeature ( ) \\
\hline Descrição: & Recupera a característica do atributo \\
\hline Parâmetros: & $\begin{array}{l}\text { Retorno: } \\
\text { SFeature - característica do atributo }\end{array}$ \\
\hline Exemplos: & $\begin{array}{l}\text { Acessa o atributo Address do objeto Person e recupera a característica } \\
\text { deste atributo: } \\
\text { SiriusAttribute *VAddr; } \\
\text { vAddr }=\text { vPerson->GetAttribute ( "Address" ); } \\
\text { SFeature ftr }=\text { vAddr->GetFeature ( ); } \\
\text { if ( ftr }==\text { TEXT ) }\{\ldots\} \text {; }\end{array}$ \\
\hline
\end{tabular}

\begin{tabular}{||l|l|}
\hline Método: & SString GetName ( ) \\
\hline Descrição: & Recupera o nome do atributo \\
\hline Parâmetros: & $\begin{array}{l}\text { Retorno: } \\
\text { SString - nome do atributo }\end{array}$ \\
\hline Exemplos: & $\begin{array}{l}\text { Recupera o nome do atributo representado no sobrestante } v A d d r: \\
\text { SString attribName }=v A d d r->\operatorname{GetName}(\text { ) } ;\end{array}$ \\
\hline
\end{tabular}

\begin{tabular}{|c|c|}
\hline Método: & SClassification GetClassificationInfo ( ) \\
\hline Descrição: & $\begin{array}{l}\text { Recupera, numa estrutura SClassification, todas as informações inerentes } \\
\text { à abstração de classificação. }\end{array}$ \\
\hline Parâmetros: & $\begin{array}{l}\text { Retorno: } \\
\text { SClassification - propriedades da abstração de classificação }\end{array}$ \\
\hline Exemplos: & $\begin{array}{l}\text { Retorna as propriedades de classificação de Age em Person: } \\
\text { SiriusAttribute *VAge; } \\
\text { SClassification classInfo; } \\
\text { vAge = vPerson->GetAttribute( "Age" ); } \\
\text { classInfo = vAge->GetClassificationInfo( ); } \\
\text { Resultado: } \\
\text { classinfo.level == } 1 ; \\
\text { classInfo.id = NON-IDENTIFIER; } \\
\text { classInfo.dflt == NON-DEFAULT; } \\
\text { classInfo.def == DEFINED; } \\
\text { classInfo.fix == FIX; }\end{array}$ \\
\hline
\end{tabular}




\begin{tabular}{|c|c|}
\hline Método: & SAggregation GetAggregationInfo ( ) \\
\hline Descrição: & $\begin{array}{l}\text { Retorna, numa estrutura SAggregation, todas as informações inerentes } \\
\text { à abstração de agregação. }\end{array}$ \\
\hline Parâmetros: & $\begin{array}{l}\text { Parâmetro de retorno: } \\
\text { SAggregation - propriedades da abstração de agregação }\end{array}$ \\
\hline Exemplos: & $\begin{array}{l}\text { Retorna as propriedades de agregação do atributo Age do objeto Person } \\
\text { SiriusAttribute *VAge; } \\
\text { SAggregation aggregInfo; } \\
\text { vAge = vPerson->GetAttribute( "Age" ); } \\
\text { aggregInfo = vAge->GetAggregationInfo( ); } \\
\text { Resultado: } \\
\text { aggregInfo.org }==\text { MONOVALUED; } \\
\text { aggregInfo.lBound }==1 ; \\
\text { aggregInfo.uBound }==2 ;\end{array}$ \\
\hline
\end{tabular}

Classe SiriusAttribText (derivada da classe SiriusAttribute)

Uma instância da classe SiriusAttribText é chamada de sobrestante atributo, e representa um atributo com característica Texto.

\begin{tabular}{|l|l|}
\hline Método: & SiriusAttribText ( ) \\
\hline Descrição: & Construtor da classe - cria um sobrestante atributo vazio \\
\hline
\end{tabular}

\begin{tabular}{|l|l|}
\hline Método: & SiriusAttribText ( SString attribName ) \\
\hline Descrição: & $\begin{array}{l}\text { Construtor da classe - cria um sobrestante atributo, criando um atributo } \\
\text { com característica Texto }\end{array}$ \\
\hline Parâmetros: & $\begin{array}{l}\text { Parâmetro de entrada: } \\
\text { attribName - nome do atributo criado }\end{array}$ \\
\hline $\begin{array}{l}\text { Exemplos: } \\
\text { viria o atributo Profession com característica Texto no sobrestante } \\
\text { Vincula o atributo Profession ao objeto Person, onde classInfo } \\
\text { encapsula as propriedades de classificação e aggregInfo as propriedades } \\
\text { de agregação: } \\
\text { vPerson->AddAttribute ( vProfession, classInfo, aggregInfo ) ; }\end{array}$ \\
\hline
\end{tabular}




\begin{tabular}{|l|l||}
\hline Método: & void SetValue( STextValue value ) \\
\hline Descrição: & Atribui um valor ao atributo \\
\hline Earâmetros: & $\begin{array}{l}\text { Parâmetro de entrada: } \\
\text { value - valor a ser atribuído ao atributo }\end{array}$ \\
\hline & $\begin{array}{l}\text { Atribui o valor "doctor" para o atributo Profession do objeto John: } \\
\text { SiriusAttribText *VProfession; } \\
\text { vProfession = (SiriusAttribText *) } \\
\text { vJohn->GetAttribute( "Profession" ) ; } \\
\text { vProfession->SetValue( "doctor" ); }\end{array}$ \\
\hline
\end{tabular}

\begin{tabular}{|c|c|}
\hline Método: & STextValue GetValue( ) \\
\hline Descrição: & $\begin{array}{l}\text { Os valores de um atributo são armazenados numa lista interna ao } \\
\text { sobrestante atributo. Um cursor percorre a lista toda e retorna um a um } \\
\text { os valores para a aplicação. } \\
\text { O método GetVa lue recupera o valor apontado pelo cursor, e o cursor } \\
\text { passa a apontar o próximo elemento da lista. }\end{array}$ \\
\hline Parâmetros: & $\begin{array}{l}\text { Retorno: } \\
\text { STextValue - valor do atributo }\end{array}$ \\
\hline Exemplos: & $\begin{array}{l}\text { Recupera o valor do atributo Profession do objeto John: } \\
\text { SiriusAttribText *vProfession; } \\
\text { vProfession = (SiriusAttribText*) } \\
\quad \text { vJohn->GetAttribute( "Profession" ); } \\
\text { STextValue value = vProfession->GetValue( ); } \\
\text { Resultado: } \\
\text { value == doctor }\end{array}$ \\
\hline
\end{tabular}

\begin{tabular}{||l|l||}
\hline Método: & void DeleteValue ( STextValue value ) \\
\hline Descrição: & Remove um valor do atributo \\
\hline Parâmetros: & $\begin{array}{l}\text { Remove o valor Jonny do atributo Nicknames do objeto John: } \\
\text { SiriusAttribText *vNicknames; } \\
\text { vNicknames = (SiriusAttribText *) } \\
\text { vNohn->GetAttribute( "Nicknames" ) ; } \\
\text { vNicknames->DeleteValue( "Jonny" ); }\end{array}$ \\
\hline
\end{tabular}

\begin{tabular}{||l|l|}
\hline Método: & SiriusAttribute operator= ( SiriusAttribute\&) \\
\hline Descrição: & $\begin{array}{l}\text { Atribui o conteúdo de um sobrestante atributo da classe SiriusAttribute } \\
\text { para um sobrestante atributo da classe SiriusAttribText }\end{array}$ \\
\hline Parâmetros: & $\begin{array}{l}\text { SiriusAttribText *textAttrib = new SiriusAttribText; } \\
\text { ExiusAttribute *vProf; } \\
\text { vProf = vJohn-GetAttribute( "Profession" ) ; } \\
\text { *textAttrib = *VProf; }\end{array}$ \\
\hline
\end{tabular}




\begin{tabular}{|c|c|}
\hline Método: & bool EndOfValues( ) \\
\hline Descrição: & $\begin{array}{l}\text { Verifica se a lista de valores foi percorrida até o final, ou seja, se ainda } \\
\text { existem valores a serem percorridos }\end{array}$ \\
\hline Parâmetros: & $\begin{array}{l}\text { Retorno: } \\
0 \text { - ainda existem valores a serem percorridos } \\
1 \text { - todos os valores foram percorridos }\end{array}$ \\
\hline Exemplos: & 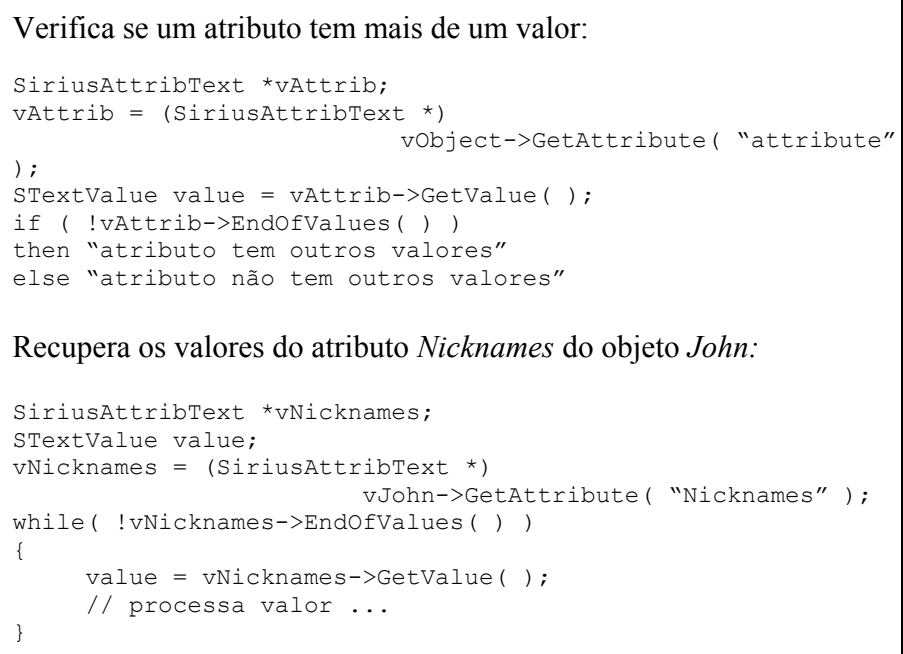 \\
\hline
\end{tabular}

\begin{tabular}{|c|c|}
\hline Método: & $\begin{array}{l}\text { void UpdateValue ( STextValue currentValue, } \\
\text { STextValue newValue ) }\end{array}$ \\
\hline Descrição: & Modifica um valor do atributo \\
\hline Parâmetros: & $\begin{array}{l}\text { Parâmetros de entrada: } \\
\text { currentValue - valor atual do atributo } \\
\text { newValue - novo valor do atributo }\end{array}$ \\
\hline Exemplos: & $\begin{array}{l}\text { Altera o valor do atributo monovalorado Profession do objeto John: } \\
\text { SiriusAttribText *vProfession; } \\
\text { STextValue currentValue = "doctor"; } \\
\text { STextValue newValue = "engineer"; } \\
\text { vProfession = (SiriusAttribText *) } \\
\text { vProfession->UpdateValue(currentValue, newValue); } \\
\text { Altera um dos valores do atributo multivalorado Nicknames do objeto } \\
\text { John: } \\
\text { SiriusAttribText *vNicknames; } \\
\text { vNicknames = (SiriusAttribText *) } \\
\text { vJohn->GetAttribute( "Nicknames" ); } \\
\text { vNicknames->UpdateValue( "Jo", "Jonny" ); }\end{array}$ \\
\hline
\end{tabular}


Classe SiriusAttribNumber

(derivada da classe SiriusAttribute)

Uma instância da classe SiriusAttribNumber é chamada de sobrestante atributo, e representa um atributo com característica Número.

\begin{tabular}{|l|l|}
\hline Método: & SiriusAttribNumber ( ) \\
\hline Descrição: & Construtor da classe - cria um sobrestante atributo vazio \\
\hline
\end{tabular}

\begin{tabular}{|c|c|}
\hline Método: & SiriusAttribNumber ( SString attribName ) \\
\hline Descrição: & $\begin{array}{l}\text { Construtor da classe - cria um sobrestante atributo, criando um atributo } \\
\text { com característica Número }\end{array}$ \\
\hline Parâmetros: & $\begin{array}{l}\text { Parâmetro de entrada: } \\
\text { attribName - nome do atributo criado }\end{array}$ \\
\hline Exemplos: & $\begin{array}{l}\text { Cria um sobrestante vAge para representar o atributo Age com } \\
\text { característica Número: } \\
\text { SiriusAttribNumber *vAge = new SiriusAttribNumber ( "Age" ); } \\
\text { Vincula o atributo Age ao objeto Person, onde classInfo e aggregInfo } \\
\text { encapsulam respectivamente as propriedades de classificação e } \\
\text { agregação: } \\
\text { vPerson->AddAttribute( vAge, classInfo, aggregInfo ); }\end{array}$ \\
\hline
\end{tabular}

\begin{tabular}{||l|l|}
\hline Método: & void SetValue ( SNumberValue value ) \\
\hline Descrição: & Atribui um valor ao atributo \\
\hline Parâmetros: & $\begin{array}{l}\text { Parâmetro de entrada: } \\
\text { value - valor a ser atribuído ao atributo }\end{array}$ \\
\hline Exemplos: & $\begin{array}{l}\text { Atribui o valor 25 para o atributo Age do objeto John: } \\
\text { SiriusAttribNumber *vAge; } \\
\text { vage = (SiriusAttribNumber *) vJohn->GetAttribute( "Age" ); } \\
\text { vage->SetValue( "25" ); }\end{array}$ \\
\hline
\end{tabular}

\begin{tabular}{||l|l|}
\hline Método: & SNumberValue GetValue( ) \\
\hline Descrição: & $\begin{array}{l}\text { Recupera o valor apontado pelo cursor, e o cursor passa a apontar o } \\
\text { próximo elemento da lista. }\end{array}$ \\
\hline Parâmetros: & $\begin{array}{l}\text { Retorno: } \\
\text { SNumberValue - valor do atributo }\end{array}$ \\
\hline Exemplos: & $\begin{array}{l}\text { Recupera o valor do atributo monovalorado Age do objeto John: } \\
\text { SiriusAttribNumber *VAge; } \\
\text { SNumberValue value; } \\
\text { vage = (SiriusAttribNumber *) vJohn->GetAttribute( "Age" ) } \\
\text { value = vAge->GetValue( ); } \\
\begin{array}{l}\text { Resultado: } \\
\text { value }=\text { = 25; }\end{array}\end{array}$ \\
\hline
\end{tabular}




\begin{tabular}{|c|c|}
\hline Método: & bool EndOfValues( ) \\
\hline Descrição: & $\begin{array}{l}\text { Verifica se a lista de valores foi percorrida até o final, ou seja, se ainda } \\
\text { existem valores a serem percorridos }\end{array}$ \\
\hline Parâmetros: & $\begin{array}{l}\text { Retorno: } \\
0 \text { - ainda existem valores a serem percorridos } \\
1 \text { - todos os valores foram percorridos }\end{array}$ \\
\hline Exemplos: & 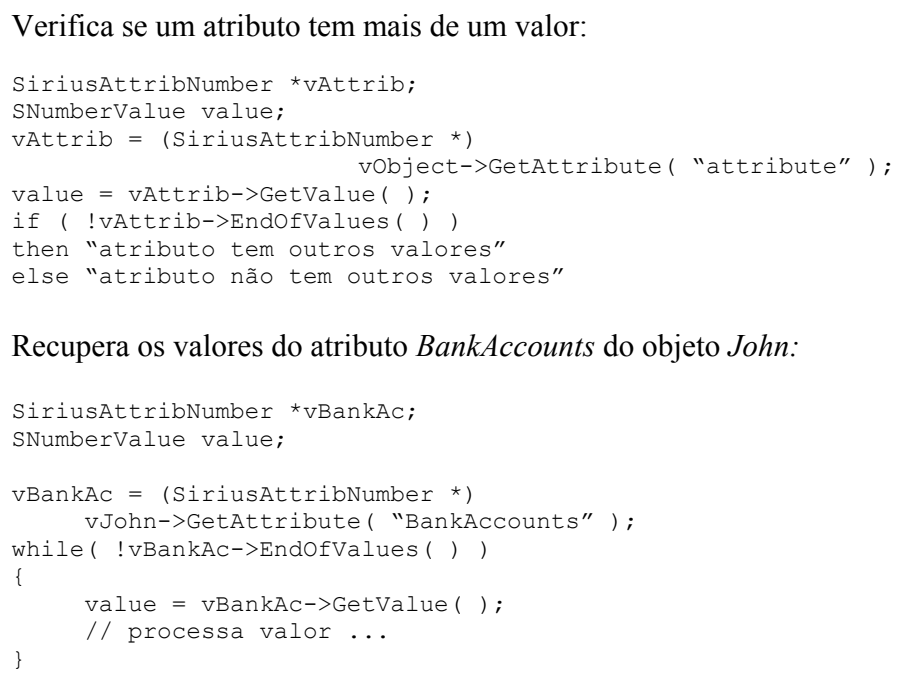 \\
\hline
\end{tabular}

\begin{tabular}{|c|c|}
\hline Método: & $\begin{array}{r}\text { void UpdateValue ( SNumberValue currentValue, } \\
\text { SNumberValue newValue ) }\end{array}$ \\
\hline Descrição: & Modifica um valor do atributo \\
\hline Parâmetros: & $\begin{array}{l}\text { Parâmetros de entrada: } \\
\text { currentValue - valor atual do atributo } \\
\text { newValue - novo valor do atributo }\end{array}$ \\
\hline Exemplos: & $\begin{array}{l}\text { Altera o valor do atributo Age do objeto John: } \\
\text { SiriusAttribNumber *vAge; } \\
\text { SNumberValue currentValue = "25"; } \\
\text { SNumberValue newValue = "26"; } \\
\text { vAge = (SiriusAttribNumber *) vJohn->GetAttribute( "Age" ); } \\
\text { vAge->UpdateValue( currentValue, newValue) ; } \\
\text { Altera um dos valores do atributo BankAccounts do objeto John: } \\
\text { SiriusAttribNumber *vBankAc; } \\
\text { vBankAc = (SiriusAttribNumber *) } \\
\text { vJohn->GetAttribute( "BankAccounts" ); } \\
\text { vBankAc->UpdateValue("22334", "22335"); }\end{array}$ \\
\hline
\end{tabular}

\begin{tabular}{|l|l||}
\hline Método: & void DeleteValue ( SNumberValue value ) \\
\hline Descrição: & Remove um valor do atributo \\
\hline Parâmetros: & $\begin{array}{l}\text { Parâmetro de entrada: } \\
\text { value - valor a ser removido }\end{array}$ \\
\hline Exemplos: & $\begin{array}{l}\text { Remove o valor 22335 do atributo BankAccounts do objeto John: } \\
\text { SiriusAttribNumber *vBankAc; } \\
\text { vBankAc }=\text { (SiriusAttribNumber *) } \\
\text { vJohn->GetAttribute( "BankAccounts" } \\
\text { vBankAc->DeleteValue( "22335" ); }\end{array}$ \\
\hline
\end{tabular}




\begin{tabular}{|l|l||}
\hline Método: & SiriusAttribute operator= ( SiriusAttribute\&) \\
\hline Descrição: & $\begin{array}{l}\text { Atribui o conteúdo de um sobrestante atributo da classe SiriusAttribute } \\
\text { para um sobrestante atributo da classe SiriusAttribNumber }\end{array}$ \\
\hline Parâmetros: & $\begin{array}{l}\text { SiriusAttribNumber *numberAttrib = new SiriusAttribNumber; } \\
\text { EiriusAttribute *vProfession; } \\
\text { vProfession = vJohn->GetAttribute( "Age" ); } \\
\text { *numberAttrib = *vProfession; }\end{array}$ \\
\hline
\end{tabular}

\begin{tabular}{|l|l|}
\hline Método: & $\sim$ SiriusAttribNumber ( ) \\
\hline Descrição: & $\begin{array}{l}\text { Destrutor da classe - libera o espaço em memória alocado para o } \\
\text { sobrestante atributo, não tendo efeito algum sobre o atributo armazenado } \\
\text { na base de dados. }\end{array}$ \\
\hline
\end{tabular}

Classe SiriusAttribAttrib (derivada da classe SiriusAttribute)

Uma instância da classe SiriusAttribAttrib é chamada de sobrestante atributo, e representa um atributo com característica Atributo de Atributo.

\begin{tabular}{||l|l|}
\hline Método: & SiriusAttribAttrib ( ) \\
\hline Descrição: & Construtor da classe - cria um sobrestante atributo vazio \\
\hline
\end{tabular}

\begin{tabular}{|c|c|}
\hline Método: & SiriusAttribAttrib ( SString attribName ) \\
\hline Descrição: & $\begin{array}{l}\text { Construtor da classe - cria um sobrestante atributo, criando um atributo } \\
\text { com característica Atributo de Atributo }\end{array}$ \\
\hline Parâmetros: & $\begin{array}{l}\text { Parâmetro de entrada: } \\
\text { attribName - nome do atributo criado }\end{array}$ \\
\hline Exemplos: & $\begin{array}{l}\text { Cria um sobrestante } v \text { Passport para representar o atributo Passport com } \\
\text { característica Atributo de Atributo: } \\
\text { SiriusAttribAttrib *vPassport = } \\
\text { new SiriusAttribAttrib( "Passport" } \\
\text { ); } \\
\text { Vincula o atributo Passport ao objeto Person, onde classInfo e } \\
\text { aggregInfo encapsulam respectivamente as propriedades de classificação } \\
\text { e agregação: } \\
\text { vPerson->AddAttribute ( vPassport, classInfo, aggregInfo ); }\end{array}$ \\
\hline
\end{tabular}




\begin{tabular}{|l|l||}
\hline Método: & $\begin{array}{c}\text { void AddSubAttribute ( SiriusAttribute *attribute, } \\
\text { IdFlag isIdentifier = NON-IDENTIFIER ) }\end{array}$ \\
\hline Descrição: & Cria um sub-atributo para estrutura do Atributo de Atributo \\
\hline Parâmetros: & $\begin{array}{l}\text { Parâmetros de entrada: } \\
\text { attribute - sobrestante atributo que representa o sub-atributo } \\
\text { isIdentifier - flag indicando se o sub-atributo é identificador na estrutura } \\
\text { do Atributo de Atributo. Default: NON-IDENTIFIER }\end{array}$ \\
\hline Exemplos: & $\begin{array}{l}\text { Cria o atributo Passport Number e vincula-o como sub-atributo } \\
\text { identificador do Atributo de Atributo Passport: } \\
\text { SiriusAttribNumber *vPassNr = } \\
\text { new SiriusAttribNumber ( "Passport Number") } \\
\text { vPassport->AddSubttribute (vPassNr, IDENTIFIER) ; } \\
\text { Cria o atributo Issued by e vincula-o como sub-atributo não identificador } \\
\text { do Atributo de Atributo Passport: } \\
\text { SiriusAttribText *vIssued = new SiriusAttribText ("Issued by") ; } \\
\text { vPassport->AddSubAttribute (vIssued) ; }\end{array}$ \\
\hline
\end{tabular}

\begin{tabular}{|l|l|}
\hline Método: & SiriusAttribute* GetSubAttribute ( SString attribName) \\
\hline Descrição: & Acessa um sub-atributo do Atributo de Atributo \\
\hline Parâmetros: & $\begin{array}{l}\text { Parâmetro de entrada: } \\
\text { attribName - nome do atributo a ser acessado } \\
\text { Retorno: } \\
\text { SiriusAttribute* - referência para o sobrestante atributo que representa } \\
\text { o sub-atributo requerido }\end{array}$ \\
\hline Exemplos: & $\begin{array}{l}\text { Acessa o sub-atributo Issue by do Atributo de Atributo Passport e atribui } \\
\text { o valor DPFB para o sub-atributo: } \\
\text { SiriusAttribText *VIssued }=\text { (SiriusAttribText*) } \\
\text { vPassport->GetSubAttribute ("Issued by") } \\
\text { vissued->SetValue ("DPFB") }\end{array}$ \\
\hline
\end{tabular}

\begin{tabular}{|l|l|}
\hline Método: & DeleteSubAttribute (SString attribName) \\
\hline Descrição: & Remove um sub-atributo do Atributo de Atributo \\
\hline Parâmetros: & $\begin{array}{l}\text { Parâmetro de entrada: } \\
\text { attribName - nome do sub-atributo a ser removido }\end{array}$ \\
\hline Exemplos: & $\begin{array}{l}\text { Remove Issued by do Atributo de Atributo Passport: } \\
\text { vPassport->DeleteSubAttribute ("Issued by") ; }\end{array}$ \\
\hline
\end{tabular}




\begin{tabular}{|c|c|}
\hline Método: & SiriusAttribute* GetIdSubAttribute () \\
\hline Descrição: & Acessa o sub-atributo identificador do Atributo de Atributo \\
\hline Parâmetros: & $\begin{array}{l}\text { Retorno: } \\
\text { SiriusAttribute* - referência para o sobrestante atributo que representa } \\
\text { o sub-atributo identificador }\end{array}$ \\
\hline Exemplos: & $\begin{array}{l}\text { Acessa o sub-atributo identificador do Atributo de Atributo Passport: } \\
\text { SiriusAttribute *VAttrib; } \\
\text { vAttrib = vPassport->GetIdSubAttribute ( ) ; } \\
\text { SString attribName = vAttrib->GetName( ); } \\
\text { Resultado: } \\
\text { attribName == Passport Number }\end{array}$ \\
\hline
\end{tabular}

\begin{tabular}{|l|l||}
\hline Método: & SiriusAttribute operator=( SiriusAttribute\&) \\
\hline Descrição: & $\begin{array}{l}\text { Atribui o conteúdo de um sobrestante atributo da classe SiriusAttribute } \\
\text { para um sobrestante atributo da classe SiriusAttribAttrib }\end{array}$ \\
\hline Parâmetros: & $\begin{array}{l}\text { SiriusAttribAttrib *attribAttrib = new SiriusAttribAttrib; } \\
\text { SiriusAttribute *VPasport; } \\
\text { EPasport = vJohn->GetAttribute ("Passport") ; } \\
\text { *attribAttrib = *VPasport; }\end{array}$ \\
\hline
\end{tabular}

\begin{tabular}{|l|l|}
\hline Método: & $\sim$ SiriusAttribAttrib ( ) \\
\hline Descrição: & $\begin{array}{l}\text { Destrutor da classe - libera o espaço em memória alocado para o o } \\
\text { sobrestante atributo, não tendo efeito algum sobre o atributo armazenado } \\
\text { na base de dados. }\end{array}$ \\
\hline
\end{tabular}

\section{Classe SiriusAttributeCursor}

Uma instância da classe SiriusAttributeCursor, chamada de sobrestante cursor atributo, armazena referências para um conjunto de atributos de um objeto recuperados numa consulta, segundo algum critério.

\begin{tabular}{|l|l|}
\hline Método: & SiriusAttributeCursor ( ) \\
\hline Descrição: & $\begin{array}{l}\text { Construtor da classe: cria uma estrutura para armazenar um conjunto de } \\
\text { atributos recuperados em uma consulta. O conjunto de atributos é } \\
\text { percorrido através de cursores definidos para esta estrutura. }\end{array}$ \\
\hline Parâmetros: & SiriusAttributeCursor *vesult = new SiriusAttributecursor; \\
\hline Exemplos:
\end{tabular}

\begin{tabular}{|l|l|}
\hline Método: & $\sim$ SiriusAttributeCursor ( ) \\
\hline Descrição: & Destrutor da classe \\
\hline
\end{tabular}

\begin{tabular}{|l|l|}
\hline Método: & void SearchAttribute ( SiriusObject *object ) \\
\hline Descrição: & Seleciona os atributos de um objeto representado num sobrestante objeto \\
\hline Parâmetros: & $\begin{array}{l}\text { Parâmetro de entrada: } \\
\text { object - sobrestante objeto que representa o objeto do qual serão } \\
\text { selecionados os atributos }\end{array}$ \\
\hline Exemplos: & $\begin{array}{l}\text { Seleciona todos os atributos do objeto Person: } \\
\text { vResult->SearchAttribute( vPerson ); }\end{array}$ \\
\hline
\end{tabular}




\begin{tabular}{|l|l||}
\hline Método: & SiriusAttribute* GetAttribute ( ) \\
\hline Descrição: & $\begin{array}{l}\text { Retorna uma referência para o sobrestante atributo apontado pelo cursor } \\
\text { no conjunto resultante de uma consulta. O cursor passa a apontar o } \\
\text { próximo sobrestante atributo do conjunto. }\end{array}$ \\
\hline Parâmetros: & $\begin{array}{l}\text { Retorno: } \\
\text { SiriusAttribute * - referência para um sobrestante atributo que representa } \\
\text { um atributo do objeto }\end{array}$ \\
\hline Exemplos: & $\begin{array}{l}\text { SiriusAttribute *attrib; } \\
\text { attrib }=\text { vResult->GetAttribute ( ); }\end{array}$ \\
\hline
\end{tabular}

\begin{tabular}{|c|c|}
\hline Método: & bool EndOfAttributes ( ) \\
\hline Descrição: & $\begin{array}{l}\text { Verifica se ainda existem sobrestantes atributo apontados pelo cursor no } \\
\text { conjunto resultante de uma consulta }\end{array}$ \\
\hline Parâmetros: & $\begin{array}{l}\text { Retorno: } \\
0 \text { - ainda existem atributos a serem percorridos } \\
1 \text { - todos os atributos foram percorridos }\end{array}$ \\
\hline Exemplos: & 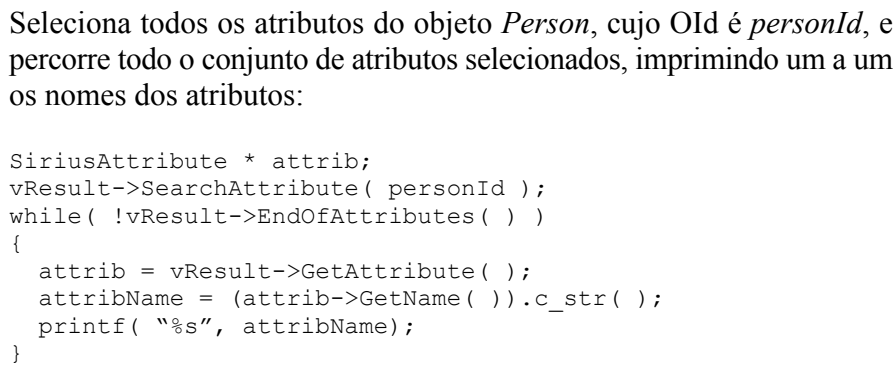 \\
\hline
\end{tabular}

\section{Classe SiriusColonyType}

Uma instância da classe SiriusColonyType, chamada de sobrestante tipo de colonia, é uma representação em memória de um tipo de colônia definido na base de dados.

\begin{tabular}{|l|l|}
\hline Método: & SiriusColonyType ( ) \\
\hline Descrição: & $\begin{array}{l}\text { Construtor da classe - cria um sobrestante tipo de colônia vazio para } \\
\text { representar um tipo de colônia definido na base de dados. }\end{array}$ \\
\hline
\end{tabular}

\begin{tabular}{|l|l|}
\hline Método: & $\sim$ SiriusColonyType ( ) \\
\hline Descrição: & $\begin{array}{l}\text { Destrutor da classe - libera o espaço em memória alocado para o } \\
\text { sobrestante tipo de colônia, não tendo efeito algum sobre o tipo de } \\
\text { colônia definido na base de dados. }\end{array}$ \\
\hline
\end{tabular}

\begin{tabular}{||l|l|}
\hline Método: & void ReadColType ( SString typeName ) \\
\hline Descrição: & Recupera um tipo de colônia definido na base de dados \\
\hline Parâmetros: & $\begin{array}{l}\text { Parâmetro de entrada: } \\
\text { typeName - nome do tipo de colônia a ser lido }\end{array}$ \\
\hline Exemplos: & $\begin{array}{l}\text { Traz para o sobrestante } v \text { Countries as informações do tipo de colônia } \\
\text { Countries: } \\
\text { SiriusColonyType *vCountries = new SiriuscolonyType; } \\
\text { vCountries->ReadColType( "Countries" ); }\end{array}$ \\
\hline
\end{tabular}




\begin{tabular}{|l|l||}
\hline Método: & SOID GetCHDObject ( ) \\
\hline Descrição: & $\begin{array}{l}\text { Recupera o OId do tipo de objeto que constringe o tipo de colônia, } \\
\text { segundo o DHC (Colonies Hierarchical Diagram - CHD). }\end{array}$ \\
\hline Parâmetros: & $\begin{array}{l}\text { Retorno: } \\
\text { SOID - OId do tipo de objeto }\end{array}$ \\
\hline Exemplos: & $\begin{array}{l}\text { Recupera o OId do tipo de objeto que constringe o tipo de colônia } \\
\text { Countries: } \\
\text { SoID object }=\text { vCountries->GetCHDobject ( ) ; }\end{array}$ \\
\hline
\end{tabular}

\begin{tabular}{|l|l||}
\hline Método: & void CreateColType( SString colName, SOID ctrObject ) \\
\hline Descrição: & Cria um novo tipo de colônia \\
\hline Parâmetros: & $\begin{array}{l}\text { Parâmetros de entrada: } \\
\text { colName - nome do tipo de colônia a ser criado } \\
\text { ctrObject - OId do tipo de objeto que constringe o tipo de colônia }\end{array}$ \\
\hline Exemplos: & $\begin{array}{l}\text { Cria um tipo de colônia Countries constrito pelo objeto Continent: } \\
\text { SiriusObject *vContinent = new Siriusobject; } \\
\text { vContinent->Readobject ( "Continent", METATYPE ) ; } \\
\text { SOID obj = vContinent->GetOId ( ); } \\
\text { SiriusColonyType *VCountries = new SiriusColonyType; } \\
\text { vCountries->CreateColType( "Countries", obj ); }\end{array}$ \\
\hline
\end{tabular}

\begin{tabular}{|l|l|}
\hline Método: & void DeleteColType ( ) \\
\hline Descrição: & Remove da base de dados o tipo de colônia representado no sobrestante \\
\hline Parâmetros: & \\
\hline Exemplos: & $\begin{array}{l}\text { Remove o tipo de colônia Countries: } \\
\text { vCountries->DeleteColType ( ); }\end{array}$ \\
\hline
\end{tabular}




\section{Classe SiriusColony}

Uma instância da classe SiriusColony, chamada de sobrestante colonia, é uma representação em memória de uma colônia definida na base de dados.

\begin{tabular}{|c|c|}
\hline Método: & SiriusColony ( ) \\
\hline Descrição: & $\begin{array}{l}\text { Construtor da classe - cria um sobrestante colônia vazio para representar } \\
\text { uma colônia da base de dados }\end{array}$ \\
\hline
\end{tabular}

\begin{tabular}{|l|l|}
\hline Método: & 〜SiriusColony ( ) \\
\hline Descrição: & $\begin{array}{l}\text { Destrutor da classe - libera o espaço em memória alocado para o } \\
\text { sobrestante colônia, não tendo efeito algum sobre a colônia armazenado } \\
\text { na base de dados. }\end{array}$ \\
\hline
\end{tabular}

\begin{tabular}{|l|l|}
\hline Método: & void OpenColony ( SString colType, SiriusObject *ctrObject) \\
\hline Descrição: & Abre uma colônia definida na base de dados. \\
\hline Parâmetros: & $\begin{array}{l}\text { Parâmetros de entrada: } \\
\text { colType - nome do tipo da colônia a ser aberta } \\
\text { ctrObject }- \text { sobrestante objeto que representa o objeto que constringe a } \\
\text { colônia , de acordo com o Diagrama de Representação de Instâncias }\end{array}$ \\
\hline Exemplos: & $\begin{array}{l}\text { Traz para o sobrestante vEuroCountries as informações da colônia do } \\
\text { tipo Countries, constrita pelo objeto Europe, representado no sobrestante } \\
\text { vEurope: } \\
\text { SiriusColony *vEuroCountries = new SiriusColony; } \\
\text { vEuroCountries->OpenColony ( "Countries", vEurope ); }\end{array}$ \\
\hline
\end{tabular}

\begin{tabular}{||l|l||}
\hline Método: & bool IsOpen ( ) \\
\hline Descrição: & Verifica se a colônia está aberta para a aplicação \\
\hline Parâmetros: & $\begin{array}{l}\text { Retorno: } \\
1 \text { - colônia aberta } \\
0 \text { - colônia fechada }\end{array}$ \\
\hline Exemplos: & $\begin{array}{l}\text { Fecha a colônia EuroCountries, se estiver está aberta: } \\
\text { if (vEuroCountries->Isopen( ) ) } \\
\text { vEuroCountries->CloseColony ( ); }\end{array}$ \\
\hline
\end{tabular}

\begin{tabular}{|l|l|}
\hline Método: & SString GetType ( ) \\
\hline Descrição: & Recupera o nome do tipo da colônia \\
\hline Parâmetros: & $\begin{array}{l}\text { Retorno: } \\
\text { SString - nome do tipo da colônia }\end{array}$ \\
\hline Exemplos: & $\begin{array}{l}\text { Recupera o nome do tipo da colônia representada no sobrestante } \\
\text { vEuroCountries: } \\
\text { SString typeName }=\text { vEuroCountries->GetType ( ); } \\
\text { Resultado: } \\
\text { typeName }==\text { Countries }\end{array}$ \\
\hline
\end{tabular}




\begin{tabular}{|l|l||}
\hline Método: & void CreateColony ( SString colName, SiriusObject *ctrObject ) \\
\hline Descrição: & Cria uma nova colônia \\
\hline Earâmetros: & $\begin{array}{l}\text { Parâmetros de entrada: } \\
\text { colName - nome do tipo da colônia a ser criada } \\
\text { ctrObject - sobrestante objeto que representa o objeto que constringe a } \\
\text { colônia }\end{array}$ \\
\hline Exemplos: & $\begin{array}{l}\text { Cria uma colônia do tipo Countries constrita pelo objeto Asia, } \\
\text { representado no sobrestante } v A \text { sia } \\
\text { SiriusColony *vAsianCountries = new SiriusColony; } \\
\text { vAsianCountries->CreateColony ( "Countries", vAsia ) ; }\end{array}$ \\
\hline
\end{tabular}

\begin{tabular}{|l|l||}
\hline Método: & void ReadColony ( SString colName, SOID ctrObject ) \\
\hline Descrição: & Lê as informações de nova colônia definida na base de dados \\
\hline Parâmetros: & $\begin{array}{l}\text { Parâmetros de entrada: } \\
\text { colName - nome do tipo da colônia } \\
\text { ctrObject - OId do objeto que constringe a colônia }\end{array}$ \\
\hline Exemplos: & $\begin{array}{l}\text { Lê a colônia do tipo Countries constrita pelo objeto Asia, cujo OId é } \\
\text { asiaId: } \\
\text { SiriusColony *vAsianCountries = new SiriusColony; } \\
\text { vAsianCountries->ReadColony ( "Countries", asiaId ); }\end{array}$ \\
\hline
\end{tabular}

\begin{tabular}{||l|l|}
\hline Método: & SOID GetIRDObject ( ) \\
\hline Descrição: & $\begin{array}{l}\text { Recupera o OId do objeto que constringe a colônia, segundo o DRI } \\
\text { (Instances Representation Diagram - IRD) }\end{array}$ \\
\hline Parâmetros: & $\begin{array}{l}\text { Retorno: } \\
\text { SOID - OId do objeto que constringe a colônia }\end{array}$ \\
\hline Exemplos: & $\begin{array}{l}\text { Recupera o OId do objeto que constringe a colônia representada no } \\
\text { sobrestante vEuroCountries: } \\
\text { SOID obj } \text { - vEuroCountries->GetIRDobject ( ); }\end{array}$ \\
\hline
\end{tabular}

\begin{tabular}{|l|l|}
\hline Método: & void DeleteColony ( ) \\
\hline Descrição: & Remove da base de dados a colônia representada no sobrestante \\
\hline Parâmetros: & $\begin{array}{l}\text { Remove da base a colônia do tipo Countries e constrita pelo objeto Asia: } \\
\text { vAsianCountries->DeleteColony ( ) ; }\end{array}$ \\
\hline Exemplos:
\end{tabular}

\begin{tabular}{|l|l|}
\hline Método: & void CloseColony ( ) \\
\hline Descrição: & Fecha a colônia aberta para a aplicação \\
\hline Parâmetros: & $\begin{array}{l}\text { Fecha a colônia do tipo Countries, constrita pelo objeto Europe. } \\
\text { EEuroCountries->CloseColony ( ); }\end{array}$ \\
\hline Exemplos:
\end{tabular}




\section{Classe SiriusColonyCursor}

Uma instância da classe SiriusColonyCursor, chamada de sobrestante cursor colônia, armazena colônias recuperadas numa consulta, segundo algum critério.

\begin{tabular}{||l|l|}
\hline Método: & SiriusColonyCursor ( ) \\
\hline Descrição: & $\begin{array}{l}\text { Construtor da classe: cria uma estrutura para armazenar um conjunto de } \\
\text { colônias recuperadas em uma consulta. O conjunto de colônias é } \\
\text { percorrido através de cursores definidos para esta estrutura. } \\
\text { Obs: a colônia é identificada pelo nome de seu tipo e pelo OId do objeto } \\
\text { que a constringe. }\end{array}$ \\
\hline Parâmetros: & SiriusColonyCursor *vesult = new SiriusColonyCursor; \\
\hline Exemplos: &
\end{tabular}

\begin{tabular}{||l|l||}
\hline Método: & void SearchCHDTypes ( ) \\
\hline Descrição: & $\begin{array}{l}\text { Busca todos os tipos de colônia definidos na base de dados, de acordo } \\
\text { com o DHC (Colonies Hierarchical Diagram - CHD). }\end{array}$ \\
\hline Parâmetros: & $\begin{array}{l}\text { Busca todos os tipos de colônia definidos na base: } \\
\text { vResult->SearchCHDTypes ( ); }\end{array}$ \\
\hline Exemplos:
\end{tabular}

\begin{tabular}{|l|l|}
\hline Método: & void SearchCHDTypes ( SOID ctrObject ) \\
\hline Descrição: & $\begin{array}{l}\text { Busca todos os tipos de colônia constritos por um tipo de objeto, de } \\
\text { acordo com o DHC (Colonies Hierarchical Diagram - CHD). }\end{array}$ \\
\hline Parâmetros: & $\begin{array}{l}\text { Parâmetro de entrada: } \\
\text { ctrObject - OId do tipo de objeto }\end{array}$ \\
\hline Exemplos: & $\begin{array}{l}\text { Busca todos os tipos de colônia constritos pelo objeto Continent, cujo } \\
\text { OId é contId }\end{array}$ \\
\hline
\end{tabular}

\begin{tabular}{||l|l|}
\hline Método: & void SearchOpenColonies ( ) \\
\hline Descrição: & Busca todas as colônias abertas para a aplicação \\
\hline Parâmetros: & \\
\hline Exemplos: & vResult->SearchopenColonies ( ); \\
\hline
\end{tabular}

\begin{tabular}{||l|l||}
\hline Método: & void SearchColony ( SOID ctrObject ) \\
\hline Descrição: & Busca todas as colônias constritas por um objeto \\
\hline Parâmetros: & $\begin{array}{l}\text { Parâmetro de entrada: } \\
\text { ctrObject - OId do objeto }\end{array}$ \\
\hline Exemplos: & $\begin{array}{l}\text { Busca todas as colônias constritas por Europe, cujo OId é EuroId: } \\
\text { vResult->SearchColony ( EuropeId ); }\end{array}$ \\
\hline
\end{tabular}




\begin{tabular}{|l|l||}
\hline Método: & void SearchColony ( SString colType ) \\
\hline Descrição: & Busca todas as colônias de um determinado tipo \\
\hline Parâmetros: & $\begin{array}{l}\text { Parâmetro de entrada: } \\
\text { colName - nome do tipo de colônia }\end{array}$ \\
\hline Exemplos: & $\begin{array}{l}\text { Busca todas as colônias do tipo Countries } \\
\text { vResult->SearchColony ( "Countries" ) ; }\end{array}$ \\
\hline
\end{tabular}

\begin{tabular}{|c|c|}
\hline Método: & bool EndOfColonies ( ) \\
\hline Descrição: & $\begin{array}{l}\text { Verifica se ainda existem colônias apontadas pelo cursor no conjunto de } \\
\text { colônias selecionadas na consulta }\end{array}$ \\
\hline Parâmetros: & $\begin{array}{l}\text { Retorno: } \\
0 \text { - ainda existem colônias a serem percorridas } \\
1 \text { - todas as colônias foram percorridas }\end{array}$ \\
\hline Exemplos: & 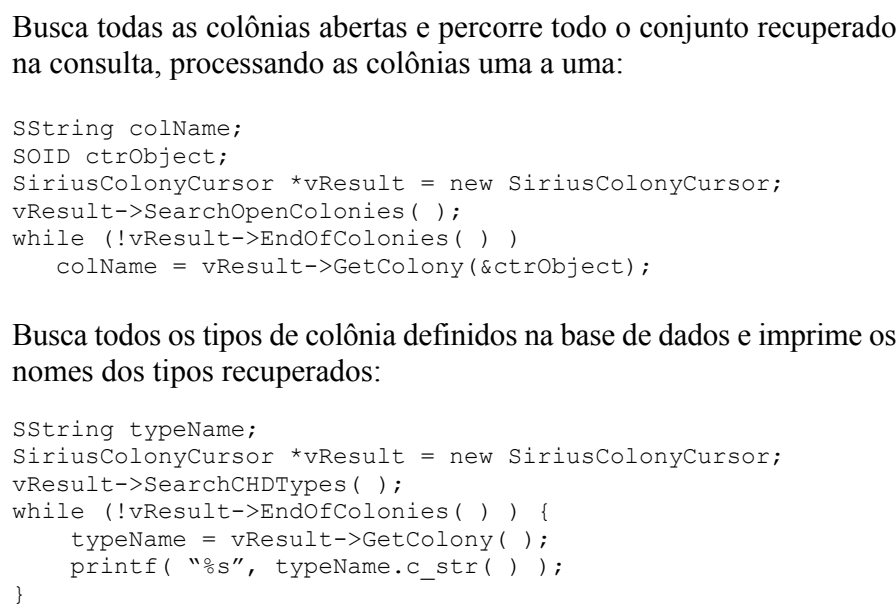 \\
\hline
\end{tabular}

\begin{tabular}{|l|l|}
\hline Método: & SString GetColony ( SOID *ctrObject $=0$ ) \\
\hline Descrição: & $\begin{array}{l}\text { Retorna a colônia apontada pelo cursor que manipula o conjunto de } \\
\text { colônias selecionadas numa consulta anterior }\end{array}$ \\
\hline Parâmetros: & $\begin{array}{l}\text { Parâmetro de retorno: } \\
\text { ctrObject } \text { - OId do objeto que constringe a colônia. O parâmetro default } \\
\text { = Null pode ser utilizado quando é feita busca de tipos de colônias, pois } \\
\text { estes podem ser identificados apenas por seus nomes. } \\
\text { Retorno: } \\
\text { SString - nome do tipo da colônia }\end{array}$ \\
\hline Exemplos: & \\
\hline
\end{tabular}

\begin{tabular}{||l|l|}
\hline Método: & $\sim$ SiriusColonyCursor ( ) \\
\hline Descrição: & Destrutor da classe \\
\hline
\end{tabular}




\section{Classe SiriusError}

A classe SiriusError destina-se ao tratamento de erros da API, numa abordagem similar ao tratamento de exceções disponível na biblioteca padrão da linguagem $\mathrm{C}++$. Na implementação da API, a ocorrência de um erro, ou de uma situação que pode gerar inconsistência na base, gera uma exceção que pode ser tratada na aplicação através dos comandos try e catch da linguagem $\mathrm{C}++$

\begin{tabular}{|c|c|}
\hline Método: & SErrorId GetErrorId ( ) \\
\hline Descrição: & Retorna o identificador do erro ocorrido \\
\hline Parâmetros: & $\begin{array}{l}\text { Retorno: } \\
\text { SErrorId - identificador do erro }\end{array}$ \\
\hline Exemplos: & 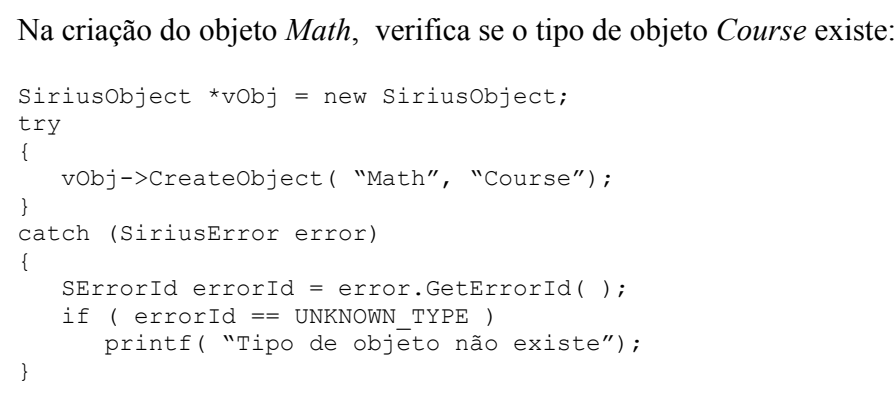 \\
\hline
\end{tabular}

\begin{tabular}{|c|c|}
\hline Método: & SString GetErrorMessage ( ) \\
\hline Descrição: & Retorna a mensagem correspondente ao erro ocorrido \\
\hline Parâmetros: & $\begin{array}{l}\text { Retorno: } \\
\text { SString - mensagem de erro }\end{array}$ \\
\hline Exemplos: & $\begin{array}{l}\text { Na criação do objeto Math, imprime mensagem de erro: } \\
\text { Siriusobject *vobj = new Siriusobject; } \\
\text { try } \\
\text { \{ vobj->Createobject ( "Math", "Course"); } \\
\text { \} catch (SiriusError error) } \\
\text { \{ SString message = error.GetErrorMessage( ); } \\
\text { printf( "Erro: os", message.c_str( )); }\end{array}$ \\
\hline
\end{tabular}

\begin{tabular}{|l|l|}
\hline Método: & $\sim$ SiriusError( ) \\
\hline Descrição: & Destrutor da classe \\
\hline
\end{tabular}




\section{Classe SIRIUS}

Esta classe é responsável por operações de interface com o gerenciador de dados. Um objeto da classe SIRIUS representa uma conexão com a base de dados.

\begin{tabular}{|l|l|}
\hline Método: & SIRIUS ( ) \\
\hline Descrição: & Construtor da classe \\
\hline
\end{tabular}

\begin{tabular}{|l|l|}
\hline Método: & $\sim$ SIRIUS ( ) \\
\hline Descrição: & Destrutor da classe \\
\hline
\end{tabular}

\begin{tabular}{|l|l||}
\hline Método: & $\begin{array}{l}\text { void Connect (SString databaseAlias, SString username, } \\
\text { SString password ) }\end{array}$ \\
\hline Descrição: & Estabelece a conexão com a base de dados. \\
\hline Parâmetros: & $\begin{array}{l}\text { Parâmetros de entrada: } \\
\text { databaseAlias - alias que identifica a base de dados } \\
\text { username - nome do usuário } \\
\text { password - senha do usuário }\end{array}$ \\
\hline Exemplos: & $\begin{array}{l}\text { Estabelece uma conexão do usuário SYSDBA com a base de dados } \\
\text { identificada através do alias SIRIUS: } \\
\text { SIRIUS *base = new SIRIUS; } \\
\text { base->Connect ("SIRIUS", "SYSDBA", "masterkey") ; }\end{array}$ \\
\hline
\end{tabular}

\begin{tabular}{||l|l|}
\hline Método: & int BeginTransaction ( ) \\
\hline Descrição: & Inicia uma transação. \\
\hline Parâmetros: & $\begin{array}{l}\text { Retorno: } \\
\text { int - identificador da transação }\end{array}$ \\
\hline
\end{tabular}

\begin{tabular}{|c|c|}
\hline Método: & void AbortTransaction ( int transId ) \\
\hline Descrição: & Aborta uma transação. \\
\hline Parâmetros: & $\begin{array}{l}\text { Parâmetro de entrada: } \\
\text { transId - identificador da transação }\end{array}$ \\
\hline Exemplos: & $\begin{array}{l}\text { Aborta a transação na ocorrência de um erro: } \\
\text { int trans }[\mathrm{N}] ; \\
\operatorname{trans}[0]=\text { base->BeginTransaction( }) ; \\
\operatorname{try} \\
\{\ldots \\
\} \\
\text { catch (SiriusError error) } \\
\{\text { base->AbortTransaction (trans }[0] \text { ); } \\
\}\end{array}$ \\
\hline
\end{tabular}




\begin{tabular}{|c|c|}
\hline Método: & void CommitTransaction ( int transId ) \\
\hline Descrição: & Finaliza uma transação. \\
\hline Parâmetros: & $\begin{array}{l}\text { Parâmetro de entrada: } \\
\text { transId - identificador da transação }\end{array}$ \\
\hline Exemplos: & 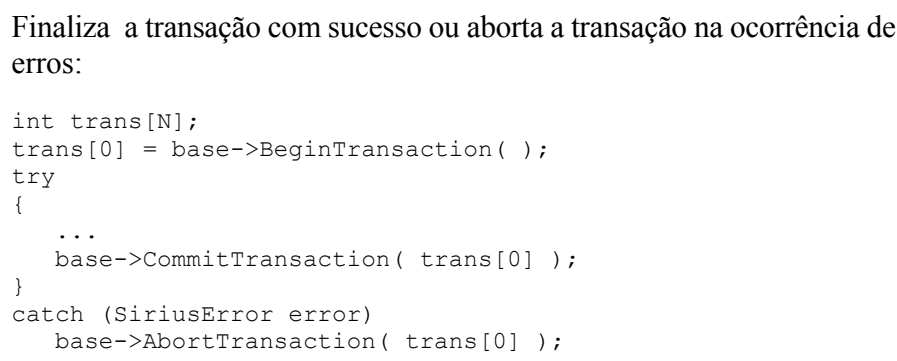 \\
\hline
\end{tabular}

\begin{tabular}{|l|l||}
\hline Método: & void Disconnect ( ) \\
\hline Descrição: & Finaliza a conexão com a base de dados. \\
\hline Parâmetros: & \\
\hline Exemplos: & base->Disconnect ( ) ; \\
\hline
\end{tabular}




\section{Tipos de dado definidos na API}

struct SOID - Object Identifier

Membros:

unsigned long int address (endereço lógico do objeto na base de dados) unsigned long int counter (identifica o objeto como n-ésimo objeto

a ocupar o endereço lógico)

SString - tipo definido para manipular strings, como nome de objeto, nome de atributo, nome de tipo de colônia e mensagem de erro.

Obs: o tipo SString utiliza uma classe específica do C++ Builder para essa tarefa: a classe AnsiString. Quando uma variável é declarada do tipo SString, qualquer string pode ser atribuída a esta variável. Quando o valor dessa variável precisa ser utilizado como um char*, como na função printf, o método $c$ str() retorna o valor da variável como char*.

SFeature - Característica de atributo: enum $\{$ TEXT, NUMBER, ATTRIBATTRIB $\}$

STextValue - Valor para atributos com característica Texto: string

SNumberValue - Valor para atributos com característica Número: inteiro ou real

SData - Valor para atributos Texto ou Número.

SOrganization - Referente à abstração de agregação - organização do atributo quando vinculado a um objeto: enum \{MONOVALUED, MULTIVALUED \}.

SBound - Referente à abstração de agregação - valor inteiro para limites inferior e superior do número de valores que podem ser assumidos por um atributo quando vinculado a um objeto.

SLevel - Referente à abstração de classificação - nível de instanciação na hierarquia de classificação.

SIdFlag - Referente à abstração de classificação - flag indicando se o atributo é ou não identificador do objeto num determinado nível de instanciação, ou se o sub-atributo identificador de um atributo de atributo: enum \{IDENTIFIER, NON IDENTIFIER \}.

SDefFlag - Referente à abstração de classificação - flag indicando se o atributo possui valor definido, indefinido ou valor nulo: enum $\{$ DEFINED, UNDEFINED, NULL_VALUE\}.

SDfltFlag - Referente à abstração de classificação - flag indicando se o atributo possui valor default ou não: enum $\{$ DEFAULT, NON_DEFAULT $\}$.

SFixFlag - Referente à abstração de classificação - flag indicando se o atributo é fixo ou não: enum $\{$ FIX, NON_FIX\}.

struct SAggregation - estrutura que armazena as propriedades da abstração de agregação. Membros:

$$
\begin{aligned}
& \text { SOrganization org; } \\
& \text { SBound lBound; }
\end{aligned}
$$$$
\text { SBound uBound, }
$$

struct SClassification - estrutura que armazena as propriedades da abstração de classificação.

Membros:

$$
\begin{aligned}
& \text { SLevel level; } \\
& \text { SIdFlag id; } \\
& \text { SDefflag def; } \\
& \text { SDfltFlag deflt; } \\
& \text { SFixflag fix; }
\end{aligned}
$$

SErrorId - identificador de erros:

$$
\begin{aligned}
& \text { enum \{ SYSTEM_OBJECT, } \\
& \text { UNKNOWN_TYPE, } \\
& \text { UNKNOWN_OBJECT, } \\
& \text { UNKNOWN_COLONY_TYPE, } \\
& \text { UNKNOWN_COLONY, } \\
& \text { UNKNOWN_ATTRIBUTE, } \\
& \text { UNKNOWN_VALUE, } \\
& \text { UNDEFINED_COLONY, } \\
& \text { UNDEFINED_IDENTIFIER, } \\
& \text { CLOSED_COLONY, } \\
& \text { TRANSIENT_OBJECT, } \\
& \text { DUPLICATED_NAME, } \\
& \text { DUPLICATED_ATTRIBUTE, } \\
& \text { DUPLICATED_IDENTIFIER, } \\
& \text { DUPLICATED_VALUE, } \\
& \text { DUPLICATED_COLONY_TYPE, } \\
& \text { DUPLICATED_COLONY, } \\
& \text { TYPE_MISMATCH, } \\
& \text { VALUES_OVERFLOW, } \\
& \text { CHD_ERROR \} }
\end{aligned}
$$




\begin{tabular}{|l|l|}
\hline Error_d & Error Message \\
\hline \hline SYSTEM_OBJECT & "Access denied - System-defined object" \\
\hline UNKNOWN_TYPE & "Type doesn't exist" \\
\hline UNKNOWN_OBJECT & "Object doesn't exist" \\
\hline UNKNOWN_COLONY_TYPE & "Colony type doesn't exist" \\
\hline UNKNOWN_COLONY & "Colony doesn't exist" \\
\hline UNKNOWN_ATTRIBUTE & "Attribute doesn't exist" \\
\hline UNKNOWN_VALUE & "Value doesn't exist" \\
\hline UNDEFINED_COLONY & "Colony not defined" \\
\hline UNDEFINED_IDENTIFIER & "Identifier not defined" \\
\hline CLOSED_COLONY & "Colony not open" \\
\hline TRANSIENT_OBJECT & "Object isn't a persistent object" \\
\hline DUPLICATED_NAME & "Name already defined" \\
\hline DUPLICATED_ATTRIBUTE & "Attribute already linked to the object" \\
\hline DUPLICATED_IDENTIFIER & "Identifier already exists for the specified level" \\
\hline DUPLICATED_VALUE & "Value already set to the attribute" \\
\hline DUPLICATED_COLONY_TYPE & "Colony type already exists" \\
\hline DUPLICATED_COLONY & "Colony already exists" \\
\hline TYPE_MISMATCH & "Incompatible value type" \\
\hline VALUES_OVERFLOW & "Upper Bound already reached" \\
\hline CHD_ERROR & "Object type doesn't constringe the colony type" \\
\hline
\end{tabular}

